Florida International University FIU Digital Commons

\title{
Promoting Positive Development: Family Processes and Risk Behavior Among Adolescents
}

Beverley E. McDermott

Florida International University, eagle_1979@hotmail.com

DOI: $10.25148 /$ etd.FI12042311

Follow this and additional works at: https://digitalcommons.fiu.edu/etd

\section{Recommended Citation}

McDermott, Beverley E., "Promoting Positive Development: Family Processes and Risk Behavior Among Adolescents" (2012). FIU Electronic Theses and Dissertations. 577.

https://digitalcommons.fiu.edu/etd/577 


\section{FLORIDA INTERNATIONAL UNIVERSITY}

Miami, Florida

PROMOTING POSITIVE DEVELOPMENT: FAMILY PROCESSES AND RISK BEHAVIOR AMONG ADOLESCENTS

A dissertation submitted in partial fulfillment of the requirements for the degree of DOCTOR OF PHILOSOPHY

in PSYCHOLOGY

by

Beverley E. McDermott

2012 
To: Dean Kenneth G. Furton

College of Arts and Sciences

This dissertation, written by Beverley E. McDermott, and entitled, Promoting Positive Development: Family Processes and Risk Behavior among Adolescents, having been approved in respect to style and intellectual content, is referred to you for judgment.

We have read this dissertation and recommend that it be approved.

William Kurtines

Jeremy Pettit

Mark Macgowan

Mary Levitt,Co-Major Professor

Jonathan Tubman,Co-Major Professor

Date of Defense: March 28, 2012

The dissertation of Beverley E. McDermott is approved.

$\begin{array}{r}\begin{array}{r}\text { Dean Kenneth G. Furton } \\ \text { College of Arts and Sciences }\end{array} \\ \hline \begin{array}{r}\text { Dean Lakshmi N. Reddi } \\ \text { University Graduate School }\end{array}\end{array}$

Florida International University, 2012 


\title{
ABSTRACT OF THE DISSERTATION \\ PROMOTING POSITIVE DEVELOPMENT: FAMILY PROCESSES AND RISK BEHAVIOR AMONG ADOLESCENTS \\ by
}

\author{
Beverley E. McDermott \\ Florida International University, 2012 \\ Miami, Florida \\ Professor Mary Levitt, Co-Major Professor \\ Professor Jonathan Tubman, Co-Major Professor
}

The present study is designed to address the problem of risk behaviors among adolescents, in an effort to promote positive developmental trajectories. Previous studies have resulted in divergent findings pertaining to the predictors of adolescent engagement in risk behaviors. In addition to considering this divergence, the focus of the study is the nature of bidirectional individual $\Leftrightarrow$ contextual relationships and their influence on adolescent engagement in risk behaviors. The study tested two models that considered whether parent-adolescent relationship or peer relationship mediated the relation between theory and research-based predictors and the endogenous variable, co-occurring substance use and sexual activity. Participants were 396 demographically diverse multiproblem adolescents from an archived dataset derived from an HIV risk reduction outpatient treatment program for alcohol and other drug use. Participants responded to questions that measured family structure, parent-adolescent relationship quality and communication, religiosity, school connectedness, peer relationship, and engagement in substance use and sexual activity. The study found that the model with peer relationship 
as the mediator fit the data better than the model with the parent-adolescent relationship mediator, and that the mediated model provided a better fit to the data than direct relations between the exogenous and endogenous variables. The results suggested also that primary caregiver was not a significant predictor of adolescent participation in cooccurring substance use and sexual activity. The present study provides a holistic theoretical and conceptual framework that highlights a constellation of factors determined to contribute significantly to co-occurring substance use and sexual activity, and thereby reshape existing models of risk behavior among adolescents.

Keywords: family structure, parent-adolescent relationship, positive adolescent development, risk and protective processes, school connectedness, risk behavior 


\section{DEDICATION}

I dedicate this dissertation to my late parents, Adrian and Lorrie Grant. Thank you for instilling in me the pursuit of academic excellence and the importance of lifelong learning.

To all the adolescents who have managed, through various efforts, to reverse course after embarking on a negative trajectory. 


\section{ACKNOWLEDGMENTS}

I would like to thank the members of my committee, for their role in this challenging and rewarding experience. Drs. Levitt, Tubman and Kurtines have, through my participation in their courses or other interaction, been particularly instrumental in shaping my academic experience, and preparing me for future pursuits. Drs. Pettit and Macgowan provided valuable feedback.

I am grateful, particularly, for Divine guidance and support that sustained me throughout this journey.

Thanks to my family who allowed me the space I needed to focus on this important undertaking.

Thanks to the former Director of my office, Carroll Coleman, who supported this undertaking from the outset, and encouraged me along the way.

I had the distinct pleasure of interacting with fellow students in the program, especially Maria Reid, Roberto Rinaldi, Sandra Williams and Calonie Gray, and appreciated the collegial atmosphere this provided.

A special thanks to Amy Miller, Broward County Inter-Library Loan supervisor, for her tireless assistance in expeditiously obtaining requested material. This was invaluable throughout my years in the program, and deeply appreciated. 


\section{TABLE OF CONTENTS}

\section{CHAPTER}

PAGE

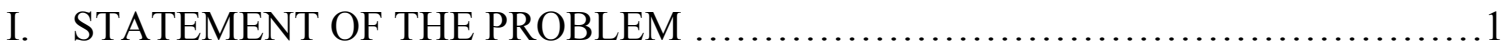

Current Research on Factors Associated with Substance Use and Risk Behavior

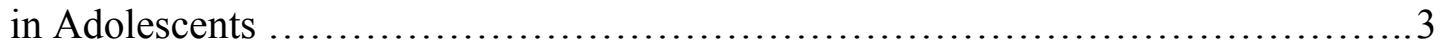

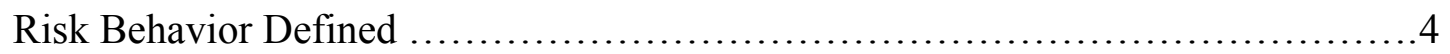

Family Structure and its Association with Substance Use and Risky Behavior

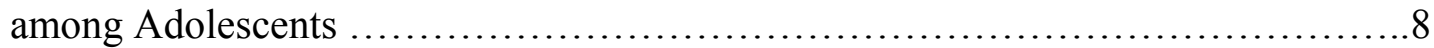

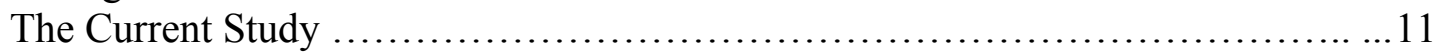

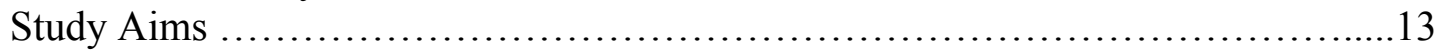

The Significance of the Current Study .........................................14

II. LITERATURE REVIEW .................................................... 17

Bioecological Framework of Adolescent Risk Behaviors ..........................2. 21

Role of Adolescents' Environment in Influencing Involvement in Risk

Behaviors ............................................................... 27

Role of Parent-Adolescent Relationships in Adolescent Substance Use and

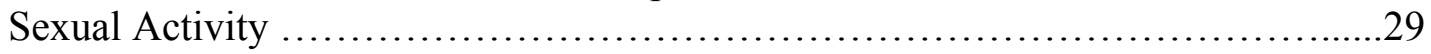

Role of Family Structure in Substance Use and Sexual Activity among Adolescents ................................................................ 35

Role of School-Connectedness in Substance Use and Sexual Activity among Adolescents ..................................................................

Role of Religiosity in Substance Use and Sexual Activity among Adolescents ......45 Role of Peer Relationships in Substance Use and Sexual Activity among

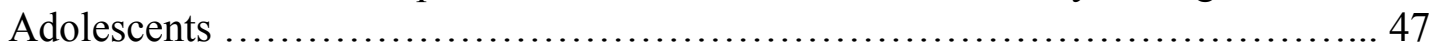

Co-occurrence of Risk Behaviors........................................... 50

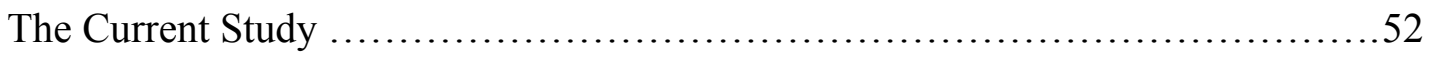

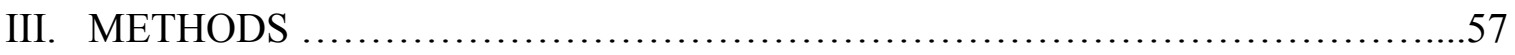

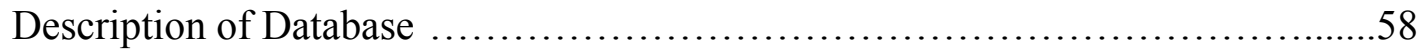

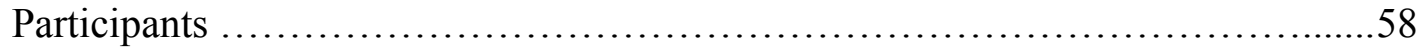

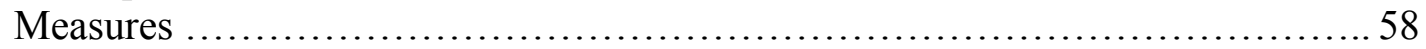

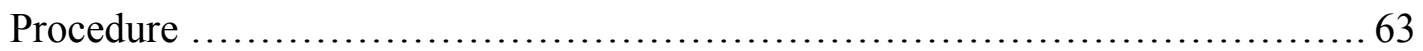

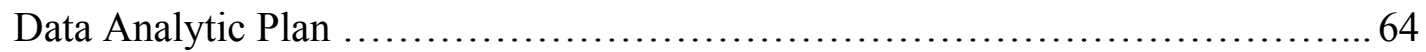

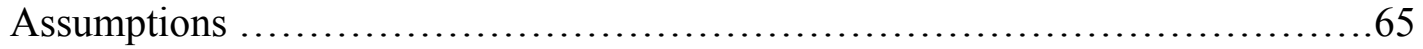

Estimation and Evaluation of the Structural Model .............................69

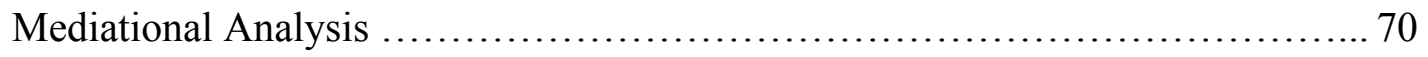

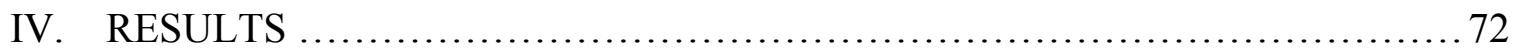

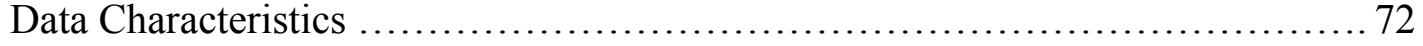

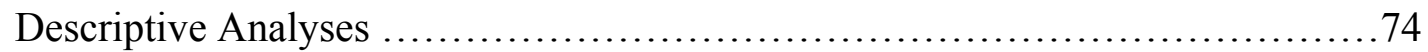

Parent-Adolescent Relationship .......................................... 75 


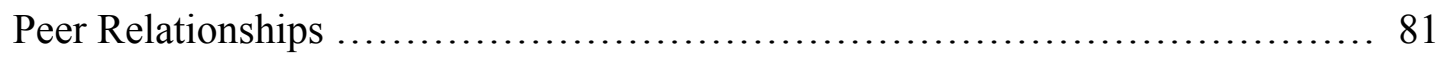

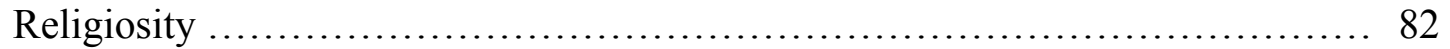

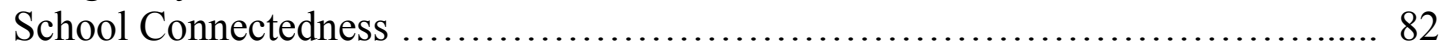

Substance Use and Sexual Activity ..................................... 83

Bivariate Analyses .......................................................... 85

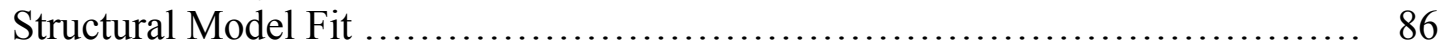

Maximum Likelihood Unstandardized and Standardized Path Coefficients .........89

Total Effects ...................................................................... 90

Mediational Analysis ....................................................... 92

Between Group Comparative Analyses .................................... 92

Multi-group Analysis ......................................................... 96

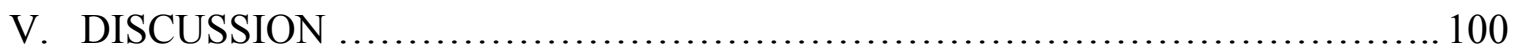

Summary of Research Findings ........................................... 102

Relationship of Study Findings to Extant Literature: Importance of the Present

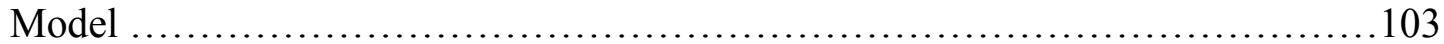

Implications of the Current Findings .............................................. 106

Clinical Implications of the Current Findings ......................................107

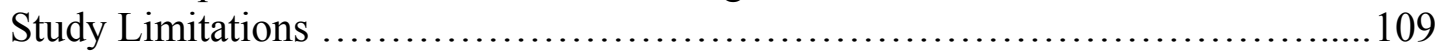

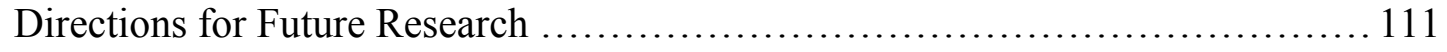

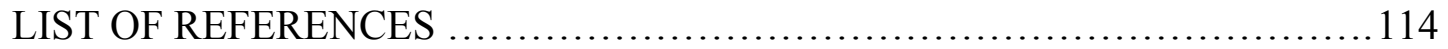

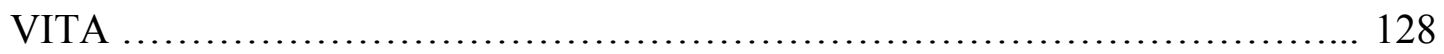




\section{LIST OF TABLES}

TABLE

PAGE

1. Ecological Risk and Protective Processes That Influence Youth Development........26

2. Mahalanobis d-squared Outlier Analysis .................................. 73

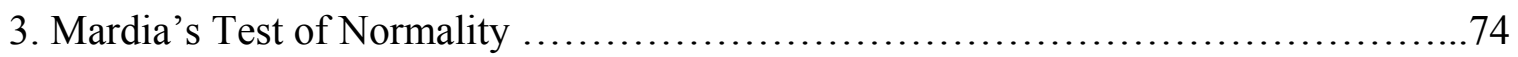

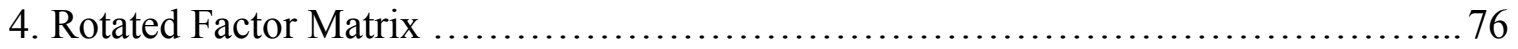

5. Statistics for Items on the Parent-adolescent Relationship Subscales ............... 78

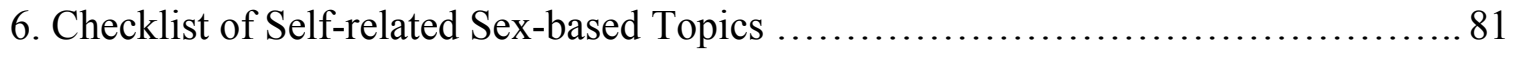

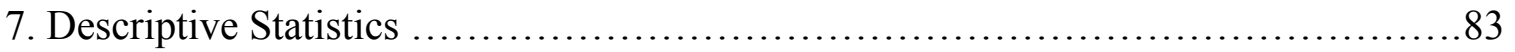

8. Bivariate Correlation Among Variables in the Study $\ldots \ldots \ldots \ldots \ldots \ldots \ldots \ldots \ldots \ldots \ldots . \ldots \ldots$

9. Unstandardized Path Coefficients ............................................ 91

10. Standardized Path Coefficients .......................................... 91

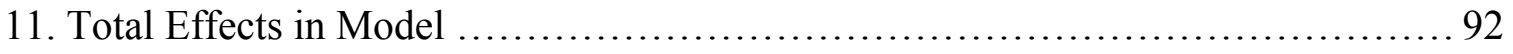

12. Mean Differences by Gender for Observed Variables ............................94

13. Mean Difference by Race/Ethnicity for Observed Variables .................... 95 


\section{CHAPTER I: STATEMENT OF THE PROBLEM}

All adolescents, in all economic and social circumstances, need generous amounts of help, instruction, discipline, support, and caring as they make their way from childhood through adolescence and into adulthood. Such assistance comes from many sources: solid families, good schools, supportive and safe neighborhoods, and a surrounding culture that emphasizes constructive lives and respectful relationships.

- National Research Council and Institute of Medicine, 2002, p.19.

Adolescence is a pivotal developmental stage in the life span that, based on bidirectional individual $\Leftrightarrow$ contextual relationships, can result in a successful transition to adulthood or a negative developmental trajectory. Optimal youth development, therefore, requires a holistic approach that not only considers eliminating/reducing risk behaviors, but also promoting positive development (Youngblade, Theokas, Schulenberg, Curry, Huang \& Novak, 2007), by providing the necessary resources and support. Positive development programs in recent decades have shifted considerably from a deficitoriented focus on addressing pathology among adolescents to one that regards them as resources to be developed (Damon, 2004). However, the lack of a generally accepted theoretical framework, to integrate findings and steer initiatives to translate research into practice, has thwarted efforts to develop more efficacious interventions (Bogenschneider, 1996). In fact, the author asserts that the "most effective prevention efforts are based on strong theoretical and empirical foundations that shape program conceptualization, design, implementation, evaluation, and institutionalization" (p.127).

Adolescents experience considerable change as individuals and also in their ecological relationships within this development stage (Bogenschneider, 1996), and failed attempts at promoting positive development and preventing engagement in risk 
behaviors can have serious consequences. The repercussions of substance use and abuse, precocious and unprotected sexual intercourse, and academic failure among adolescents can have a devastating effect on developmental trajectories and, in some situations, such as contracting HIV/AIDS, have lasting and life threatening consequences. Yet, interventions designed to address risk behaviors among adolescents have had negligible impact, despite the expenditure of more than a billion dollars annually to educate them about the deleterious consequences of risk behaviors, such as smoking, drinking alcohol, drug use, unprotected sexual intercourse, and reckless driving (Steinberg, 2008), which tend to co-occur (Biglan \& Cody, 2003; Biglan \& Hinds, 2009; Centers for Disease Control (CDC), 2008; Guilamo-Ramos, Litardo \& Jaccard, 2005; Harris, Duncan \& Boisjoly, 2002; Jessor \& Jessor, 1977; Jessor, Van Den Bos, Vanderryn, Costa \& Turbin, 1995; Kotchick, Shaffer, Forehand \& Miller, 2001; Langer \& Tubman, 1997; Riesch, Anderson \& Krueger, 2006; Wolfe, Jaffe, \& Crooks, 2006).

This finding of co-occurrence is among the most consistent in studies of adolescent problem behavior, whereby delinquent youth are more inclined to smoke, engage in excessive alcohol consumption and sexual risk behavior, or attempt suicide (Biglan \& Cody, 2003). Annual government surveys have also confirmed the significant role of alcohol consumption in conduct problems, such as drunk driving, criminal activity and sexual risk behavior, among adolescents. Research also found that prevalence rates for substance use increased over time (Wills, Resko, Ainette \& Mendoza, 2004). Substance use among adolescents poses considerable developmental risks, and has been considered, at a minimum, a central contributor to behavioral problems (Mayes \& Suchman, 2006). The apparent failure of interventions to have a meaningful impact on 
adolescents' engagement in risk behaviors raises the issue of the factors that influence their decision to participate in these behaviors, in order to facilitate the development of more efficacious approaches.

Current Research on Factors Associated with Substance Use and Risk Behavior in Adolescence

Numerous studies (e.g., Blum, Beuhring \& Rinehart, 2000; Bonino, Cattelino \& Ciairano, 2005; Langer \& Tubman, 1997; Riesch et al., 2006; Wolfe et al., 2006), have investigated a range of factors in an effort to identify the major contributors motivating adolescents' maladaptive behavior. It is important to determine what influences risk behaviors among adolescents in order to increase the likelihood of developing models that facilitate the development of more efficacious interventions. This requires that studies examine the relation between factors in multiple contexts that promote or deter positive outcomes (Youngblade et al., 2007). It is also important to ensure that the content and delivery of interventions are appropriate to the developmental stage of participants. A generic, universal approach is less likely to generate expected outcomes, because it is unsuited to the age and stage of development of each participant (Wolfe et al., 2006). It is apparent that the onset of risk behaviors among adolescents begins by the ninth grade, which makes the transition from elementary to middle school a timely period to commence prevention efforts (Riesch et al., 2006).

Experimentation and the need to assume adult roles have been cited among the factors responsible for precocious and unprotected sexual activity among adolescents, with the majority of those who initiate sex at an early age more likely to lack an 
emotional attachment to their sexual partner, less likely to use contraception, and more inclined toward promiscuity (Bonino et al., 2005). These adolescents not only risk exposure to sexually transmitted diseases and premature pregnancy, but also psychosocial consequences manifested in negative outcomes, such as the burden of raising a child and the diminished opportunity for personal fulfillment when school dropout occurs (Bonino et al., 2005). In seeking to assume adult roles prematurely, adolescents also often decide to drink alcohol without considering the consequences of their actions.

\section{Risk Behavior Defined}

What constitutes risk behavior among adolescents? Risk connotes potential loss, and implies behavior that is intentional and consciously deliberated. Igra \& Irwin (1996) consider risk-taking behaviors "the most serious threat to adolescent health and wellbeing" and define them as "those behaviors, undertaken volitionally, whose outcomes remain uncertain with the possibility of an identifiable negative health outcome" (p. 35). Among the potentially deleterious consequences of specific risk behaviors are unwanted pregnancy, sexually transmitted diseases, severe disability and death. Some of the behaviors being discussed, when engaged in responsibly at a later developmental stage, are normative. Hence, it is the developmental stage and the potential negative impact on the developmental trajectory that underscore the characterization of risk in behaviors, such as premature alcohol use and precocious sexual intercourse (Igra \& Irwin, 1996).

Key developmental processes of adolescence entail increasing autonomy from parental control, more peer affiliation, sexual awareness, identity formation, and physiological and cognitive maturation (Igra \& Irwin, 1996; Rolison, 2002). Thus, these authors distinguish between constructive exploratory behavior that facilitates adaptive 
development, and destructive risk-taking behavior that threatens health and positive developmental trajectories. Based on (Jessor \& Jessor, 1977; Jessor, 1982) Problem Behavior Theory, behavioral problems are inherent in normal adolescent development and they are integral to the process of crossing the threshold to adulthood. They are tantamount to a rite of passage, as adolescents ignore the boundaries of behavioral norms and eschew conventional authority to obtain peer approval, and deal with discouragement, apprehension and prospective failure (Jessor, 1991).

Government surveys provide evidence not only of the co-occurrence of delinquent and risk behaviors in adolescence, but also of the intractable pervasiveness of the problem. The 2009 CDC data indicated that $72.5 \%$ of high school students had consumed alcohol, with a little less than half (41.8\%) considered current users. Almost a quarter, (24.2\%) were current binge drinkers (i.e. five or more drinks per day). Approximately half (46.3\%) had tried cigarette smoking, with 19.5\% continuing this activity. Almost half $(46 \%)$ had engaged in sexual intercourse, with more than a third (34.2\%) currently sexually active, $38.9 \%$ of whom failed to use a condom during their last sexual encounter (CDC, 2009). The CDC also determined that annually there were almost 757,000 pregnancies among teens between 15 and 19 years old, and approximately 9.1 million sexually transmitted diseases among individuals aged 15 to 24 years old. Among this latter age group, an estimated 5,089 were diagnosed with human immunodeficiency virus/acquired immunodeficiency syndrome (HIV/AIDS).

The age of initiation is also important when considering risk behaviors, due to the potential for prolonged exposure to deleterious effects. Mid-adolescence is considered the developmental stage when youth are most prone to engagement in risky and reckless 
behaviors (Steinberg, 2008). Study data reveal that before age 13, only $14.2 \%$ of students had smoked a cigarette, $23.8 \%$ had consumed alcohol, and $7.1 \%$ had engaged in sexual intercourse. Also noteworthy, it was determined that $14.9 \%$ of all sexually active students had participated in sexual relations with at least four partners. It appears indisputable, and is consistent with the CDC's conclusion, that more efficacious interventions are needed to reduce adolescent health risk behavior and improve health outcomes among youth.

The tendency for specific risk behaviors to co-occur is well documented. Of the $34.2 \%$ of students who indicated they were currently sexually active, $21.6 \%$ admitted they had consumed alcohol or used drugs before their last sexual encounter (CDC, 2009). Despite their apparent co-occurrence, typically, these risk behaviors are addressed individually through specific interventions, although an integrated approach is considered more efficacious (Wolfe et al., 2006). Even the best programs, according to Steinberg (2008), have had more impact on increasing knowledge about risk behaviors than achieving behavioral changes. Knowledge of adverse consequences, it seems, is insufficient to produce changes in many risk behaviors (Kotchick et al., 2001). This finding has led to the argument that social and emotional, not cognitive, factors are responsible for adolescents' engagement in deleterious activities (Steinberg, 2008). Methodological deficiencies have been implicated in failed attempts to determine the factors associated with adolescent sexual risk behavior, and hence the ability to develop efficacious interventions (Bogenschneider, 1996; Kotchick et al., 2001).

The other issue germane to the discussion of risk behaviors among adolescents is related to the environments in which they occur. Adolescents are products of their 
environment (Wolfe et al., 2006) which, seemingly, does not always provide the guidance and support they need to transition successfully to adulthood. This environment comprises, primarily, family, school, peer and community contexts that together nurture and play a critical role in the decision-making and behavioral choices of adolescents. Larson et al. (2004) cited several factors that are conducive to positive youth development, and consider supportive relationships to be a key determinant of whether youth succeed in life or experience behavioral problems. The other factors include physical and psychological safety, clear and consistent structure and appropriate supervision, opportunities to belong, positive social norms, support for efficacy and mattering, skill-building opportunities, and the integration of family, school, and community efforts (Benson et al., 2006; Damon, 2004; Theokas \& Lerner, 2006; Youngblade et al., 2007). A supportive relationship serves an important protective function that may result in youth having more resilient outcomes in the face of multiple risk factors, decreases their vulnerability to negative experiences, and promotes their social, emotional and cognitive development (Larson et al., 2004).

It has also been determined that successful youth development is contingent on the availability of other supports and opportunities. These include: adequate nutrition, health and shelter; multiple supportive relationships with adults and peers; challenging and engaging activities and learning experiences; meaningful opportunities for involvement and membership; and physical and emotional safety (Theokas \& Lerner, 2006). This position provides further support for the need to adopt a holistic ecological framework that examines risk and protective processes impacting individual-contextual relationships. It is also consistent with Lerner's (2006) developmental contextualism, 
which postulates that human development is characterized by a fused system of bidirectional individual $\Leftrightarrow$ context relationships.

Family Structure and its Association with Substance Use and Risky Behavior among Adolescents

The focus on the family, as a significant domain in the ecological framework, also warrants increasing attention, given the transformation in family structure that has occurred in recent years in the United States. Over the past three decades, the proportion of children living in nonmarital unions has increased substantially (Brown, 2004). Unwed parenting, manifested in cohabitation and single parent households, has increased dramatically, and there is no indication that the abatement of this trend is imminent. Based on information from the National Center for Health Statistics, unwed births in the U.S. increased from 18\% to 40\% between 1980 and 2007 and, according to the National Vital Statistics Report (2010), grew to $40.6 \%$ in 2008 . Teenagers accounted for $22 \%$ of unwed births, which represents 6 of 7 teen births (National Vital Statistics Report, 2010). These figures assume more gravity, when one considers that in $1960,88 \%$ of all children lived with two parents, compared to 68\% in 2007 (U.S. Census, 2008). Among children under age 18 in $2005,23 \%$ lived with only their mothers, $5 \%$ lived with only their fathers, and 4\% lived without either parent (Federal Interagency Forum on Child and Family Statistics, 2006). Children are more likely to be present in minority than in White cohabiting couple households (67\% of Black, $70 \%$ of Hispanic, and 35\% of White households) (Manning \& Bulanda, 2006).

Cohabitation, or "marriage-lite" (Morgan 2000) has become the predominant choice in nonmarital unions, and an increasing proportion includes children (Wu, Hou \& 
Schimmele, 2008). Cohabitation accounts for at least one half of first unions in the U.S., and almost half of cohabiting couples have children (Bachman, Coley \& Chase-Lansdale, 2004). Compared to marriage, cohabitation represents an "incomplete institution" because it lacks common meaning and predictability (Manning, 1999). Cohabiting relationships are also more unstable than marriages, have more conflicts, and more than half dissolve within five years (Morgan, 2000). This environment is unlikely to provide the stability adolescents need as they search for direction when making transitions to adulthood. Cohabiting unions are sufficiently different from marital relationships that family structure is an important variable in determining children's behavioral outcomes, and it is also among the factors considered to have a significant impact on adolescents' decision to engage in risk behaviors. Family structure provides information about the social environment in which one lives, but the dynamics and relationships supporting the structure are less evident, thereby making it difficult to explain their role in promoting adaptive developmental outcomes (Brown, 2004). It is generally accepted that the best interest of children is served when they reside with both biological parents who are married to each other, because they are more capable of providing the economic and parental resources needed to achieve positive developmental outcomes (Amato, 1995; 2001; 2005).

The family creates one key social environment that promotes compliance to socially sanctioned behavior. There have, however, been contradictory findings regarding whether family structure is a key explanatory factor in adolescent sexual activity (Upchurch, Mason, Kusonuki \& Kriechbaum, 2004; Wilder \& Watt, 2002). Based on the literature on psychology and adolescent development, the parent-child relationship is 
considered to be the stronger predictor of adolescent outcomes and the transition to adulthood (Apel \& Kaukinen, 2008; Blum et al., 2000). Given the unprecedented transformation that has occurred in family structure in recent decades, it is even more imperative to determine if, indeed, empirical evidence suggests that the type of family structure in which adolescents are raised has a stronger association than parent-child relationships concerning their involvement in risk behaviors.

Parental resources constitute parental involvement, autonomy support, and structure. Involvement reflects the parents' active interest in the child, knowledge about the child, and time and resources dedicated to the child-rearing process. Autonomy support pertains to the framework from which parents motivate their children, through techniques that promote independent problem-solving, choice, and participation in decisions. Structure is the extent to which parents provide clear and consistent guidelines, expectations, and rules for behavior. Children need to be aware of the association between their actions and outcomes (Grolnick \& Ryan, 1992). Cohabiters have less parental resources, because the uncertainty of the relationship, and the inherent stressors, manifest relatively higher levels of depression, and a diminished capacity for effective parenting (Brown, 2004).

Family stability may be more important to a child's outcomes than the specific family structure experienced by the child (Manning \& Bulanda, 2006). Family change leads to more negative outcomes regardless of the family structure (Hao \& Xie 2001; Wojtkiewicz 1993; Wu \& Martinson 1993). Parental behavior (e.g., the strength and warmth of the parent-child bond, parental involvement and investment, and the parenting practices used in monitoring, disciplining and supervising children), is also an important 
determinant of behavioral outcomes in children (Apel \& Kaukinen, 2008). The inference is that non-intact families, particularly single-parent families, differ from intact families across these key characteristics (Apel \& Kaukinen, 2008). Hence, the trend towards more single-parent households, and their inherent instability, makes it imperative to focus increasingly on parent-adolescent relationships and the factors therein that influence the likelihood of positive psychosocial outcomes.

Another key influence on adolescents' substance use is their peer relationships, and there are divergent views regarding whether parental or peer relations are dominant in this regard. Hence, although theory and research documented significant parental influence on adolescents' risk of substance use, there is evidence that this impact is diminished and insignificant after accounting for peer influence (Bahr, Hoffman \& Yang, 2005). This is an important finding for developing models of adolescent risk for problem behavior, and the likelihood of developing efficacious interventions to mitigate or eradicate these risks.

\section{The Current Study}

There is significant disagreement in the literature concerning the differential role of family structure, parent-adolescent relationship, and peer relationship as the predominant factor influencing risk behavior among adolescents (Apel \& Kaukinen, 2008; Bahr et al., 2005; Blum et al., 2000; Upchurch, Mason, Kusonuki \& Kriechbaum, 2004; Wilder \& Watt, 2002). Hence, the current study seeks to examine relations among pertinent variables to resolve this issue. An integrated conceptual approach, reflected in Bronfenbrenner's ecological theory, Lerner's developmental contextualism, as well as Jessor's Problem Behavior Theory, provides a broader theoretical framework to 
investigate associations between a) family structure and co-occurring substance use and sexual activity; b) family processes and co-occurring substance use and sexual activity; and c) the role of peers in co-occurring substance use and sexual activity. Associations between family factors, grade retention and religiosity, and their influence on proneness to engage in problem behavior were evaluated also. Thus, the purpose of the present study is to use a secondary data set to identify relations between and among variables, reflecting person-environment characteristics, measured at entry into an HIV risk reduction intervention designed to serve the needs of multi-problem adolescents engaging in sexual risk behaviors. It is necessary to simultaneously consider these personenvironment systems to coherently explain human behavior (Jessor, Donovan \& Costa, 1991).

The current study focused on the contexts in which risk behaviors occur, and the degree to which patterns detected in the current sample are consistent with existing research and conceptual models. This research study sought to determine which variables are most significantly associated with self-reported problem behaviors, and to facilitate the development of models more predictive of risk behavior among adolescents. It supports the contention that "research is needed to facilitate a deeper understanding of the fundamental processes of psychological development, as an essential precursor to the field's development of more comprehensive models of human behavior" (Roberts \& Llardi, 2003, p. 5). The study also advances current discussions concerning the role of family process and peer variables in promoting risk behaviors among adolescents, and which variables are more significantly correlated with adolescent risk behaviors. The 
findings also generate hypotheses for future longitudinal research, based on key associations identified among variables modeled in the current study.

Study Aims

Consistent with developmental science, theoretical and empirical work pertaining to extant social problem research has become more multidisciplinary, multivariate, process-focused, contextually situated and person-centered (Jessor, 1998). The present study focused on person-environment characteristics pertaining to the individual, family, school, and peers to analyze the bivariate and multivariate relationships associated with substance use and sexual activity among adolescents. The dynamic systems nature of these relationships is captured in Bronfenbrenner's ecological framework and Bogenschneider's (1996) ecological risk and protective theory, which integrates Bronfenbrenner's ecological conceptualization with Lerner's developmental contextualism. Jessor's Problem Behavior Theory, considered to be, perhaps, the most prominent conceptual framework that identifies the factors influencing multiple risk behaviors (Guilamo-Ramos et al., 2005), also provides the basis for analyzing study data. Hence, the study examined how adolescents differ with regard to self-reported risk behaviors, and the degree to which contextual factors, at the inception of the larger study, influenced risk behaviors.

Specifically, the study addressed several research questions. The associations among (a) a family structure variable, (b) parent-child relationship variables, and c) peer relations, and adolescents' self-reported risk behaviors were examined. Differences in the magnitude of these relations were documented. The differential contribution of these contextual factors to adolescent problem behaviors was examined also. It was expected 
that parent-child relationships would be inversely correlated with adolescent problem behaviors, and that parent-child relationships would be more highly correlated with problem behavior outcomes than would be the family structure variable. The study considered also two alternative hypotheses pertaining to the mediating role of parentadolescent relationship and peer relationship. Both were expected to have a direct and mediating effect on co-occurring substance use and sexual activity. It was also expected that variables indexing prosocial/conventional behaviors and attitudes would be inversely correlated with problem behavior variables, and that variables indexing nonconventional behaviors and attitudes would correlate directly with problem behavior variables.

Data for the present study was based on information provided in questionnaires that a sample of multi-problem youth participating in a HIV risk reduction intervention completed while receiving outpatient substance use treatment in South Florida. In addition to measures of central tendency and dispersion, to assess normality and variability in the data, a correlational analysis of specific variables was conducted to identify significant associations and concurrent patterns with the conceptual framework of the model on which the study is based. A structural equation model was tested to assess how well the hypothesized conceptual framework fits the data.

\section{The Significance of the Current Study}

In a changing society where, increasingly, adolescents lack the guidance necessary to pursue their goals and have a sense of purpose, by believing in their ability to achieve these goals, it is critically important to develop multivariate behavioral models that embody the factors associated with risk behavior. This increases the likelihood of developing efficacious interventions that deter participation in these behaviors and 
promote positive development. There are numerous interventions from a range of disciplinary traditions that seek to address the multifaceted, multidimensional issues of adolescent development with varying degrees of success. It has been suggested that the chasm between the controlled research environment and the actuality of practice is partly responsible for less than efficacious interventions (DeAngelis, 2010). This study attempts to bridge that chasm by considering and incorporating current empirical trends, such as the pronounced shift towards more single-parent households, and the impact on parentadolescent relationship as well as co-occurring substance use and sexual activity. It also considers a plurality of factors that have yet to be studied simultaneously to determine their role in co-occurring substance use and sexual activity among adolescents. The communication of findings from the study to the practical arena may also serve to bridge the gap between research and psychosocial interventions.

The trend toward unwed births and more single parenthood, even with an immediate social marketing campaign to stall its momentum, is unlikely to abate in the near future. The potential ramifications on the developmental trajectory of adolescents, which research has shown include the proclivity for engagement in risk behaviors, such as substance use and precocious sexual activity, make it imperative to identify the factors most associated with these co-occurring behaviors. The indictment of failed interventions as being more effective at increasing knowledge than changing behavior, suggests that the frameworks on which they are based are flawed. The divergent results pertaining to the role of family structure, parent-adolescent relationship, and peer relationship in adolescent participation in risk behaviors support this contention. This study seeks to determine not only the role of these variables, but which is more significantly associated 
with adolescent participation in substance use and premature sexual activity. However, as Jessor (1998) cogently and intuitively states, “......the accomplishments by the various new perspectives are only one more step along the road to a fully comprehensive understanding of adolescent risk behavior. Much still remains to be done" (p. 9). This study was conducted in the hope of being a step toward that end, based on identifying the relationships that support a viable framework, and thereby provides the basis for the development of more efficacious interventions. 
CHAPTER II: LITERATURE REVIEW

"...... all behavior is the result of person-environment interaction"

-Jessor, Donovan \& Costa, 1991, p. 20.

The primary purpose of this section is to present and discuss the underlying research that supports the rationale for the present study. Interest in problem behaviors among adolescents dominated the adolescent development research literature during the 1980s and 1990s, with Jessor's Problem Behavior Theory being the most commonly cited explanatory model (Steinberg \& Morris, 2001), and regarded as, arguably, the most prominent (Guilamo-Ramos et al., 2005). There is no indication that this interest has waned in recent years. Jessor's Problem Behavior Theory has evolved over several decades, and is a psychosocial model aimed at explicating adolescents' engagement in risk behaviors through a person-environment framework (Jessor, 1987; Jessor, Donovan \& Costa, 1991). In essence, Jessor postulated that risk behaviors, such as substance use and unprotected sexual intercourse, were motivated by three distinct but interrelated systems - the perceived-environment system, the personality system, and the behavior system (Jessor et al., 1991).

Each system is comprised of variables that promote or dissuade participation in risk behaviors, and it is the equilibrium among these opposing factors that determines the proclivity or dynamic state of proneness for participation in risk activities. The overall inclination or proneness to problem behavior that is the product of all three systems reflects the extent of psychosocial conventionality-nonconventionality that each adolescent demonstrates (Jessor et al., 1991). Hence, the present study examines to what extent the data, collected from a sample of multi-problem youth participating in an 
outpatient substance use treatment program, coincide with Jessor's conceptual model concerning risk behaviors among adolescents.

Embodied in the personality system are motivational-instigation structures, the personal beliefs structure and the personal control structure, each of which has attributes with predispositions toward participation in or avoidance of risk behaviors. In the motivational-instigation structure, there are seven component variables including: value on academic achievement; value on independence; value on affection; independenceachievement value discrepancy; and the expectation for affection. These variables impact the individual's motivation toward goal attainment, and they also have consequences associated with the development of problem behaviors (Jessor \& Jessor, 1977; Rew, 2004). The variables with an inverse relationship to risk behaviors are adolescents' value on academic achievement and expectations for academic achievement, while those that make adolescents more prone to participation in risk behaviors are their values on independence, the independence-achievement value discrepancy, and their expectations for independence. Therefore, when their values on independence are high and those on achievement are low, adolescents are more prone to engage in problem behaviors. The inversely related variables in the personal beliefs structure are self-esteem and locus of control, and those that promote risk behaviors are social criticism and alienation. In the personal control structure, intolerance of deviance and religiosity discourage problem behavior, while the discrepancy between positive-negative functions increases its likelihood (Donovan, 2004; Jessor et al., 1991). There were divergent findings pertaining to religiosity and sexual behavior among adolescents, with some studies specifying that higher scores for religiosity were associated with the reduced likelihood of sexual 
activity, while other studies found no relation among minority youth (Kotchick et al., 2001). Elaboration on this divergence, with a plausible rationale, is presented later in this study.

The perceived-environment system is comprised of two structures of environmental variables, distal and proximal, that predispose adolescents toward participation in or avoidance of risk behaviors (Donovan, 2004; Jessor et al., 1991). Distal variables inversely related to problem behavior participation include: Parents' and friends' controls; parents' and friends' support; and less compatibility between parents' and friends' expectations; with parents and friends exerting opposite influences. The proximal variables in this system have a greater impact on adolescents' predisposition to involvement in risk behaviors, and include lower parental disapproval of problem behavior, friends' approval of problem behavior, and friends' modeling of problem behavior (Donovan, 2004; Jessor et al., 1991).

The behavior system consists of problem behaviors and conventional behaviors. Problem behaviors include: Alcohol use, problem drinking, cigarette smoking, marijuana use, other drug use, precocious sexual activity and delinquent behavior. Conventional behaviors include: Church attendance, school-related activities, and academic performance. The conceptual framework of Problem Behavior Theory also integrates specific demographic characteristics and the socialization process. The demographic factors include: Parental education, occupation, religion and family structure.

Components of the socialization process, that are characterized as parental ideology, include: parental traditional beliefs, parental religiosity and intolerance for deviance. These are among the factors deemed to limit adolescent problem behavior. 
Maternal controls regulation and maternal affectional interaction are also included in the socialization process, as a part of the home environment (Donovan, 2004; Jessor et al., 1991). Risk behavior negatively impacts the psychosocial outcomes among adolescents. However, adolescents are motivated to engage in risk behaviors to gain peer approval and to feel more confident in social situations, and to establish independence from parental authority. Problem Behavior Theory also highlights the tendency for these behaviors to co-occur among adolescents, because of their connectedness in the social environment and adolescents' opportunities to learn about and engage in them in these settings. Participation in risk behaviors also represents a rejection of conventional norms and more autonomy from parental control. It is also symptomatic of differences in adolescent norms, for example, in disadvantaged circumstances, where adolescence may not be a distinct developmental stage. In these situations, adolescents may assume adult roles, such as employment to augment household income and/or substantial child care responsibilities for siblings. In such instances, adolescents may consider adult behavior, such as alcohol use, normative due to the other adult roles they have assumed (CSR, 1997). Socioeconomic status, therefore, needs to be considered in determining motivation for what may be deemed problem behavior among adolescents.

Despite being criticized as less than parsimonious (Rew, 2005), the generality and robustness of Problem Behavior Theory has been established in multiple empirical studies. The reformulation of the model to incorporate risk and protective factors retains the direct correlation of the theoretical constructs to behavioral outcomes, and also integrates the moderating effects of protective factors on elements of risk to be modeled (Jessor, 1991). A significant amount of variance has been accounted for in adolescent 
problem behaviors, health behaviors and prosocial behaviors, based on analyses derived from this model that capture risk and protective factors. Empirical findings show that there is substantial support for the moderating influence of protective factors on the impact of risk factors, with substantial protection weakening the impact of risk factors on adolescents' participation in problem behaviors, health enhancing behaviors, and prosocial behavior (CSR, 1997; Yates \& Masten, 2004). The robustness of risk and protective factors in accounting for significant variance in specific risk behavior outcomes continues over time, and extends across multiple outcome criteria, for males and females, younger and older adolescents, different socioeconomic groups, races and ethnicities, and national and international samples (Jessor, 2004). The current study seeks to determine if these findings are evident in a clinical sample of multi-problem adolescents receiving substance use treatment services.

\section{Bioecological framework of adolescent risk behaviors}

A holistic, developmental contextualist approach that examines the genesis of multiple problems in a broader ecological framework is germane to a comprehensive understanding of risk behaviors among adolescents. Theories of risk-taking behaviors have been encapsulated in three major frameworks: biological, psychological/cognitive, and environmental/social (Igra \& Irwin, 1996). Biologically-based theories contend that risk behaviors are associated with hormonal effects, asynchronous pubertal development, and genetic susceptibility. Psychological/cognitive theories suggest risk-taking may be attributed to poor self-esteem, underdeveloped intellect, being emotionally unbalanced or having an affinity for sensationalism. Social/environmental theories seek explanations for risk behaviors in family and peer interactions or typical societal and community 
conditions (CSR, 1997; Lee, Akers \& Borg, 2004). The biopsychosocial model pertinent to adolescent risk behavior contends that the interaction of asynchronous pubertal maturation with cognitive and social factors increases the likelihood that adolescents will participate in risk behaviors (Igra \& Irwin, 1996). For example, premature pubertal development is associated with early onset of sexual activity, regardless of gender or race (Kotchick et al., 2001).

It is counterintuitive to distinguish between the role of each type of theory, since there are likely to be overlapping aspects in available theoretical models of adolescent risk behavior (Igra \& Irwin, 1996). Bronfenbrenner and Morris' (1998) bioecological framework and Bogenschneider's (1996) ecological risk and protective theory provide a compelling conceptual model, one that integrates an ecological perspective with developmental contextualism, to elucidate risk factors, mediation processes and outcomes associated with risk behaviors among adolescents (Riesch et al., 2006). Bronfenbrenner and Morris (1998) postulated that the interrelated components of person, process, context and time determine participation in risk behavior, and they provided a model of an integrated, dynamic developmental system to study human ontogeny. A dynamic, developmental systems theoretical model emerged in the late 1980s, and gained momentum in the 1990s, to encompass a new, nonreductionist, integrative, and multidisciplinary framework to describe, explain and optimize ontogenetic change (Jelicic, Theokas, Phelps \& Lerner, 2007; Magnusson \& Stattin, 2006).

Bronfenbrenner and Morris' (1998) bioecological model is based on two propositions that emphasize the dynamic, contextual and relational perspectives of developmental processes. Proposition I stipulates that human development requires active 
participation in complex, reciprocal interactions with the people, objects and symbols in the individual's proximal environment. The effectiveness of these interactions, conceptualized as the engines that drive development, is predicated on their frequency over a prolonged period. Proposition I underscores the role of the agency of the individual in his/her own development, a key aspect of the bioecological model throughout the life course, but particularly important in early developmental stages. Proposition II stipulates that the form, power, content and direction of the proximal processes impacting development vary systematically as an integrated function of the characteristics of the individual, the proximal and distal environments in which these processes are occurring, the specific developmental outcomes, evolving social contexts over the life course, and the historical period during which the individual lives. Both propositions underscore the importance of proximal processes to individual development.

Bronfenbrenner and Morris (1998) delineated three types of Person characteristics that, through their capacity to influence the direction and power of proximal processes over the life span, impact developmental trajectories. These include dispositions that can activate proximal processes in a specific developmental domain and sustain their operation. The traits associated with developmentally disruptive dispositions are impulsiveness, explosiveness, distractibility, failure to defer immediate gratification or, more succinctly, the inability to control emotions and behavior. Second, are bioecological resources necessary for proximal processes to function effectively, and these include ability, experience, knowledge and skills during particular developmental stages. Finally, specific demand characteristics can encourage or inhibit reactions from the social environment, and also can have positive or negative impacts on the operation of proximal 
processes. Based on the importance Bronfenbrenner and Morris (1998) attributed to these person characteristics, they appear germane to the conceptual framework explaining risk behaviors among adolescents.

The importance of person characteristics in understanding risk behaviors among adolescents is supported by existing research literature. Chan, Wenzel, Orlando, Montagnet and Mandell (2004) contend that adolescents with substance use disorders have specific characteristics that had their genesis in childhood exposure to environmental and biological adversities, and are key determinants of their developmental trajectories (Riggs, 2003). These characteristics include behavioral problems, skills deficits, academic difficulties, family problems and mental health problems. It is conceivable that adolescents without the coping skills to successfully navigate environments containing multiple adversities are likely to experience associated negative impacts.

Bogenschneider's (1996) bioecological theory stipulates the need to identify risk and protective processes in individual, family, school, peer and community contexts. This framework is designed to promote an understanding of human ontogeny, and to facilitate the development of principles that can steer the design, delivery and evaluation of interventions. The theory posits that human development is seldom threatened by the presence of a single risk factor, but rather, it is the accumulation of multiple risks or adversities that imperil optimal adolescent development. Hence, Bogenschneider stipulates that research studies have confirmed the improbability that adolescents with few risks engage in substance use or precocious sexual activity. The theory also focuses on delineating risk and protective processes, as opposed to the more static factors, such as 
poverty, to underscore the significance of why and how the associated maladaptive outcomes ensue from contextual relationships or the interaction of the individual and the environment.

Persuaded by the proposition that "no single model can capture the complexity of human development" (p.130), Bogenschneider (1996) contends that an approach that integrates risk and protective factors provides a more powerful and holistic conceptualization of human development, to circumvent the limitations associated with a focus narrowly limited to either domain of variables, and presents a more complete understanding of the complex individual. The risk approach is characteristic of processes that can potentially impair adolescent development, while the protective approach pinpoints processes that can enhance the adaptive outcomes associated with positive development. These divergent approaches, rather than being conflicting, may transcend the inadequacies of disconnected, isolated efforts to construct univariate explanations of developmental outcomes (Bogenschneider, 1996). While it is important that prevention efforts concentrate on reinforcing protection processes, especially for individuals, the author considers the failure to concomitantly expend efforts to diminish potential risks myopic. Mitigating risks may potentially limit the degree of protection adolescents need, whereas endeavors to strengthen protective processes enable youth to cope with greater risks. The protective model is particularly appropriate when geared toward high risk adolescents, while the risk model is potentially advantageous to all adolescents (Bogenschneider, 1996). Table 1 depicts the risk and protective processes associated with the individual, family, peers, school and community. Church affiliation is protective, and is included at the community level in terms of bonding to social institutions. 
Table 1

Ecological Risk and Protective Processes That Influence Youth Development

\begin{tabular}{|c|c|c|}
\hline Level & Risk Processes & Protection Processes \\
\hline Individual & $\begin{array}{l}\text { Antisocial behavior } \\
\text { Alienation of rebelliousness } \\
\text { Early initiation }\end{array}$ & $\begin{array}{l}\text { Well-developed problem-solving skills and } \\
\text { intellectual abilities } \\
\text { Self-esteem, self-efficacy, and personal } \\
\text { responsibility } \\
\text { Well-developed social and interpersonal } \\
\text { skills } \\
\text { Religious commitment }\end{array}$ \\
\hline Family & $\begin{array}{l}\text { Poor parental monitoring } \\
\text { Distant, uninvolved, and inconsistent } \\
\text { parenting } \\
\text { Unclear family rules, expectations, and } \\
\text { rewards }\end{array}$ & Clear relationship with at least one person \\
\hline Peer & $\begin{array}{l}\text { Association with peers engaged in risk } \\
\text { behaviors }\end{array}$ & Close friend \\
\hline School & $\begin{array}{l}\text { School transitions } \\
\text { Academic failure } \\
\text { Low commitment to school }\end{array}$ & Positive school experiences \\
\hline Community & $\begin{array}{l}\text { Low socioeconomic status } \\
\text { Complacent or permissive community } \\
\text { laws and norms } \\
\text { Low neighborhood attachment, } \\
\text { community disorganization, and high } \\
\text { mobility } \\
\text { Media influences }\end{array}$ & $\begin{array}{l}\text { Belonging to a supportive community } \\
\text { Bonding to family, school, and other social } \\
\text { institutions }\end{array}$ \\
\hline
\end{tabular}

Source: Bogenschneider, K. (1996). An ecological risk/protective theory for building prevention programs, policies, and community capacity to support youth. Family Relations, 45(2), p. 129.

The variables in the present study, family structure, parent-adolescent relationship, school connectedness, peer relationship, and religiosity, are consistent with the ecological framework germane to adolescent development and their proclivity to engage in risk behaviors. 
The parent-adolescent relationship and communication processes are integral to the ecological framework, and are considered to mediate the effects of risk factors on risk behaviors. "Parent-child communication processes are the degree to which the parent and the child are satisfied with how the family functions in terms of rules, relationships, and connectedness; the degree of openness with which communication is perceived between a parent and a child; the parent and child's ability to manage conflicts; and to what degree the child perceives their family meets their care needs" (Riesch et al., 2006, p. 50). There is substantial support for this contention in the literature (CSR, 1997; Dishion, Kavanagh \& Kiesner, 1999; Larson, Eccles \& Gootman, 2004).

Role of adolescents' environment in influencing involvement in risk behaviors

It is generally accepted that a confluence of factors is responsible not only for adolescent development, but also for maladaptive behavior, and that no one risk factor is independent in its impact on life course development (Howard \& Johnson, 2000). Mayes and Suchman (2006) discuss the role of societal and cultural risk factors, such as accessibility of drugs and relationships with family members and peers, ascribing considerable importance to these relationships in determining developmental pathways. Increasingly, there is consensus that the early years of childhood are crucial to the quality of subsequent developmental outcomes (Davies et al., 2002; Shonkoff \& Phillips, 2000; Sullivan, 2006). The rationale for this contention is that the quality of early experiences helps to establish an "indelible blueprint," and early adversities and resources also provide a foundation for successive developmental transitions (Shonkoff \& Phillips, 2000). The social, emotional, intellectual and moral development of children require increasingly complex interactions with at least one adult with whom the child has a 
strong attachment, and who has a long-term commitment to the child's development and well-being (Bronfenbrenner, 1990; CSR, 1997; Sullivan, 2006).

In order to successfully reduce the occurrence of risk behaviors among adolescents, it is necessary to understand individual-context interactions that either reduce or promote risk behaviors, to facilitate the development of interventions that are likely to positively impact their developmental trajectories. Positive youth development programs seek not only to address deviance or psychopathology among participants, but also to provide a framework that allows adolescents, in general, to develop a sense of purpose, achieve self-mastery and thrive (CSR, 1997; Kurtines et al., 2008). Such a holistic approach, that avoids being solely problem-focused, and provides opportunities for the development of prosocial behaviors among adolescents while targeting negative behaviors, is considered more appropriate for successfully deterring harmful activities, and for promoting positive development (Bogenschneider, 1996; CSR, 1997; Wolfe et al., 2006; Youngblade et al., 2007).

Adolescents are engaged in a number of social resource domains, such as family, peers, school and the community, that expose them to positive and negative social influences. Wolfe et al. (2006) identified several protective factors that diminish the likelihood of adolescents' participation in risk behaviors. For example, positive parentchild relationships, regardless of family form, race and ethnicity or socioeconomic status, serve as a protective factor against the early onset of sexual activity and substance use in adolescents. Positive peer association can be a powerful influence for encouraging attitudes that embrace school achievement. School connectedness, despite being a more recently defined and measured phenomenon, is considered a significant protective factor 
for youth. Communities that promote positive adolescent development through mentoring, tutoring, leadership and community service opportunities also serve a protective role (CSR, 1997).

Role of parent-adolescent relationships in adolescent substance use and sexual activity

The family is a critical foundation for adolescent development, and is the context that has received the most consistent attention, concentrating primarily on parentadolescent relationships (Steinberg \& Morris, 2001). Substance use is considered perhaps the most researched outcome in relation to parent-adolescent relationship, and several studies have found that positive parent-adolescent relationship is linked to less use or abstention from substances (Hair, Moore, Garrett, Kinukawa, Lippman \& Michelsen, 2003). Parent-adolescent relationship quality and parent-adolescent communication are considered key variables in processes that mitigate adolescent problem behavior (Dekovic, Janssens \& Van As, 2003; Kotchick et al., 2001). Contrary to the contention professing the diminished role of parents in adolescent psychosocial well-being, research studies have determined that quality parent-adolescent relationship and parental support are associated with positive teen outcomes that include fewer risk behaviors, such as substance use, delinquency and sexual activity. Parental acceptance is believed to impact positively adolescents' psychosocial developmental outcomes. The implication is that adolescents respond to different aspects of their parents' behavior, with poor parentadolescent relationship or negative behavior toward them likely to result in undesirable outcomes (Wills et al., 2004).

The influence of the parent-adolescent relationship is also evident in school connectedness and academic outcomes, with prosocial behavior at school, fewer 
suspensions, less high school dropout, better grades and higher academic expectations being associated with the quality of the relationship (Hair et al., 2003). The Hair et al. (2003) study also found, however, that the percentage of youth reporting positive parental relationship decreased among older adolescents. There was also a same sex gender association in parental relationships, with girls more inclined to rate their relationship with their mother as positive, while more boys tended to rate their relationship with their father as positive. Also, there was a higher percentage of positive relationships in families with two biological parents, which again highlights the influence of family structure. The scale used in the study to measure parent-adolescent relationships generated more positive findings for White adolescents from a higher socioeconomic background, compared to Black and Hispanic adolescents from a similar socioeconomic status. Low income Black and Hispanic adolescents had the least positive findings pertaining to parent-adolescent relationships. The difference in findings was attributed to the possibility that other factors were more important to the outcomes in the study among low income and minority subgroups, and these factors needed to be included in the scale for future studies (Hair et al., 2003).

The parent-adolescent construct has been described in various ways. It has been characterized in terms of parent-child attachment, connectedness, the extent of communication on major issues, and a relationship that includes warmth or affection (Hair et al., 2003). As the most proximal influence in children's daily experience, parents are responsible for providing a safe and nurturing environment that fosters their individuality, and facilitates the pursuit of new physical, social and cognitive capabilities. Parents are expected also to establish and enforce reasonable rules and standards and 
monitor their child's activities. The quality of the parent-child relationship is important to parenting practices, and failure to accomplish parental responsibilities is associated with problem behavior in adolescents (Dekovic et al., 2003).

The family provides the support and internal working models that drive decisionmaking and behavior. This process begins in the early stages of childhood when, based on attachment theory, children develop secure attachments to their caregivers. As they emerge from childhood, and seek more independence, adolescents are inclined to associate more with peers and emulate their behavior, while parents' influence may become less exclusive and more complementary to other sources. A battle is often waged between internal working models and peer influences in decision-making processes, and the outcome, more often than not, determines the direction of the behavioral compass toward innocuous activities or risky pursuits. Too often, decisions to engage in risk and/or inappropriate behaviors are detrimental to the well-being of adolescents (Borawski, Ievers-Landis, Lovegreen \& Trapl, 2003; Jaccard, Blanton \& Dodge, 2005; LoConte, O’Leary \& Labouvie, 1997).

Dekovic et al. (2003) in their study of problem behavior among adolescents examined the relation between proximal factors, such as parent-adolescent relationship, and problem behavior among adolescents. They also considered whether proximal factors mediated the relation between global factors, such as family structure, and adolescent problem behavior. These authors determined that there is a unique and significant association between parent-adolescent relationship and adolescent problem behavior, and that parent-adolescent relationship mediated the association between family structure and 
problem behavior among adolescents. However, family structure was deemed a weak predictor of parent-adolescent relationship and problem behavior.

CSR (1997), in its report, adopted a different perspective, however, and did not attribute adolescents' failure to achieve positive psychosocial outcomes to participation in problem behavior. Rather, they suggested that "it may be the absence of support from families, societal institutions, communities and friends - rather than any given problem behavior - that explains the failure of some adolescents to achieve successful adulthood" (p.5). This contention is plausible, because as CSR stated many adolescents experienced problem behavior at some point during this stage, and managed to follow successful pathways to adulthood.

Guiding adolescents to achieve their full potential and a successful transition to adulthood is integral to the process of promoting positive development. Adolescents need a life purpose to pursue, and someone to coach them in the direction of achieving their life goals. A parent or primary caregiver would appear to be the logical choice to assume this role, but when these relationships are fractured or dysfunctional, there needs to be capable and suitable surrogates to assume this critical role. Adolescents without a life purpose are more inclined to engage in risk behaviors (Harris et al., 2002), and have negative developmental trajectories with maladaptive outcomes.

Parent-child relationships change during adolescence (Hair et al., 2003), to coincide with normative age-graded and socially-mediated developmental changes and needs that occur during this stage, as adolescents seek to establish more autonomy from parents and peer relationships become more important (Steinberg, 2001). This author also found that authoritative parenting proved more effective than other parenting styles in 
achieving positive parent-adolescent relationships, and there was a diminished likelihood of the "storm and stress" predicted to be evident in the transition from childhood to adolescence. In fact, studies revealed that nearly $75 \%$ of adolescents had harmonious relationships with their parents, and that the majority of the other $25 \%$ had problematic parent-child relationships that preceded adolescence (Steinberg, 2001). Authoritative parents are characterized as "warm and involved, but firm and consistent in establishing and enforcing guidelines, limits, and developmentally appropriate expectations" (Steinberg, 2001, p. 7). There is, however, another feature of authoritative parenting in adolescence that pertains to "psychological autonomy," or the degree to which parents allow and encourage adolescents to develop their own opinions and beliefs, which fosters social competence, and serves a protective role.

Adolescents with the support of authoritative parents or caregivers tend to be resilient to normative challenges that typically occur during this developmental stage. Steinberg (2001) and colleagues studied the impact of authoritative parenting on adolescents across different socioeconomic, racial and ethnic groups, and found that this parenting style was the most conducive to positive psychological development, with a diminished likelihood for these adolescents to engage in antisocial activities, such as delinquent behavior and drug use. These adolescents were found also to have higher academic achievement, except for Black adolescents, and to report higher scores for selfreliance and self-esteem, which according to Jessor's (1987) Problem Behavior Theory diminished proneness for participation in risk behaviors. For Black adolescents, the influence of their peers against academic achievement counteracts the influence of authoritative parenting in their homes (Steinberg, 2001). Firmness was the characteristic 
of authoritative parenting considered most important as a restraint against participation in problem behaviors, such as substance use and delinquent behavior, because it sets expectations consistent with prosocial behaviors, and fostered academic competence (Steinberg, 2001). In another study of risk behaviors among adolescents, Borawski et al., (2003) found that trust established between female participants and their parents was a strong deterrent for participation in risk behaviors, but had little effect on behaviors of adolescent males, because males attributed less importance to parental trust. This underscores the need to be cognizant of gender differences in response to similar motivation.

The effectiveness of authoritative parenting transcends developmental stages as children progress along a trajectory and achieve more competence and psychological well-being in their transition to adulthood. According to Steinberg (2001), there are several factors responsible for the effectiveness of authoritative parenting. Parental nurturance and involvement promotes receptivity to parental influence, thereby facilitating more effective and efficient socialization of adolescents. A family setting that provides support and structure also promotes the development of self-regulatory skills, which are conducive to competent and responsible socio-emotional functioning. Effective communication, that encourages mutually beneficial exchanges between parents and adolescents in authoritative families, cultivates cognitive and social competence, and enhances individual functioning outside the home. Adolescents with authoritative parents also benefit from enhanced psychological autonomy, and they are considered relatively more competent than other teenagers, which enhances their interactions with peers. 
In acknowledging the importance of authoritative parenting in promoting positive developmental trajectories during adolescence, it is imperative to enlighten parents regarding the process of raising and nurturing prosocial children (Steinberg, 2001), in order to facilitate their positive psychosocial development, and reduce their participation in risk behaviors during adolescence. Steinberg states that parents and other primary caregivers need three types of information. Basic information pertaining to normative developmental changes in adolescents is necessary to facilitate parents' better understanding and response to their children's behavior. Basic information pertaining to the principles of effectively parenting adolescents is required also, so that parents can adapt to the changing needs and characteristics of their children. Finally, parents need some insight into the changes occurring within each member of the family during the adolescent transition.

Role of family structure in substance use and sexual activity among adolescents

Considerable research on associations between family structure variables and developmental outcomes for children and adolescents has been conducted over the last several decades. There seems to be considerable consensus that families with two married biological parents create environments more conducive to the cognitive, social, emotional, and behavioral well-being of children and adolescents. Moreover, children born to two married parents are twice as likely $(70 \%$ v $36 \%)$ to spend their entire childhood with both biological parents, compared to children born to cohabiting couples (Morgan, 2000). However, despite several research studies supporting the finding that the traditional nuclear family structure is more conducive to positive developmental outcomes and the avoidance of risk behaviors among adolescents, at least one study 
(Blum et al., 2000) considers this insufficient grounds on which to predict adolescent behavior.

Blum et al. (2000), in their study, found that family structure contributed significantly to the likelihood that adolescents engaged in risk behaviors. Their study used a representative sample of 11,000 adolescents (71.1\% White, 16.3\% Black, and 12.6\% Hispanic) from the Add Health Study to examine the role of race, ethnicity, income and family structure in the development of adolescents' use of cigarettes and alcohol, engagement in violence and sexual activity, and risk of suicide. A little less than one-third (31.1\%) of the participants were from single-parent families, while just over two-thirds (68.9\%) reported intact family status. No distinction was made regarding stepparent, adoptive or foster parents among those who reported membership in twoparent families, since no significant difference was detected when biological families were studied separately.

Controlling for the other variables, the impact of each variable in the Blum et al., (2000) study was examined independently. It was determined that regardless of grade, race or income, adolescents from single-parent families were significantly more likely to smoke. Adolescents from single-parent families were also more inclined to consume alcohol, to have a higher prevalence of suicidal thoughts and attempts, to be involved in violent activities, and to engage in sexual intercourse. Despite their findings, the authors considered these demographic factors an insufficient basis for accurately developing targeted interventions or policies, because of the confluence of other factors that need to be considered in understanding and effectively addressing the development of risk behaviors among adolescents. 
Lee, Akers and Borg (2003) argued that, all things considered, two parents are more capable than a single parent to supervise their children, ensure normative behavior, prevent association with deviant peers and counter adverse peer influences. However, they also maintained that the parent-adolescent relationship had to be considered, because adolescents in single-parent households that provided consistent discipline, a loving environment, adequate supervision, firm but fair parental control, and insulation from deviant peer and other influences would be less likely to participate in deviant activities than adolescents from two-parent households where these features of family control and socialization did not exist. Moreover, in order to address the family process issues that adolescents from non-intact families experience, mentoring and other related initiatives could be incorporated into risk behavior interventions, and thereby potentially mitigate the presumed negative impacts adolescents in single-parent families experience.

Research has found that external factors, such as mentoring, positively impact the parent-adolescent relationship. In their study, Rhodes, Grossman and Resch (2000) determined that not only did mentoring improve parent-adolescent relationships, but also had a direct positive effect on scholastic competence and school attendance. When both direct and indirect effects were considered, mentoring was associated with statistically significant improvements in parental relationships, the value of school, scholastic competence, grades and school attendance. The effect on the value of school and grades was primarily indirect and derived through mentoring's impact on the parental relationship, and the adolescent's perceived academic competence. Rhodes et al. (2000) concluded that although it was not the only determinant, improved parental relationships represent key mediators of change in adolescent's academic outcomes and behavior. The 
Blum et al. study found that adolescents' positive relationships with parents and family members were protective across all risk behaviors, and the authors considered demographic factors to be weak predictors of risk behaviors among adolescents, accounting for less than $10 \%$ of the variance in them. It appears, therefore, that despite the presumed advantage adolescents in intact families have, parent-adolescent relationships are more important than specific family structures. This finding is consistent with that of the Dekovic et al. (2003) study discussed earlier.

It seems incontrovertible that family structure, as the framework for parent-child relationships, plays a role, albeit weaker than the parent-adolescent relationship, in the quality of adolescents' developmental outcomes. Brown (2004) conducted a study of family structure and adolescent well-being, which found that cohabitation, including households with two biological parents and those with one biological and a stepparent, was not conducive to the well-being of adolescents. Adolescents in homes with cohabitating adults had more behavioral and emotional problems than adolescents reared in households with married biological parents. They were also more likely to have academic problems and lower scores for cognitive abilities compared to children from family with more traditional married two-parent structures. Adolescents in cohabiting stepfamilies experienced significantly higher levels of behavioral and emotional problems and lower levels of school engagement, on average, than those in marital unions with two biological parents, because considerable levels of instability they experienced in the past exacerbated brief disruptions in educational performance that often had protracted consequences. Adolescents, especially boys, with two biological cohabiting parents also had more behavioral and emotional problems, on average, than 
their counterparts in married families, but there was no difference between the two groups with regard to school engagement.

The likelihood of graduating from high school is lower for adolescents born outside of married, two biological parent families. There is, however, no differential effect between being born to cohabiting parents or a single parent. This finding supports previous research, which suggests that living outside of a two married parent family is more important than the specific family type at the time of birth (Manning \& Bulanda, 2006).There are significant differences among youth from "intact" families based on whether both biological parents are married or cohabiting, and if there are children in the household from previous relationships (Apel \& Kaukinen, 2008).

Delinquency research has consistently found that youth from "broken" homes were at greater risk for participation in antisocial behavior than those from biologically "intact" households, with the prevalence rate being 10-15 percent higher in families with unmarried, divorced, single-parent, or separated parents (Apel \& Kaukinen, 2008). These authors conducted a study with a sample of 8,330 adolescents to determine if there is a significant relationship between family structure and antisocial behavior. Antisocial behavior was operationalized as a 24-item summed score of self-reported problem behaviors, such as running away from home, school suspensions, substance use, property crime, violence, and illegal income. The study found that children residing in a cohabiting family with a single biological parent and a nonbiological partner had an unusually high rate of antisocial behavior, particularly when the biological father was the custodial parent. Serial cohabitation was also considered to have an adverse influence 
upon a number of domains for children and adolescents (Bachman, Coley \& ChaseLansdale, 2004; Manning \& Bulanda, 2006).

It is evident that family structure influences parent-adolescent relationships and developmental outcomes among adolescents. It has also been determined that parentadolescent relationship mediates the association between family structure and adolescent problem behavior. In a study of the relation between family structure and its role in family processes and adolescent antisocial behavior, Zeiders, Roosa and Tein (2011) found that parent-child conflict was a significant mediator of the association between family structure and adolescent outcomes. However, research indicates there is divergence concerning this relation. In a study of parent-adolescent relationship in single versus two-parent families, it was determined that there was more conflict, less positive communication, and lower family cohesion among adolescents in single-parent families. One study determined that these differences mediated the association between family structure and adolescent outcomes, while another study reached a different conclusion (Zeiders et al., 2011).

It was suggested that the disparate findings could be due to cultural factors, because the effects of family structure and associated processes might be different in Latino families, due to the importance of extended family members. There was disagreement here also, as some suggested less deleterious effects of single parenthood, based on the reliance on extended family members, while others believed the impact would be greater because single parenthood contravened the conventional two-parent family norms (Zeiders et al., 2011). The Zeiders et al. (2011) study disavowed these contentions, and found the difference between the outcomes for adolescents in Mexican- 
American families, based on family structure, was consistent with previous findings pertaining to European-American and Black families. The study determined that family structure accounted for less than $2 \%$ of the overall variance in adolescent outcomes. There was also no difference in the parent-adolescent relationship between two-parent and single-parent families. Findings from the current study should contribute, not only to an understanding of the multivariate association influencing adolescent outcomes, but also to the discussion on the role of cultural factors in relation to family structure and adolescent outcomes, because of the racial, ethnic and cultural diversity in the sample.

Regardless of parental or economic resources, the developmental outcomes for adolescents in cohabiting families were worse, on average, than comparable outcomes for adolescents in two biological parent married families, except for the levels of school engagement in two biological parent cohabiting families. It is surmised that adolescents were less likely to accept the presence of a cohabiting partner as legitimate, or that parental cohabitation may negatively impact family processes in a more profound manner at this developmental stage. Adolescents considered the cohabiting relationship as being more sexual, and also viewed the cohabiting partner as a threat to their parental relationship (Bachman, Coley \& Chase-Lansdale, 2004; Brown, 2004).

Considerable research on associations between family structure variables and specific developmental outcomes for children and adolescents has been conducted during the past several decades. Despite methodological difficulties associated with the operationalization of measures and divergent findings, there seems to be consensus that families with two married biological parents create more stable home environments most conducive to the cognitive, social, emotional, and behavioral well-being of children and 
adolescents, as indicated by more positive psychosocial outcomes (Amato, 1995, 2005). Approximately $52 \%$ of children in cohabiting unions experience the dissolution of their parents before age 5, compared to $8 \%$ for children of married couples (Brown, 2004). Children and teens involved in substance use and the juvenile justice system were more likely to be the product of divorced or dysfunctional families (CASA, 2004).

Children in single-parent or nontraditional family structures often lacked the parental social resources that contributed to the development of desirable psychosocial outcomes (Brown, 2004; Grolnick \& Ryan, 1992). Wallace and Bachman (1991) concurred with this contention, indicating that adolescents in two-parent households were less likely to engage in substance use. Although family structure is given, efforts may be made through targeted interventions to circumvent the potentially adverse effects of presumably less than optimal family forms, for example, linking adolescents with positive adult models to promote prosocial behavior is considered protective (Yates \& Masten, 2004). Mentoring, through role modeling, tutoring and encouragement, provides the guidance and support from a non-resident adult that improve parent-adolescent relationship and lead to associated improvements in academic and behavioral outcomes (Rhodes et al., 2000). The synergistic association between mentors and parents can have a positive impact on adolescents' improvement in several domains (Rhodes et al., 2000), and perhaps mitigate the negative effects attributed to growing up in a dysfunctional or fragmented family.

Adolescents who feel cared for and connected to others are significantly less likely to engage in substance abuse, premature sexual activity or other risk behaviors (Resnick, Bearman, Blum \& Bauman, 1997). There is also the contention that caring 
adults have more profound impacts on the life course of children and adolescents than any threat posed by specific risk factors (Werner \& Johnson, 2004). Children who experienced positive developmental outcomes had warm, sensitive and cohesive family relationships, positive peer relationships, faith and religious affiliation, as well as supportive kinship networks. Protective community networks have excellent educational systems, nurturing teacher-child relationships, safe housing and neighborhoods, and available adult models to promote prosocial involvement.

In the course of probabilistic interactions among variables, the impact of specific risk factors on children's behavior may be mediated completely by intervening factors and associated processes operating at broader contexts (Clarke-Stewart \& Dunn, 2006). They posited that the significant mediator could be any system that influenced the child's behavior, such as the family, neighborhood and schools. The family, they contended, had the capacity to generate various risks, assets and opportunities over the developmental trajectory from genes to the environment (Clarke-Stewart \& Dunn, 2006).

\section{Role of school connectedness in substance use and sexual activity among adolescents}

Another factor impacting adolescent participation in risk behavior is the lack of connectedness to school, as reflected in poor grades, grade retention and dropping out of high school. The social development model contends that weak school connectedness gives adolescents license to abandon conventional norms that deter problem behaviors, specifically substance use (Henry \& Slater, 2007). School is considered one of the most essential ecological contexts for promoting positive development among adolescents. It is the principal environment for adolescent social interaction with peers, the development of interpersonal skills, the establishment of peer groups, self-expression and self- 
development (Henry \& Slater, 2007). School failure has been implicated as a risk factor in the development and maintenance of risk behavior among adolescents (Blum et al., 2000), and grade retention was considered a major predictor of dropping out of school.

Grade retention describes the practice of students repeating the same grade for a subsequent year to meet grade level academic standards for promotion to the next grade. It has been determined that, nationally, approximately a third to a half of students will experience grade retention at least once by the ninth grade. The increased emphasis on standards and accountability, in recent years, has resulted in an upward trend in retention rates among students, as calls for the termination of social promotion have become more pronounced. Nationally, almost $5 \%$ to $10 \%$ or more than 2.4 million students are retained annually (Jimerson, 2001). Students who were retained were considerably more likely to exit the school system (Alexander, Entwisle, \& Kabbani, 2001; Hirschman, PharrisCiurej, \& Willhoft, 2006). Academic achievement is believed to be a significant protective factor in dissuading substance use among adolescents (Bachman, O'Malley, Schulenberg \& Johnston, 2007; Henry \& Slater, 2007; Petraitis, Flay \& Miller, 1995), and deterring delinquency, teen pregnancy, and dropping out of school (Henry \& Slater, 2007). It has been determined also that adolescents with high academic and career aspirations are less inclined to engage in delinquent behavior (Hirschi, 1969).

Research indicates that the quality of the parent-adolescent relationship mediates the association between school connectedness and developmental outcomes by "modifying the impact of other sources of influence and by transmitting them to adolescents through moment-moment exchanges between parents and children" (p. 346, Collins \& Laursen, 2004). 


\section{Role of religiosity in substance use and sexual activity among adolescents}

There is mounting evidence that religiosity is an important influence on problem behavior in adolescents. Research has found that adolescents with strong religious beliefs are more inclined to demonstrate more prosocial behaviors and less high risk behaviors (Dollahite \& Thatcher, 2008; Longest \& Vaisey, 2008; Sinha, Cnaan \& Gelles, 2007). Religiosity is associated with social networks and activities that deter problem behaviors among adolescents (Donovan, 2004; Jessor et al., 1991; Longest \& Vaisey, 2008). There have been divergent findings, however, pertaining to bivariate relations between religiosity and problem behavior, as mentioned earlier in this study (Kotchick et al., 2001), and also regarding multivariate relationships among religiosity, parental processes and problem behaviors. This has been attributed to methodological issues, specifically the measurement of religiosity (Pickering \& Vazsonyi, 2010).

Pickering and Vazsonyi (2010) distinguish between ritualistic and relational religious behavior, in their characterization of religion as a multidimensional concept with distinct and separate influences on problem behavior. Ritualistic religiosity, such as church attendance or spiritual reading, represents a formal commitment to behaviors or beliefs that have little or no correlation to the inculcation of moral standards. Conversely, relational religiosity underscores the incorporation of moral standards into behavioral practice. The importance of this distinction is evident in disparate findings among research studies examining the influence of religiosity on problem behaviors, and the strength of the relationship. Pickering and Vazsonyi (2010) put it succinctly in stipulating "there is more to being "religious" than just going to church" (p.111), and emphasized the 
need to use reliable scales rather than single items to measure the influence of religiosity on behavior.

The impact of the distinction between ritualistic and relational religiosity, and associated measurement issues, is illustrated in pertinent research studies. In their pivotal study, Hirschi and Stark (1969) determined there was no difference in the proclivity to participate in delinquent behavior between adolescents who attended church versus those who did not attend. Several subsequent studies were conducted by various authors and the overwhelming majority found that there was a statistically significant negative effect of religiosity on deviant behavior. Pickering and Vazsonyi (2010) suggested that the divergent results were due to the use of single-item versus multi-item scalar measurement of religiosity, which failed to capture the spectrum of the concept. Thus, the deficiency inherent in studies using single-item measures of religiosity has been increasingly acknowledged in the literature (Pickering \& Vazsonyi, 2010). The present study used a scalar single-item self-report measure on how religious adolescents considered themselves and, despite the criticism of a single-item measure of religiosity, there is still the expectation to capture both ritualistic and relational religious commitment among participants that is manifested in the practice of moral behavior.

In addition to its direct effect on behavior, there is evidence that parent-adolescent relationships mediate the relationship between adolescent religiosity and participation in risk behaviors. Parents have a tremendous influence on adolescent religiosity, and religiosity has a positive impact on parent-adolescent relationship. Highly religious adolescents had the highest quality parent-adolescent relationship in every area considered, including levels of honesty, acceptance and understanding; getting along; and 
feeling close to their parents (Dollahite \& Thatcher, 2008). The quality of parentadolescent relationships is predictive of risk behaviors among adolescents, with positive relationships associated with less participation in these behaviors (Davies, Crosby \& DiClemente, 2009). Honoring one's parents is a familiar biblical exhortation of which religious adolescents would be expected to be aware. Pickering and Vazsonyi (2010) conducted a study, however, which determined that family processes did not mediate the relationship between religiosity and deviance. The present study tests the relationship between religiosity and parent-adolescent relationship, and whether parent-adolescent relationship mediates the relationship between religiosity and risk behaviors among adolescents.

Role of peer relationships in substance use and sexual activity among adolescents Steinberg (2001) argues that it is inconceivable for adolescents to be more influenced by their interactions with peers, while they are unaffected by their relationships with parents with whom they have spent their entire lives and who have raised and tried to socialize them during childhood. Garnier and Stein (2002) found that "consistent with the body of research on adolescent problem behaviors, peer behaviors were by far the strongest predictors of adolescent problem behaviors" (p. 53). Jaccard et al. (2005) concluded from their study of peer influence on risk behavior that there was a correlation between engaging in substance use and sexual activity and having friends who participate in these behaviors. The similarities among adolescents and their friends are based on the tendency for adolescents to choose friends with similar traits, values and inclinations. However, parents also play a significant role in choosing their children's 
peer associations, and tend to steer them toward prosocial peers and away from antisocial peer and social influences (Steinberg, 2001; Steinberg \& Morris, 2001).

Research suggests that both family and school connectedness influence peer associations. Adolescents who have close parental relationships are more inclined to affiliate with peers whose values are congruent with those of their parents, thereby strengthening parental values. However, those lacking close parent-adolescent relationships tend to seek friends whose values are discordant to their parents. Hence, while it appears peers exert considerable influence on adolescent behavior, early parental influences determine peer associations, with involvement in problem behavior dependent on whether these peers have prosocial or antisocial proclivities (Garnier \& Stein, 2002). The exception to parental influences superseding peer influences was mentioned earlier, with regards to academic achievement among Black adolescents, where among other racial and ethnic groups authoritative parenting had a positive influence in this area (Steinberg, 2001). The parent-adolescent relationship is a mediator through which peer influences determine participation in substance use and sexual activity.

Thus, the characteristics attributed to peer influence have been established in large part prior to the development of peer relationships. This contention is supported in a longitudinal study Sullivan (2006) conducted, in which it was suggested that childhood emotional and behavioral problems significantly influenced later developmental outcomes. However, despite these early and continuing parental influences, peer associations are important in enhancing dispositional characteristics of adolescents. In their study of family and peer effects on adolescent drug use, Garnier and Stein (2002) 
found that teen drug use was highly correlated with peer drug use, and explained $76 \%$ of the variance.

Bahr et al. (2005) conducted a study to determine the direct and indirect effects of family characteristics on the risk of adolescent drug use, and how peer influence mediated these characteristics. Based on social learning theory, where attitudes and behavior are learned, they concluded peer influence mediated the effect of family characteristics on adolescent substance use. Predicated on Sutherland's differential association theory, they maintained that learning occurs according to the frequency, duration, intensity, and priority of social interaction. Adolescents are, therefore, predisposed to acquire favorable drug attitudes, if they interact frequently with others who use drugs and have similar attitudes toward drug use. They stipulated that "learning is more likely to occur when interactions are intense as opposed to casual and superficial. Intense interactions tend to occur in primary groups such as families or close friends" ( $p$. 530). Adolescents are inclined to heed and regard individuals they admire and consider role models, and if these individuals have a favorable disposition to drug use and engage in this activity, they are likely to emulate and internalize these attitudes and behaviors (Bahr et al., 2005).

Social control theory maintains that deviance is normal and conformity rather than deviation needs to be explained. Hence, adolescents' natural instinct is toward deviance, to which they would gravitate without prosocial controls that families and social institutions provide. Adolescents who have distant parental relationships may not feel as obliged to conform to parental controls and, therefore, more likely to experiment with drugs. According to social learning and social control theories, parent-adolescent 
and peer relationships are key predictors in determining adolescents' proclivity toward substance use (Bahr et al., 2005). The Bahr et al., (2005) study concluded that family variables had significant impacts on adolescents' substance use, and the effects of these variables were partially mediated by peers. The present study tests the association between parent-adolescent relationship, peer relationship and adolescent substance use, and whether parent-adolescent relationship or peer relationship is the mediator.

Co-occurrence of risk behaviors

Based on the literature review conducted for this study, research has documented the prevalence of substance use in the context of other risk behaviors, such as precocious and unprotected sexual activity (Biglan \& Cody, 2003; Biglan \& Hinds, 2009; Centers for Disease Control (CDC), 2008; Harris, Duncan \& Boisjoly, 2002; Jessor \& Jessor, 1977; Jessor, et al., 1995; Kotchick et al., 2001; Langer \& Tubman, 1997; Riesch et al., 2006; Wolfe et al., 2006). Substance use has also been cited for the considerable developmental risks it posed for adolescents and its major contribution to behavioral problems (Mayes \& Suchman, 2006). Numerous studies (e.g., Blum et al., 2000; Bonino et al., 2005; Langer \& Tubman, 1997; Riesch et al., 2006; Wolfe et al., 2006), have investigated multiple factors to identify their role in maladaptive behaviors, and billions of dollars spent on interventions to address these behaviors among multi-problem adolescents have had minimal impact in effecting change (Steinberg, 2008). The lack of an integrated approach and presumed methodological deficiencies (Bogenschneider, 1996; Kotchick et al., 2001) have been indicted for this failure.

There is a lack of research adopting a multivariate, integrated approach to study the hypothesized model of the relations between contextual variables and co-occurring 
substance use and sexual activity among a sample of multi-problem adolescents participating in outpatient substance use treatment. The current study aims to fill this gap in the literature. The present study uses an integrated conceptual model, based on four theoretical approaches and findings from research studies presented in the literature review, to examine the hypothesized relationships among the variables and whether they fit the data collected. The independent variables in the study are family structure, parentadolescent relationship, school connectedness, peer relationship, and religiosity.

Research indicated that, compared to non-intact family structures, intact families were more conducive to positive developmental pathways and psychosocial outcomes among adolescents (Apel \& Kaukinen, 2008; Amato, 1995; 2001; 2005; Brown, 2004; Manning \& Bulanda, 2006). However, Yates and Masten's (2004) resilience framework, Bogenschneider's (1996) risk and protective processes, and research studies (Blum et al., 2000; CSR Incorporated, 1995) considered the parent-adolescent relationship more protective than family form with regard to positive developmental outcomes. The studies that considered family structure to be more predictive than parent-adolescent relationships, either did not consider parent-adolescent relationships or deemed non-intact structures to be detrimental to these relationships. The Blum et al. (2000) study regarded demographic factors, including family structure, as weak predictors of risk behaviors among adolescents, and being responsible for less than $10 \%$ of the variance in them. Conversely, they found that positive relationships with parents and family members were protective across all risk behaviors. The present study seeks to address divergent findings evident in prior research conducted with regards to family structure, parent-adolescent relationship, and peer relationship. 
The other contextual variables in the hypothesized model, school connectedness, and religiosity, are also research-driven and reflect the conceptual framework and/or studies outlined in the literature review that document the correlation between each of the independent variables and the outcome variable co-occurring substance use and sexual activity. There is also evidence that parent-adolescent relationship and peer relationship are important mediators that influence the association between the independent variables in the study - religiosity (Dollahite \& Thatcher, 2008); and school connectedness (Collins \& Laursen, 2004) - and the outcome variable co-occurring substance use and sexual activity. However, Pickering and Vazsonyi (2010) determined that family processes did not mediate the association between religiosity and deviance among adolescents.

\section{The Current Study}

It is well-documented that an integrated, holistic approach is more conducive to understanding the factors associated with risk behaviors among adolescents (Bogenschneider, 1996; Kotchick et al., 2001). The study seeks to determine whether family structure or parent-child relationships are more predictive of adolescent participation in co-occurring substance use and sexual activity. It also seeks to determine the explanatory contribution of the other variables, school connectedness, peer relationship, and religiosity to the hypothesized model, and whether parent-adolescent relationship or peer relationship mediates the association between these variables and problem behavior among adolescents. In essence, what is the effect of these contextual variables on the outcome variables co-occurring substance use and sexual activity among multi-problem youth participating in outpatient substance use treatment? 
The study, therefore, seeks to address the following questions and associated hypotheses.

- Question 1: What is the association between the independent variable family structure and the outcome variable co-occurring substance use and sexual activity?

- Hypothesis 1: The type of family structure in which adolescents live will have a direct effect on adolescents' participation in substance use and sexual activity.

- Question 2: What is the association between parent-child relationships and a) peer relationship; and b) co-occurring substance use and sexual activity?

- Hypothesis 2: Parent-adolescent relationship will a) have a direct effect on adolescents' participation in substance use and sexual activity, and b) parentadolescent relationship will mediate the association between peer relationship and co-occurring substance use and sexual activity.

- Question 3: What is the association between the independent variable grade retention and (a) parent-adolescent relationship and (b) the outcome variable cooccurring substance use and sexual activity?

- Hypothesis 3: Grade retention will have a direct effect on adolescents' participation in substance use and sexual activity, and parent-adolescent relationship will mediate the relationship between grade retention and substance use and sexual activity. There will be an inverse relationship between grade retention and co-occurring substance use and sexual activity. 
- Question 4: What is the association between the independent variable peer relationship and (a) parent-adolescent relationship and (b) the outcome variable co-occurring substance use and sexual activity?

- Hypothesis 4: Peer relationship will have a direct effect on adolescents' participation in substance use and sexual activity, and parent-adolescent relationship will mediate the relationship between peer relationship and substance use and sexual activity. There will be a direct association between peer relationship and co-occurring substance use and sexual activity, with stronger peer relationship linked to more risk behavior.

- Question 5: What is the association between the independent variable religiosity and the outcome variable co-occurring substance use and sexual activity?

- Hypothesis 5: Religiosity will have a direct effect on adolescents' participation in substance use and sexual activity. There will be an inverse relationship between religiosity and co-occurring substance use and sexual activity.

In summary, it is hypothesized, and supported in the literature, that parent-adolescent relationship would predict substance use and sexual activity among adolescents, and mediate the effects of having repeated a grade and peer relationships. The alternative model was tested with peer relationship as the mediator. 
Figure 1. Conceptual Model of Hypothesized Relationships

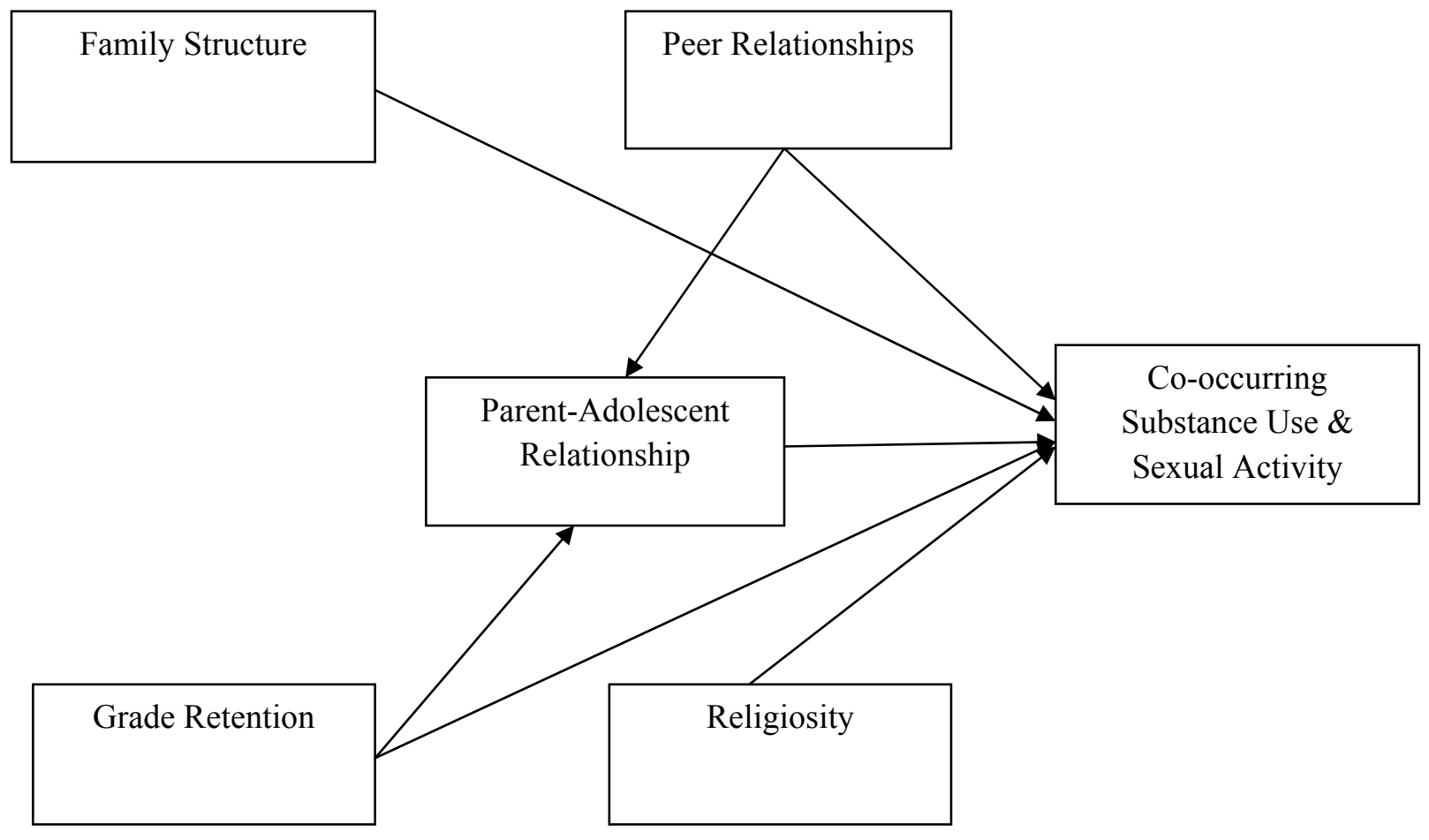


Figure 2. Conceptual Model of Hypothesized Relationships (Alternative)

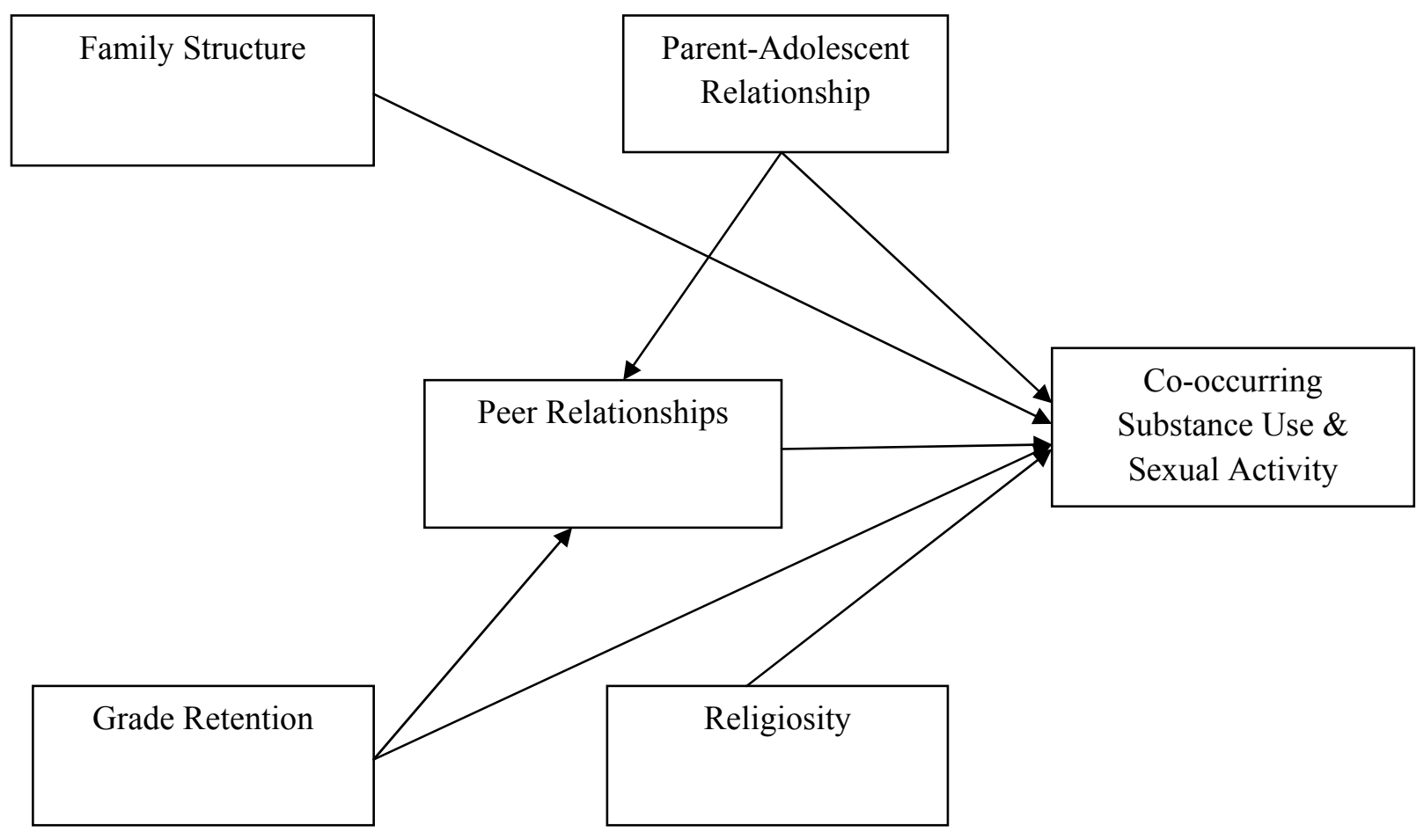




\section{CHAPTER III: METHODS}

“.... the literature lacks a consistent and thorough conceptual framework by which to frame our understanding of adolescent sexual behavior, particularly risk behavior."

-Kotchick et al., 2001, p. 494

Kline, Canter and Robin (1987) point to the failure of primary, secondary and tertiary prevention programs to meaningfully deter underage drinking as an indication that there is a need for "a precise theoretical framework to guide program planning, modification, and implementation" (p.522). It is evident that this need transcends underage drinking, and extends to other adolescent risk behaviors which, as indicated earlier, are believed to co-occur. Thus, structural equation modeling provides the approach most conducive to testing theoretical and conceptual frameworks, from which to construct efficacious interventions that address risk behaviors among adolescents.

In the present study, structural equation modeling (SEM), with AMOS 17.0, was used in a cross-sectional study to determine the direct and mediated relations among the exogenous and endogenous variables, and their patterns of covariation. The theoretical basis of hypothesized relations among predictor and criterion variables is an advantage of structural equation modeling over the use of multiple regression, because conceptuallyderived, empirically-based models may be constructed and evaluated. In essence, structural equation modeling represents a substantial advance over other multivariate analytical techniques because it integrates measurement with fundamental theory. It also allows the simultaneous testing of all structural relations in the model, which reduces the likelihood of Type 1 errors (Guo, Perron \& Gillespie, 2008). Other advantages of structural equation modeling include the capacity to specify measurement error in the 
path model, and statistics that allow an evaluation of the degree to which the entire hypothesized model supports the data (Tremblay \& Landon, 2003).

\section{Description of Database}

The data for the current study was obtained from a NIAAA-funded study (R01 AA014322; PI: Tubman), a randomized clinical trial designed to evaluate the efficacy of a brief motivational HIV risk reduction intervention for adolescents in an outpatient substance abuse treatment program.

\section{Participants}

The current study is based on an archived, cross-sectional data set representing a multicultural sample of 396 adolescents. Males comprised $71.2 \%$ of the sample. The racial/ethnic composition was 25.3\% White; 21\% Black; 5.3\% Asian; and 3.8\% other, that is, being from more than one race or ethnicity, or representing other races or ethnicities. Hispanics, who may be of either race, comprised 44.7\%. Participants ranged in age from 12-18 years old, with a mean age of 16.4 years old. This mean age allowed the study to focus on mid-adolescence, when many changes occur (Dekovic, Wissink \& Meijer, 2004). During recruitment, participants were limited to this age range because they were more likely to be experiencing similar developmental transitions; and had not crossed the threshold to adulthood, where risk behaviors were more likely to become entrenched.

\section{Measures}

Demographics. The study included demographic data that a research interviewer collected on an intake form. The baseline data included age, race, ethnicity, gender, grade point average, extracurricular activities, family structure, socioeconomic status, parent 
occupation and parent educational level. Family structure was defined as primary caregiver, based on the information adolescents provided. Primary caregiver was used as a proxy for family structure, and coded based on responses to the question "who takes care of you on a day to day basis." Responses ranged from mother (1) to other (10). No information was collected on the marital status of parents, so no distinction was made pertaining to living in a family with married, cohabiting or stepparents. Further, in the Blum et al. (2000) study, it was determined that this distinction did not impact the findings of their research on whether family structure was more important than parentadolescent relationship in influencing risk behaviors among adolescents.

Religiosity. Participants' religiosity was measured on a 4-point Likert scale and was assessed based on responses to the question "How religious are you?" Responses ranged from very religious (1) to not at all religious (4).

Parent-Child Relationship Quality and Communication. The quality of parentchild relationships was assessed via parallel parent and child forms of the brief 39-item Children's Rating of Parental Behavior Inventory (CRPBI: Schluderman \& Schluderman, 1970), and operationalized based on three subscales - acceptance, psychological control, and firm control. The CRPBI is predicated on socialization theory, with socialization construed as the role of the parent-child relationship in the social, emotional and cognitive development of children (Grotevant \& Carlson, 1989). It is based on the theoretical assumption that children's perceptions of their parents' behavior toward them influence their social and personality development (Miller \& Hauser, 1989). The measures assess three dimensions of parenting behavior (i.e., acceptance, psychological 
control, and firm/lax control) via 5-point Likert formats rated from "Almost never" (1) to "Almost always" (5).

The first subscale, the Acceptance vs. Rejection factor, assesses parental acceptance of and closeness to the child, and states, for example, "showed me that he/she liked me just the way I am.” The Acceptance factor includes: Positive Involvement, Acceptance, Child-Centered, Acceptance of Individuation, Rejection (reversed), and Hostile Detachment (reversed). The second subscale, the Firm Control vs. Lax Control factor, addresses the degree to which the parent regulates and monitors the child's activities, and states, for example, "my primary caregiver quickly forgot the rules that he/she made." The Firm Control factor includes: Enforcement, Control, Inconsistent Discipline (reversed), Non-enforcement (reversed), and Lax Discipline (reversed). The third subscale, the Psychological Control vs. Autonomy factor, assesses the use of anxiety or guilt induction as a means of discipline, and states, for example, "my primary caregiver tried to control whatever I did." The Psychological control factor includes: Intrusiveness, Control via Guilt, Hostile Control, Possessiveness, Instilling Persistent Anxiety, and Withdrawal of Relations. Cronbach Alpha coefficients for the three factors ranged from .74 to .87 (Kilmann, Vendemia, Parnell, Urbaniak, 2009).

Based on the exploratory factor analysis (EFA) conducted in the present study, there was good internal consistency for the three subscales. The Cronbach Alpha for the Acceptance subscale was .92, the Psychological Control subscale had an Alpha of .83, and the Alpha for the Firm Control subscale was .77. The questions that loaded on each subscale, and their associated factor loadings are shown in the results section of the study. The subscales of the CRPBI have shown good discriminant and convergent validity in 
previous studies (Schwartz, Barton-Henry, \& Pruzinsky, 1985). In addition, this measure has been reliably utilized in studies of parenting practices in ethnic minority families (e.g., Taylor, Casten, \& Flickinger, 1993).

Timeline Follow-Back-Substance Use. Alcohol and other drug consumption at each contact point was measured using the Timeline Follow-Back Interview (TLFB; Sobell, Sobell, \& Ward, 1980; Sobell \& Sobell, 1992, 1996). The TLFB is a widely-used research and clinical assessment tool with good reliability and validity for various groups of individuals with AOD use problems. Alcohol and other drug consumption information was collected using a calendar format to provide temporal cues (e.g., holidays, special occurrences) to assist in recall of days when substances were used. A standard drink was defined as a 12-ounce beer, 5-ounces of wine, 3-ounces of fortified wine, or 1.5 ounces of hard liquor (Sobell \& Sobell, 1992). The TLFB takes approximately 10 minutes to complete, and the computerized version of the interview (Sobell \& Sobell, 1995) was used to collect data on the sample. The TLFB was conducted for the last 180 days at preintervention. The typical TLFB recall period is 180 days and this standard was chosen for a baseline measure. A similar approach to TLFB administration was used in the current community-based intervention study. Data from the TLFB were summarized to yield the following variables: total number of alcohol use days; total number of drug use days; number of days abstinent from alcohol; and, number of days abstinent from drugs. Average number of drinks per drinking day, latency to first drink and latency to first drug use were assessed also.

Timeline Follow-Back-Sexual Risk Behavior (TLFB-SRB).The standard TLFB instrument was modified to collect data regarding adolescents' self-reported sexual risk 
behaviors (i.e., co-occurring substance-use and sexual behavior). Information about sexual risk behavior was collected using a similar calendar format to assist in recall of days when target sexual risk behaviors occurred. To provide a comparable measure of days when sexual risk behaviors occurred, participants completed the TLFB-SRB for the last 180 days at pre-intervention. While this strategy to assess sexual risk behavior is innovative regarding its use with adolescents with AOD use problems, it has been used to study the sexual risk behavior of adult MSM with AOD use problems (Midanik, Hines, Barrett, Paul, Crosby, \& Stall,1998) and psychiatric inpatients (Carey, Carey, Maisto, Gordon, \& Weinhardt, 2001). While estimated sexual risk behaviors generated via the TLFB may be slightly lower than those generated by traditional summary methods, the reliability and validity of this methodology is clearly supported even among population known to have difficulty with self-report measures (Carey et al., 2001). A summary measure of substance use and sexual activity was used, and participants responded to questions pertaining to whether they had used substances before or during sexual intercourse in the last 12 months. A Likert scale was used to collect the responses, which ranged from "Always" (1) to "Never" (5).

Grade Retention. Because failing students experiencing grade retention are more likely to drop out of school, connectedness to school was determined based on measuring grade retention for participants in the study. In the present study, grade retention is a dichotomous measure in which participants responded yes or no to the question "Have you ever repeated a grade?"

Peer Relationships. Communication with peers on several sexual topics, including sexual risk behaviors was used to measure a specific aspect of peer relationships, and was 
assessed by responses to 14 dichotomous items on a checklist of self-reported discussions of sex-related topics (DiIorio, Kelley \& Hockenberry-Eaton, 1999). Items addressed the type of sexual topics adolescents discussed with the following categories of discussants: "their mother, their father, friends, other family members, or no one." The 14 topics included: STD/AIDS; using a condom; sexual intercourse; dating and sex behavior; getting a girl pregnant/getting pregnant; what friends think about teens having sex; the dangers of many sex partners; what mother thinks about teens having sex; how life would change if I became a parent; not having sex at all; birth control; wet dreams; what father thinks about teens having sex; and, menstrual cycle.

Items can be used individually, or they can be summed to generate a total score for topics discussed for each of the four categories of discussants, as well as a count of the issues not discussed with any of these groups of people. Adolescents' willingness to share information with peers on sexual issues is believed (a) to facilitate peer relationship and, (b) to indicate comfort with the discussion of sexual topics. In the present study, items were summed based on the person with whom each topic was discussed. The categories were collapsed also into mothers, fathers, friends, other relatives, and no one. There was good internal consistency for the items participants in the study discussed with their peers, yielding an alpha of .89. Peer relations represented the total number of sexual topics discussed with friends, and was used to indicate the peer relationship variable.

\section{Procedure}

Based on their responses to an HIV intake questionnaire, an intake coordinator identified sexually active clients of the Starting Place or Here's Help as potential

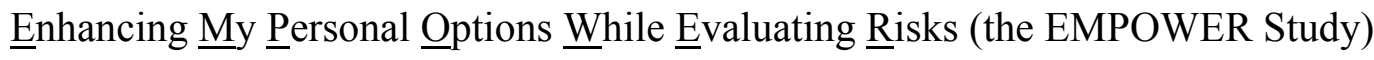


participants. In order to be included in the study, participants were required to be sexually active, and to continue to have opportunities to maintain that status. Exclusion criteria included: lack of sexual activity in the preceding 180 days; participation in inpatient treatment for substance use problems during the preceding 90 days; current suicidal risk as determined using the Distress Scale from the General Health Questionnaire (GHQ); or cognitive or developmental delays as indicated by school evaluations and educational placement. The intake coordinator subsequently contacted parents of potential participants to describe the EMPOWER program, and determine if they would consent to their child's participation. The program was then described to adolescents whose parents provided written consent, and written consent was then sought from adolescents who agreed to participate in the study.

Trained interviewers, using computer-assisted personal interview (CAPI) technology, administered to each participant, at entry to the study, a comprehensive assessment of: (a) HIV relevant risk behaviors; (b) alcohol and other drug use; (c) putative mediators of treatment effects; and (d) individual and contextual variables representing distinct subgroups of participants. The original and present studies were approved by the Institutional Review Board at Florida International University. Participants were compensated with a $\$ 25$ gift certificate for each assessment completed. Data Analytic Plan

The Statistical Package for the Social Sciences (SPSS) 17.0, and AMOS 17.0 were used to perform the data analyses in the present study. Initial data analytic procedures were conducted to determine and address identified data problems. Descriptive analyses were conducted with the variables in the model. Univariate analyses 
were performed for demographic variables in the study. Bivariate analyses were conducted to determine the degree of correlation between continuous variables. The data were also assessed to determine the presence of missing data, outliers and non-normality in the distributional characteristics of key variables included in the analyses.

Multivariate assumptions associated with structural equation modeling were also evaluated. The assumptions pertain to sample size and statistical power, missing data, outliers, normality, and model specification. The factor structure of the measurement scale associated with parent-adolescent relationships was determined using exploratory factor analysis. Maximum likelihood estimation was used to test the structural model based on the variables hypothesized to be associated with adolescents' participation in co-occurring substance use and sexual activity. The variables in the model are family structure, grade retention, peer relationships, religiosity, parent-adolescent relationship, and co-occurring substance use and sexual activity.

\section{Assumptions}

Sample size and statistical power. Structural equation modeling has several assumptions, which if violated can lead to questionable results that could undermine a study's internal and external validity. The technique requires a reasonable sample size, which it is surmised should be a minimum of approximately 15 cases per measured variable (Stevens, 1996). A violation of this assumption would result in more convergence failures, improper solutions, and diminished accuracy of parameter estimates, especially standard errors, since this is predicated on large sample sizes (Loehlin, 1987). There is a lack of consensus on the sample size needed for adequate power, but there is general agreement that a sample size of at least 200 will generate 
meaningful and interpretable results (Quintana \& Maxwell, 1999). The present study has 34 measured variables and a sample of 396, which equates to approximately 12 cases per measured variable. This is less than the recommended 15 cases, but the sample size substantially exceeds the suggested minimum of 200 .

Larger sample sizes are required to circumvent problems associated with data that are not normally distributed, and it is difficult to determine an adequate sample size when data are skewed, kurtotic, incomplete or have other distributional problems (Loehlin, 1987). A general approximation of power can be obtained through a limited information approach with single indicators of the path models in Figures 1and 2. This allows the use of a traditional power analysis program to determine sample size demands (Jaccard \& Wan, 1996). The sample size of 396 was deemed adequate in terms of anticipated power. An alpha level of 0.05 and a two-tailed test were used throughout the data analyses.

Missing data. Structural equation modeling also assumes that the data in the study are complete or that incomplete data are appropriately addressed. Missing data are likely to occur, for example, when participants fail to respond to some items in the questionnaire, refuse to answer sensitive questions, or due to attrition from the research study. Regardless of the reason for missing or incomplete data, the problem needs to be addressed to avert severely biased conclusions in empirical studies, based on the extent and pattern of missing values (Byrne, 2001). It is suggested that the missing data should be less than $10 \%$ of the sample (Byrne, 2001). Most approaches for addressing missing data assume the pattern of data loss is unsystematic (Kline, 2005). Primary patterns of missing data include: missing completely at random (MCAR) and the less restrictive, missing at random (MAR). 
Compared to ad hoc indirect methods such as listwise and pairwise deletion, for dealing with missing data, the maximum likelihood (ML) approach provides a direct procedure that is theoretically based. Moreover, ML provides several important advantages over listwise and pairwise deletion, based on whether data are MCAR or MAR. In situations where data are MCAR, listwise and pairwise deletion are consistent but statistically inefficient, whereas ML estimates are both consistent and efficient. For MAR data, both listwise and pairwise deletion can yield biased estimates, whereas ML estimates are asymptotically unbiased. There is also the contention that even when the MAR condition is not definitive, ML estimation will reduce bias. Pairwise estimation, compared to ML estimation, cannot generate standard error estimates or provide a procedure for testing hypotheses. However, all approaches for dealing with missing data can yield biased results, when unobserved values are systematic, but ML estimates will have the least bias (Byrne, 2001). The maximum likelihood estimation approach has been found to outperform traditional methods (Kline, 2005), and was used to resolve the problem of missing data in the present study. Typically, full information maximum likelihood is the recommended parameter estimation approach when data are missing in structural equation model analyses (Schumacker \& Lomax, 2004).

Outliers. SPSS descriptives and AMOS Mahalanobis values were examined to detect outliers in the data. The univariate analysis did not identify any values that were several standard deviations from the mean or substantially disparate from other observations. Leverage statistics, using Mahalanobis distance, were also reviewed to detect extreme cases from a multivariate perspective. 
Non-normality. The assumption of multivariate normality is required for maximum likelihood estimation in SEM (McDonald \& Ho, 2002). However, multivariate normality is frequently not the case in social and behavioral science data (Micceri, 1989). Maximum likelihood estimation and its associated statistics are considered sufficiently robust to overcome normality violations, and are more amenable to modest sample sizes than the alternative asymptotically distribution-free (ADF) estimator, which is contingent on extremely large samples, not standard in existing SEM applications, to generate reliable weight matrices (McDonald \& Ho, 2002). Multivariate skewness and kurtosis coefficients were used to determine normality among the variables in the study (Mardia, 1970). In addition, univariate indices of skewness and kurtosis were examined to determine if the absolute value of any of these indices was greater than 2.0.

Model identification. Model identification is another assumption of structural equation models, and refers to the existence of sufficient information to derive a solution for a set of structural equations. The model must be overidentified to test the hypothesis that a good fit exists between the theoretical model and the sample data. Identification problems prevent the model from generating unique estimates, and could prevent the program from providing results (Hair et al., 2006).

Model specification. There is also the assumption of a theoretical basis for model specification and causality in structural equation modeling (Byrne, 2001; Hair et al., 2006; Kline, 2011). The current study used problem behavior theory, the integration of an ecological conceptual framework with developmental contextualism, and research presented in the introduction to this study to determine if the hypothesized model fits the data. 
Primary Analyses. The current study used an integrated conceptual and theoretical approach, that included Jessor's Problem Behavior Theory, and Bogenschneider's (1996) integration of Bronfenbrenner's ecological framework with Lerner's developmental contextualism, as well as research studies cited and discussed, to determine if the results of the data analyses concur with this multivariate framework. An analysis of the variables associated with adolescents' participation in risk behaviors was conducted, based on the theoretical framework to be evaluated. It was expected that this would highlight risk and protective factors associated with individual and contextual variables, and evident in the study's sample of multi-problem youth. The study tested the direct and mediated relationships reflected in the path models represented in Figure 1 and a plausible alternative model in Figure 2. Multi-group analysis was used to identify group differences in the sample of multi-problem youth for variables in the study.

\section{Estimation and evaluation of the structural model}

A structural model of risk behaviors among adolescents, represented by the diagrams in Figures 1 and 2, was evaluated to test the hypotheses, based on the theoretical framework. The chi-square test statistic and the root mean square error of approximation (RMSEA) were used to assess how well the data fit the overall model. A chi-square test was performed to determine exact fit but, empirically, it is impractical to expect this to materialize. It is more realistic to expect a proximal fit based on RMSEA, which detects anomalies based on the degrees of freedom. RMSEA is particularly sensitive to misspecification, and reacts punitively to increasingly complex models in which the fit of the data has not been significantly enhanced. 
According to Browne and Cudeck (1993), a RMSEA of zero is considered a perfect fit and, a RMSEA less than .05 represents a "close fit," a value between .05 and .08 reflects a "fair fit," a "mediocre fit" falls between .08 and .10 , and values exceeding .10 constitute a poor fit. Browne and Cudeck (1993) also indicated that chi-square significance levels greater than .05 and comparative fit indices above .90 represent a good model fit. In addition to the global fit indices, more focused tests of fit were examined. These include assessment of the standardized residual covariances, which should be between -2.00 and 2.00, and modification indices, which should be less than 4.00. The parameter estimates were examined also for negative error variance or Heywood cases. SEM programs may render improper solutions when Heywood cases are present (Hair et al., 2006).

\section{Mediational Analysis}

Once it was established that the direct effect between the predictor and the outcome was consistent with the data in the study, further analysis was conducted to determine whether the mediator influenced the relation between these variables. To demonstrate mediation, it is necessary that the indirect effect of the predictor through the mediator be significant, which will result in the direct effect being diminished, thereby establishing a pattern consistent with a mediational hypothesis. When the direct effect approaches zero, the mediator is considered to account fully for the relation between the

predictor and the outcome. Partial mediation occurs if the indirect effect is significant and the direct effect falls but maintains significance at a level greater than zero (Hoyle \& Smith, 1994). These authors stipulate that structural equation modeling is the most efficient and least convoluted manner of testing Baron and Kenny's (1986) concept of 
mediation. This is based on the capacity of structural equation modeling to estimate simultaneously multiple equations and include latent variables, which "a) avoids problems of over- and underestimation of mediated effects by controlling for measurement error; b) permits isolation of the direct effect by including problematic third variables in the model; and c) permits estimation of models that include multiple mediators and combinations of mediated and moderated effects" (p. 438). The mediational analysis in this study used structural equation modeling, and was based on the conditions outlined in Baron and Kenny's (1986) treatise. 


\section{Chapter IV: RESULTS}

"Assessment of model adequacy must be based on multiple criteria that take into account theoretical, statistical, and practical considerations."

-Byrne, 2001, p. 88.

\section{Data Characteristics}

Missing Data. Missing data in the present study did not exceed the $10 \%$ threshold considered acceptable in SEM analysis. The indicators for parent-adolescent relationship had missing data that ranged between $5.8 \%$ and $6.1 \%$, the peer relationship variable had missing responses of $6.1 \%$ to $6.3 \%$, and data pertaining to substance use and sexual activity had missingness of $3.3 \%$. The other variables in the study - primary caregiver, grade retention, and religiosity had no missing data. Given the lack of severity pertaining to missing data, the SPSS Missing Value Analysis (MVA) module was used to analyze and impute values for missing responses. Specifically, Expectation Maximization (EM) was the procedure used to address missing data for the variables in the study. EM belongs to a family of model-based imputation methods in which a missing value is replaced with an estimated score from theoretical distributions that model both the complete and incomplete data. EM derives predicted scores for each missing value based initially on a series of regressions, then further refines these estimates through additional analyses with the entire dataset (Enders, 2001). Based on the convergence of results for the mean, median and standard deviation, it was determined that the imputed values did not impact the integrity of the data in the study.

Outliers. The data were inspected to determine the presence of outliers. The two cases furthest from the centroid had Mahalanobis d-square values of 26.908 with p1 of 
.001 and $\mathrm{p} 2$ of .252 ; and 20.999 with $\mathrm{p} 1$ of .007 and $\mathrm{p} 2$ of .775. These $\mathrm{p}$ values are not indicative of outliers (Byrne, 2001), and inspection of these cases did not detect any outliers in their associated data. Table 2 reflects the results of the multivariate outlier analysis, with the top 20 cases furthest from the centroid in the present dataset.

Table 2

Mahalanobis d-squared Outlier Analysis

\begin{tabular}{rrrr}
\hline Observation number & Mahalanobis d-squared & $\mathrm{p} 1$ & $\mathrm{p} 2$ \\
\hline 54 & 26.908 & .001 & .252 \\
118 & 20.999 & .007 & .775 \\
27 & 20.898 & .007 & .564 \\
115 & 19.936 & .011 & .604 \\
325 & 18.061 & .021 & .915 \\
147 & 17.404 & .026 & .948 \\
306 & 17.360 & .027 & .903 \\
206 & 17.319 & .027 & .838 \\
28 & 17.123 & .029 & .808 \\
123 & 16.863 & .032 & .803 \\
341 & 16.840 & .032 & .716 \\
336 & 16.446 & .036 & .779 \\
90 & 16.284 & .038 & .757 \\
80 & 16.055 & .042 & .768 \\
71 & 16.039 & .042 & .687 \\
227 & 15.709 & .047 & .758 \\
131 & 15.703 & .047 & .677 \\
45 & 15.286 & .054 & .800 \\
76 & 15.259 & .054 & .741 \\
255 & 15.238 & .055 & .674 \\
\hline
\end{tabular}

Non-normality. None of the study variables had absolute skewness or kurtosis values of two or greater, which would be indicative of non-normality. The Mardia multivariate coefficient was -1.484 , with a statistically non-significant critical ratio of 1.167, and also not considered non-normal. It was determined, therefore, that there was no univariate or multivariate non-normality in the data, and this is reflected in Table 3. 
Table 3.

Mardia's Test of Normality

\begin{tabular}{lrrrrrr}
\hline Variable & Min & Max & Skew & c.r. & Kurtosis & c.r. \\
\hline Psychological Control & 1.000 & 4.833 & .202 & 1.643 & -.386 & -1.567 \\
Firm Control & 1.000 & 5.000 & .485 & 3.940 & -.071 & -.287 \\
Acceptance & 1.000 & 5.000 & -.468 & -3.805 & -.385 & -1.562 \\
Religiosity & 1.000 & 4.000 & -.331 & -2.692 & -.452 & -1.837 \\
Primary Caregiver & 1.000 & 10.000 & 1.476 & 11.994 & .613 & 2.490 \\
Grade Retention & 1.000 & 5.000 & .101 & .822 & -1.990 & -8.082 \\
Peer Influence & .000 & 14.000 & .059 & .481 & -1.177 & -4.781 \\
Co-occur & 1.000 & 5.000 & -.346 & -2.808 & -.612 & -2.486 \\
Multivariate & & & & & -1.484 & -1.167 \\
\hline
\end{tabular}

Descriptive Analyses

The present study focused on a racially diverse, multiethnic sample of 396 multiproblem adolescents receiving outpatient treatment for substance use problems. Male participants were disproportionately represented and accounted for 282 (71\%) compared to $114(29 \%)$ females in the sample. Hispanic participants accounted for just under half $(45 \%)$ of the sample. The family structure was consistent with the growing national trend, where single-parent, particularly single-mother, households have become more prominent. Participants were mostly (60.1\%) from single-mother households, with substantially fewer $(8.3 \%)$ participants living in two-parent families, with undetermined marital status. There were $6.8 \%$ residing in single-father households, $10.9 \%$ lived with relatives, and $13.9 \%$ lived with other caregivers to whom they were not related.

Interestingly, in relation to socioeconomic status, there was less available information on the fathers' educational attainment and employment status. The educational attainment for $113(28.5 \%)$ of fathers was unknown, while the employment status of $76(19.2 \%)$ was also reported as unknown. The lack of information could be 
attributed to their absence from the household. Almost three-quarters (74\%) of the fathers for whom information was available had an educational level of high school or more. Of the 236 fathers for whom employment information was available, a similar percentage was employed. For mothers, unknown information was 49 (12.4\%) for educational attainment, and 16 (4\%) for employment status. Of the mothers for whom information was known, $85 \%$ had at least a high school diploma, while $75.8 \%$ were employed. Parent-adolescent Relationship

Based on existing research, a three-factor structure was assumed and confirmed in the exploratory factor analysis conducted to determine on which factors items in the CRPBI scale loaded. The rotated factor matrix depicted in Table 4 displays the items in the three subscales and their factor loadings. The item pertaining to primary caregivers being able to cheer adolescents when they were sad, and an understanding of adolescents' problems and worries loaded highest on the acceptance subscale. Attempting to control whatever adolescents did, and being disgusted when they did something wrong loaded highest on the psychological control subscale. Insisting that adolescents follow a rule one day then forgetting about it the next day, and primary caregivers quickly forgetting the rules they made loaded highest on the firm control subscale. The items on the firm control subscale were more consistent with harsh and inconsistent parenting. 
Table 4

Rotated Factor Matrix ${ }^{1}$

\begin{tabular}{|c|c|c|c|}
\hline \multirow[b]{2}{*}{ Measured Predictor Variable } & \multicolumn{3}{|c|}{ Factor $^{2}$} \\
\hline & 1 & 2 & 3 \\
\hline Made me feel better after talking over problems with him or her & .652 & -.116 & -.046 \\
\hline Quickly forgot the rule he/she made $\AA^{3}$ & -.032 & .069 & .619 \\
\hline Went to my school events or community events & .519 & .041 & -.123 \\
\hline Hit or slapped me when I did something wrong & -.133 & .311 & .148 \\
\hline Saw good things about me more than bad things & .557 & -.214 & -.076 \\
\hline Spoke to me in a nice way & .660 & -.293 & -.071 \\
\hline Made sure I did my homework & .598 & .033 & -.132 \\
\hline Told me how I should behave & .503 & .147 & -.077 \\
\hline Spent time with me or did things just with me alone & .681 & -.043 & .078 \\
\hline Kept reminding me about things I was not allowed to do & .324 & .417 & -.056 \\
\hline Punished me for doing something one day, but forgot about it the next $₫$ & .027 & .117 & .573 \\
\hline Found out about programs that could help me & .361 & .409 & .033 \\
\hline Made me get out of the house or locked me out to punish me $®$ & -.208 & .311 & .283 \\
\hline Understood my problems and worries & .733 & -.162 & -.008 \\
\hline Sat down and worked with me on my homework and projects & .704 & -.035 & -.002 \\
\hline Allowed me to do things that he/she said was wrong $\AA$ & .032 & -.036 & .441 \\
\hline Reminded me about the things I did wrong & .087 & .531 & .013 \\
\hline Mood influenced whether a rule was enforced or not $®$ & -.045 & .258 & .385 \\
\hline Only kept rules when it pleased him/her ${ }^{\circledR}$ & -.267 & .250 & .440 \\
\hline Helped me to get involved in programs or extra classes & .513 & .251 & -.038 \\
\hline Got so mad at me, he/she called me names ${ }^{\circledR}$ & -.338 & .422 & .361 \\
\hline Able to make me feel better when I was upset & .712 & -.164 & -.035 \\
\hline Changed rules I was supposed to follow $®$ & -.012 & .144 & .470 \\
\hline Talked with my teachers to find out how I was doing in $s$ & .529 & .334 & \\
\hline
\end{tabular}

${ }^{1}$ Items in bold reflect subscale on which factor loaded.

2 1= Acceptance; 2= Psychological Control; 3= Firm Control

${ }^{3} \AA=$ Reverse scored 


\begin{tabular}{|c|c|c|c|}
\hline Demanded that I do exactly what he/she told me to do ${ }^{\circledR}$ & .149 & .529 & .014 \\
\hline Got angry when I was noisy around the house ${ }^{\circledR}$ & -.052 & .509 & .107 \\
\hline Cheered me up when I was sad & .771 & -.141 & -.013 \\
\hline Screamed at me when I did something wrong & -.096 & .497 & .175 \\
\hline Lost his or her temper with me when I did not help around the house & -.242 & .584 & \\
\hline Tried to control whatever I did $®$ & -.125 & .658 & 7 \\
\hline Asked me how things were going with me & .627 & .065 & .004 \\
\hline Enjoyed the time we spent together & .671 & -.048 & -.051 \\
\hline Told me he or she was disgusted with me when I did something wrong & -.096 & 615 & .147 \\
\hline Bothered me until I did what he/she wanted me to do ${ }^{\circledR}$ & -.054 & .606 & .125 \\
\hline Helped out with school or community activities that I was involved in & .642 & .123 & .068 \\
\hline Insisted I follow a rule one day then he/she forgot about it the next $®$ & -.074 & .140 & .722 \\
\hline Showed me that he or she liked me just the way I am & 689 & -.210 & -.042 \\
\hline Punished me in front of my friends when I did something wrong ${ }^{\circledR}$ & .105 & .450 & .211 \\
\hline Changed his/her mind to make things easier for himself/herself $₫$ & -.128 & .374 & 4 \\
\hline
\end{tabular}

Extraction Method: Principal Axis Factoring.

Rotation Method: Varimax with Kaiser Normalization.

Table 5 portrays means and standard deviations for items in the three CRPBI subscales, acceptance, psychological control, and firm control. Although it did not load strongly on the acceptance factor, the item told me how I should behave had the highest mean of $4.23(\mathrm{SD}=1.23)$ on that factor. The high mean score is consistent with participants' agreement regarding this statement. The item enjoyed time we spent together loaded more convincingly, and followed closely with a mean of $4.03(\mathrm{SD}=1.10)$. On the psychological control subscale, kept reminding about things I was not allowed to do also had a weak loading, but had the highest mean of $3.84(\mathrm{SD}=1.17)$. Reminded me about the things I did wrong loaded a little better on this subscale, and had the second highest mean of $3.68(\mathrm{SD}=1.22)$. The item on the firm control subscale with the highest mean of 
$3.14(\mathrm{SD}=1.29)$, mood influenced whether a rule was kept or not, was also consistent in having a weak loading but the highest mean. The item with the second highest mean of $2.75(\mathrm{SD}=1.32)$ punished me for something one day, but forgot about it the next day loaded higher on this subscale.

Table 5

Statistics for Items on the Parent-adolescent Relationship Subscales* Subscale: Acceptance

\begin{tabular}{llll}
\hline Item & $\mathrm{N}=396$ & $\mathrm{M}$ & $\mathrm{SD}$
\end{tabular}

2. Made me feel better after talking over problems with him or her

$3.43 \quad 1.37$

4. Went to my school or community events

6. Saw good things about me more than bad things

7. Spoke to me in a nice way

8. Made sure I did my homework

9. Told me how I should behave

11. Spent time with me or did things just with me alone

16. Understood my problem and worries

17. Worked with me on my homework and projects

22. Helped me to get involved in programs or extra classes

24. Made me feel better when I was upset

26. Talked with my teachers to find out how I was doing in school

29. Cheered me up when I was sad

33. Asked how things were going with me

34. Enjoyed time we spent together

$4.03 \quad 1.10$


37. Helped with school and community activities

$*$ Items coded: Almost never $=1 ;$ Once in a while $=2 ;$ Sometimes $=3 ;$ A lot of the time $=$ 4; Almost always $=5$

\section{Subscale: Psychological Control}

\begin{tabular}{llll}
\hline Item & $\mathrm{N}=396$ & $\mathrm{M}$ & SD
\end{tabular}

5. Hit or slapped me when I did something wrong

$2.08 \quad 1.23$

12. Kept reminding me about things I was not allowed to do

$3.84 \quad 1.17$

14. Found out about programs that could help me

15. Made me get out of the house or locked me out to punish me

19. Reminded me about things I did wrong

23. Got so mad at me, she/he called me names®

27. Demanded that I do exactly what he/she told me to do®

28. Got angry when I was noisy around the house $\circledast$

30. Screamed at me when I did something wrong

31. Lost temper when I did not help around the house

32. Tried to control whatever I did®

35. Disgusted when I did something wrong

36. Bothered me until I did what he/she wanted me to do®

40. Punished me in front of my friends when I did something wrong® 
*Items coded: Almost never $=5 ;$ Once in a while $=4$; Sometimes $=3 ;$ A lot of the time $=$ 2; Almost always $=1$

®Reverse coded

Subscale: Firm Control

\begin{tabular}{llll}
\hline Item & $\mathrm{N}=396$ & $\mathrm{M}$ & $\mathrm{SD}$
\end{tabular}

3. Quickly forgot rules that he/she made $®$

2.451 .28

13. Punished me for doing something one day, but forgot about it the next巴 2.751 .32

18. Allowed me to do things that she/he said was wrong®

1.951 .22

20. Mood influenced whether a rule was kept or not $\AA$

$3.14 \quad 1.29$

21. Only kept rules when it pleased him/her®

$2.37 \quad 1.30$

25. Changed rules I was supposed to follow ${ }^{\circledR}$

38. Insisted I follow a rule one day, then forgot about it the next day®

41. Changed his/her mind to make things easier for himself/herself®

$*$ Items coded: Almost never $=5 ;$ Once in a while $=4$; Sometimes $=3 ;$ A lot of the time $=$ 2; Almost always $=1$

®Reverse coded

Besides participants' responses to items in the CRPBI questionnaire, responses pertaining to psychological maltreatment provided evidence that some adolescents were unhappy at home. More than half (51.7\%) wanted to leave their family and live with another family, and $58.7 \%$ thought seriously about running away from home. Nearly half (44.5\%) experienced unpredictable violence in the home, $47.2 \%$ felt left out or lonely, and almost two-thirds (61.4\%) reported having a stressful childhood. 


\section{Peer Relationships}

Participants were more inclined to discuss a variety of sex-related subjects with friends rather than their parents or other relatives (Table 6). The exceptions to this trend were discussions about pregnancy, and how parenthood would change one's life, where a higher percent of adolescents preferred talking to their mothers about these issues. What friends think about sex, what mothers think about teens having sex, sexual abstinence, wet dreams, what father thinks about teens having sex, and the menstrual cycle were topics less likely to be discussed with anyone.

Table 6

Checklist of Self-related Sex-based Topics

\begin{tabular}{lccccc}
\hline Topic & $\mathrm{M}$ & $\mathrm{F}$ & $\mathrm{FR}$ & $\mathrm{OR}$ & $\mathrm{NO}$ \\
\hline HIV-AIDS & 48.0 & 24.0 & 53.0 & 27.8 & 20.5 \\
Using a condom & 53.3 & 31.8 & 59.6 & 32.3 & 9.3 \\
Sexual intercourse & 42.4 & 24.7 & 64.6 & 31.6 & 10.4 \\
Dating and sex behavior & 47.5 & 25.0 & 62.9 & 30.3 & 11.9 \\
Pregnancy & 53.0 & 26.5 & 50.5 & 30.8 & 14.4 \\
What friends think about sex & 25.0 & 11.6 & 37.9 & 18.2 & 40.7 \\
Dangers of many sex partners & 35.1 & 18.9 & 47.0 & 25.0 & 26.0 \\
What mother thinks about teens having sex & 38.1 & 8.6 & 30.6 & 16.4 & 39.6 \\
How parenthood would change life & 52.3 & 30.1 & 50.3 & 31.1 & 15.2 \\
Sexual abstinence & 29.8 & 11.1 & 26.5 & 15.4 & 46.5 \\
Birth control & 38.1 & 12.6 & 38.4 & 18.7 & 35.4
\end{tabular}


Table 6 (continued)

\begin{tabular}{lcccccc}
\hline Topic & M & F & FR & OR & NO \\
\hline What fathers think about teens having sex & 11.4 & 18.7 & 14.4 & 7.8 & 65.9 \\
Menstrual cycle & 39.4 & 8.6 & 35.1 & 19.7 & 41.4 \\
& & & & & & \\
\hline
\end{tabular}

Legend: $\mathrm{M}=$ Mother; $\mathrm{F}=$ Father; $\mathrm{FR}=$ Friend; $\mathrm{OR}=$ Other Relative; NO = No One Religiosity

Almost a third of participants (31.3\%) indicated that they were affiliated with a church or synagogue. More than three-quarters (78\%) reported some degree of religiosity, with $6.1 \%$ being very religious. Half of participants attended religious services at least once a month, with $25 \%$ attending at least weekly.

\section{School Connectedness}

Participants were in the $5^{\text {th }}$ thru $12^{\text {th }}$ grades, with the majority $(293 / 74 \%)$ being in the $8^{\text {th }}$ thru $10^{\text {th }}$ grades. Approximately $40 \%$ had not reached high school $\left(9^{\text {th }}\right.$ grade $)$ at their entry to the study. The majority $(349 / 88.1 \%)$ indicated they had attended school in the past school year. Of those who had stopped going to school, the primary reasons were problems with drugs or alcohol (22.6\%), expulsion (16.9\%), and trouble with law enforcement (13.7\%). Those who were suspended or expelled from school cited fighting $(28.6 \%)$, using drugs $(28.6 \%)$, and excessive truancy or absences $(23.8 \%)$ as the major reasons. Most of the participants (52\%) were "C" students, with $22.7 \%$ receiving "As" and "Bs," and the remainder (25.3\%) getting "Ds" and "Fs." More than half (52.5\%) had experienced grade retention, with 37 of the 208 retained having repeated more than one grade. Forty-seven $(11.9 \%)$ participants reported that they had not attended school in the 
previous year. As noted earlier, grade retention is a major risk factor for dropping out of school.

\section{Substance Use and Sexual Activity}

Almost all (92\%) of participants had tried marijuana or hashish. Half had tried powder cocaine, and 10\% had used crack. Heroin (3\%) was not a popular choice, while $30 \%$ reported using hallucinogens, and $40 \%$ had used ecstasy or something similar. Significantly more than half $(60.8 \%)$ reported drinking before or during sexual intercourse, with $41.7 \%$ stating that both they and their partner engaged in this activity. Alcohol use was prevalent with $44.8 \%$ of participants indicating that they had consumed 11 or more drinks in 1 day in the past 12 months. Not surprisingly, $41 \%$ met the criteria for alcohol abuse, while 15\% were considered alcohol dependent. Noteworthy also, more than half $(54.4 \%)$ of participants had parents who drank heavily or abused drugs. Table 7 summarizes the descriptive data analysis related to the sample in the present study.

Table 7

Descriptive Statistics

\begin{tabular}{|c|c|c|c|c|}
\hline Variable & $\mathrm{N}$ & $\%$ & $\mathrm{M}$ & $\mathrm{SD}$ \\
\hline Male & 282 & 71.2 & & \\
\hline Female & 114 & 28.8 & & \\
\hline White Non-Hispanic & 100 & 25.3 & & \\
\hline White Hispanic & 146 & 36.9 & & \\
\hline Black Non-Hispanic & 83 & 21.0 & & \\
\hline Black Hispanic & 31 & 7.8 & & \\
\hline Asian & 21 & 5.3 & & \\
\hline
\end{tabular}


Table 7 (continued)

\begin{tabular}{|c|c|c|c|c|}
\hline Variable & $\mathrm{N}$ & $\%$ & $\bar{M}$ & $\mathrm{SD}$ \\
\hline Other & 15 & 3.8 & & \\
\hline Age & & & 16.37 & 1.18 \\
\hline Grades & & & 3.07 & .94 \\
\hline Grade Retention & 208 & 52.5 & & \\
\hline Single Parent (Mother) & 238 & 60.1 & & \\
\hline Single Parent (Father) & 27 & 6.8 & & \\
\hline Mother and Father & 33 & 8.3 & & \\
\hline Relative & 43 & 10.9 & & \\
\hline Other & 55 & 13.9 & & \\
\hline Very Religious & 24 & 6.1 & & \\
\hline Moderately Religious & 101 & 25.5 & & \\
\hline A Little Religious & 184 & 46.5 & & \\
\hline Not Religious & 87 & 22.0 & & \\
\hline Acceptance & 396 & 100.0 & 3.46 & .86 \\
\hline Firm Control & 396 & 100.0 & 2.39 & .82 \\
\hline Psychological Control & 396 & 100.0 & 2.94 & .77 \\
\hline Peer Relationships & 396 & 100.0 & 5.89 & 4.20 \\
\hline Alcohol and Sex & 243 & 61.4 & & \\
\hline Drugs and Sex & 288 & 72.7 & & \\
\hline Sex and Substances & & & 3.6 & 1.03 \\
\hline
\end{tabular}


It seems evident from the descriptive results presented that participants in the sample of multi-problem youth were experiencing life challenges that made it difficult, if not impossible, to achieve positive developmental outcomes. Most of the study participants were from single parent households, experienced grade retention, had suboptimal parental relationships, were more likely to rely on peer relationships to discuss sexual issues, and participated in co-occurring substance use and sexual activity. Parental participation in substance use not only modeled unacceptable behavior, but also contributed to an undesirable home environment for those in the sample who experienced this activity.

\section{Bivariate Analyses}

A bivariate analysis of variables in the study, as reflected in Table 8, revealed several significant correlations, consistent with the results of the tested hypotheses. There were significant correlations between grade retention and peer relationships. Primary caregiver had significant correlations with co-occurring substance use and sexual activity and psychological control. Religiosity was significantly correlated with age and psychological control, while the peer relationship variable was significantly correlated with co-occurring substance use and sexual activity and age. Co-occurring substance use and sexual activity was significantly correlated with age and the parent-adolescent relationship variables. The strongest correlation was between psychological control and firm control, which is highly conceivable since they are both, to different degrees, attempting to control child behavior. 
Table 8

Bivariate Correlation Among Variables in the Study

\begin{tabular}{|c|c|c|c|c|c|c|c|c|}
\hline Variable & 2 & 3 & 4 & 5 & 6 & 7 & 8 & 9 \\
\hline 1. Grade retention & .05 & -.07 & $.12 *$ & -.02 & .10 & -.04 & -.04 & -.05 \\
\hline 2. Primary caregiver & 1 & .02 & -.08 & $.10^{*}$ & -.01 & .02 & $-.16^{* *}$ & -.08 \\
\hline 3. Religiosity & & 1 & -.00 & -.01 & $-.10 *$ & .05 & $-.15^{* *}$ & -.03 \\
\hline 4. Peer relationship & & & 1 & $-.16^{* *}$ & $.14 * *$ & -.05 & .09 & -.05 \\
\hline 5. Co-occur & & & & 1 & $-.22 * *$ & $.11^{*}$ & $-.10^{*}$ & $-.10^{*}$ \\
\hline 6. Age & & & & & 1 & -.07 & -.05 & -.07 \\
\hline 7. Acceptance & & & & & & 1 & -.05 & $-.17 * *$ \\
\hline 8. PControl & & & & & & & 1 & $.38^{* *}$ \\
\hline 9. FControl & & & & & & & & 1 \\
\hline
\end{tabular}

Structural Model Fit

The fit of both cross-sectional models was tested using the maximum likelihood (ML) algorithm in AMOS 17.0. The models were recursive and statistically overidentified. Several indices of fit were used to evaluate the models. The original model had some evidence of ill fit, with modification indices that exceeded 4.0, and suggested adding predictor paths between primary caregiver and psychological control and religiosity and psychological control. The adjustment to the model was made, and resulted in good model fit (Figure 3), with substantially significant paths between primary caregiver and psychological control, $p<.014$, and between religiosity and psychological control, $p<.002$. These modifications are supported in the literature, where research studies have found significant relations between family structure and parent-adolescent relationships, as well as between religiosity and parental relationship. 
Barrett and Turner (2006) conducted a study in which they found that adolescents in single-parent families experienced less parental support than those in two-parent families. In another study by Day, Orthner, Hair and Kaye (2008) results indicated that adolescent religiosity was a factor in parent-adolescent relationships. Adolescents who experience warm and close family relationships are more inclined to have religious beliefs and to participate in religious practices.

The modified model (Figure 3) had a chi-square of $4.29(5 d f), p<.508$, consistent with good model fit. The CMIN/DF was .859, which is deemed acceptable when it is less than 3. The Root Mean Square Error of Approximation (RMSEA) was .000 (90\% CI 0 to .065$)$, and the PCLOSE was .867 , both consistent with good model fit. The Comparative Fit Index (CFI) was 1.000 and the Tucker-Lewis Index (TLI) was 1.037. Both indices compare the absolute fit of the specified model to the independence model, and the TLI which is a non-normed index may be greater than 1 , under specific circumstances. The traditional Goodness of Fit Index (GFI), which reflects the proportion of the observed covariance explained by the model covariance, was .997, and the Adjusted Goodness of Fit Index (AGFI), which incorporates an adjustment for model complexity, was .98. The Normed Fit Index (NFI) was .97, and compares the fit of the tested model to the independence model, based on the sample. Thus, the value of .97 indicates that the fit of the tested model is $97 \%$ better than the independence model. Models with values $>0.9$ for the CFI, GFI, AGFI, TLI and NFI are considered to demonstrate good fit.

The results of the alternative peer mediated model (Figure 4) supported the data with no indication of ill fit. Since it is accepted that there are several competing models 
that can fit the data well (Hoyle \& Smith, 1994), and there was strong theoretical support for the alternative model, the alternative model became the focus for testing the theory on which the study was based. The chi-square "badness-of-fit" index was not statistically significant, with a value of $2.48(2 d f), \mathrm{p}<.289$, suggesting good model fit. The CMIN/DF was 1.24, which is considered acceptable when it is less than 3 . The RMSEA was .03 (90\% CI 0 to.106), and represents the average discrepancy between the observed and predicted covariances, with increases in discrepancy increasing the RMSEA. A value of .05 or less indicates close model fit. It is worth noting that sample size and model complexity can impact confidence intervals, with small samples and complex models generating wide confidence intervals (Byrne, 2001). However, the PCLOSE of .58 further suggests that the hypothesized model fits the data well.

The standardized Root Mean Square Residual (SRMR) was .013, and reflects the difference between the predicted and observed covariances in the model, that is, unexplained variance, based on standardized residuals. A SRMR of 0 is considered perfect fit, while a value $<.05$ indicates good model fit. The modification indices had no indication of poor fit within the model. The CFI was .996 and the TLI was .94. Both indices compare the absolute fit of the specified model to the independence model. The traditional GFI was .998, and the AGFI was .97. The NFI was .98, and compares the fit of the tested model to the independence model, based on the sample. Thus, the value of .98 indicates that the fit of the tested model is $98 \%$ better than the independence model. Models with values $>0.9$ for the CFI, GFI, AGFI, TLI and NFI are considered to indicate good fit to the observed data. 


\section{Maximum Likelihood Unstandardized and Standardized Path Coefficients}

The unstandardized and standardized parameter estimates and significance levels for the hypothesized paths in the final structural equation model are presented in Tables 9 and 10, and Figure 4. The paths between the three predictor parent-adolescent relationship variables - acceptance, firm control, and psychological control - and the peer relationship variable, as indexed by the number of sexual topics discussed with peers, were in the expected direction. Increases in parental acceptance and firm control were associated with lower numbers of sexual topics discussed with peers, while increased psychological control was associated with higher numbers of sexual topics discussed with peers. The firm control and psychological control paths were statistically significant $(p=$ $.04 ; p=.01$, respectively), but the acceptance path $(p=.22)$ was not. Grade retention also influenced discussion of sexual topics with peers, as expected, with a statistically significant path $(p=.02)$ between the two variables. The parent-adolescent relationship and grade retention variables accounted for $4 \%$ of the variance in discussion of sexual topics with peers. Family structure, parent-adolescent relationship, grade retention, discussion of sexual topics with peers, and religiosity collectively accounted for $5 \%$ of the variance in co-occurring substance use and sexual activity. The path between sexual discussion with peers and co-occurring substance use and sexual activity had the highest statistical significance $(p=.003)$. Higher scores for discussion of sexual topics with peers reduced participation in co-occurring substance use and sexual activity. The results suggest that characteristics of parent-child relationships, such as firm control and psychological control, and grade retention significantly influence participation in co- 
occurring substance use and sexual activity indirectly through features of peer relationship, as indexed by peer communication on sexual topics.

The hypothesized direct paths between the predictor variables and the dependent variable co-occurring substance use and sexual activity were not significant. Grade retention, religiosity, firm control, and psychological control all had a statistically nonsignificant inverse influence on the outcome variable. There was a direct association between the other predictor variables, primary caregiver and parental acceptance, and the endogenous variable adolescents' participation in co-occurring substance use and sexual activity. Only acceptance demonstrated proximity to a statistically significant $(p=.10)$ relationship.

\section{Total Effects}

The study also examined the total effects, that is, the direct and indirect effects, of the variables, as reflected in Table 11. Psychological control had a statistically significant $(p<.01)$ total effect on peer relationship, as indexed by communication on sexual topics, which suggests that based on the direct and mediated effects, a one unit increase in psychological control results in a .72 increase in discussion of sexual topics with peers. Firm control and grade retention also had a statistically significant $(p<.05)$ total effect on peer relationships. A one unit increase in firm control resulted in a .56 decrease in discussion of sexual topics with peers, while a one unit increase in grade retention resulted in a .25 increase in discussion of sexual topics with peers. Acceptance did not have a statistically significant total effect on discussion of sexual topics with peers.

Acceptance $(p=.10)$ trended toward statistical significance, while discussion of sexual topics with peers $(p<.001)$ had a statistically significant total effect on co- 
occurring substance use and sexual activity. A one unit increase in acceptance resulted in a .11 increase in co-occurring substance use and sexual activity, while a one unit increase in discussion of sexual topics with peers resulted in a .04 decrease in co-occurring substance use and sexual activity. The total effect of psychological control, firm control, religiosity, primary caregiver, and grade retention on co-occurring substance use and sexual activity was not statistically significant.

Table 9

\section{Unstandardized Path Coefficients}

\begin{tabular}{|c|c|c|c|c|c|c|}
\hline Path & & & Estimate & S.E. & C.R. & $\mathrm{P}$ \\
\hline Peer relation & $<---$ & Grade retention & .251 & .104 & 2.407 & $.016^{* *}$ \\
\hline Peer relation & $<---$ & Acceptance & -.303 & .244 & -1.238 & .216 \\
\hline Peer relation & $<---$ & Firm control & -.557 & .276 & -2.017 & $.044 * *$ \\
\hline Peer relation & $<---$ & Psychological control & .719 & .292 & 2.467 & $.014 * * *$ \\
\hline Co-occur & $<---$ & Peer relation & -.037 & .012 & -3.019 & $.003 * * * *$ \\
\hline Co-occur & $<---$ & Grade retention & -.005 & .025 & -.195 & .846 \\
\hline Co-Occur & $<---$ & Religiosity & -.029 & .061 & -.479 & .632 \\
\hline Co-occur & $<---$ & Primary caregiver & .026 & .017 & 1.570 & .116 \\
\hline Co-occur & $<---$ & Firm control & -.095 & .067 & -1.416 & .157 \\
\hline Co-occur & $<---$ & Psychological control & -.062 & .072 & -.855 & .392 \\
\hline Co-occur & $<---$ & Acceptance & .099 & .059 & 1.671 & $.095^{*}$ \\
\hline
\end{tabular}

Table 10

Standardized Path Coefficients

\begin{tabular}{lclc}
\hline Path & & & Estimate \\
\hline Peer relation & $<---$ & Grade retention & .119 \\
Peer relation & $<---$ & Acceptance & -.062 \\
Peer relation & $<---$ & Firm control & -.109 \\
Peer relation & $<---$ & Psychological control & .132 \\
Co-occur & $<---$ & Peer relation & -.151 \\
Co-occur & $<---$ & Grade retention & -.010 \\
Co-occur & $<---$ & Religiosity & -.024 \\
Co-occur & $<---$ & Primary caregiver & .078 \\
Co-occur & $<---$ & Firm control & -.076 \\
Co-occur & $<---$ & Psychological control & -.047 \\
Co-occur & $<---$ & Acceptance & .083 \\
\hline
\end{tabular}


Table 11

Total Effects in Model

\begin{tabular}{lllllllc}
\hline & $\begin{array}{l}\text { Psy } \\
\text { Control }\end{array}$ & $\begin{array}{l}\text { Firm } \\
\text { Control }\end{array}$ & Acceptance & Religiosity & $\begin{array}{l}\text { Primary } \\
\text { Caregiver }\end{array}$ & $\begin{array}{l}\text { Grade } \\
\text { Retention }\end{array}$ & $\begin{array}{l}\text { Peer } \\
\text { Relation }\end{array}$ \\
\hline $\begin{array}{l}\text { Peer } \\
\text { Relation }\end{array}$ & $.719^{* * *}$ & $-.557^{* *}$ & -.303 & .000 & .000 & $.251^{* *}$ & .000 \\
Co-occur & -.088 & -.075 & $.110^{*}$ & -.029 & .026 & -.014 & $-.037 * * * *$ \\
\hline$* * * * \mathrm{p}<.001 ; * * \mathrm{p}<.01 ; * * \mathrm{p}<.05 ; * \mathrm{p}<.10$. & & & &
\end{tabular}

Mediational Analysis

The study also evaluated the hypothesized mediating role of discussion of sexual topics with peers in the multivariate model, based on maximum likelihood estimation using AMOS 17.0. The results supported the hypothesis that peer relationship, as indexed by communication on sexual topics, mediated the association between the predictor variables grade retention, firm control, and psychological control and the outcome variable co-occurring substance use and sexual activity. There was an unstandardized indirect effect of -.03 for the mediated association from psychological control to the outcome variable co-occurring substance use and sexual activity. The indirect effect from firm control was .20 , and -.01 for grade retention.

\section{Between Group Comparative Analyses}

The study performed one-way analysis of variance (ANOVA) tests to examine differences across variables for different groups, specifically race/ethnicity and gender, with the results reflected in Tables 12 and 13. There was no statistically significant gender difference for adolescent participation in co-occurring substance use and sexual activity, $F(1,394)=.63, p=.43$. Females were considerably more inclined than males to discuss sexual topics with peers, with a highly statistically significant mean difference for the peer relationship variable, $F(1,394)=30.2, p<.001$. The difference across gender 
for religiosity was not statistically significant, $F(1,394)=.42, p=.52$. While males were more likely than females to experience grade retention, the difference was not statistically significant, $F(1,394)=.17, p=.68$. Males scored slightly higher on the three parentadolescent relationship variables, acceptance, psychological control, and firm control, but the differences across gender groups were not statistically significant, acceptance $F$ (1, $394)=1.24, p=.27$; psychological control $F(1,394)=2.22, p=.14$; firm control $F(1$, $394)=.05, p=.83$.

Statistically significant mean differences were more evident across variables in the study for race/ethnicity. Non-Hispanic White participants were more inclined to participate in co-occurring substance use and sexual activity, and race/ethnicity differences were statistically significant, $F(6,389)=2.78, p=.01$. Black Hispanics, more than any other group, preferred to discuss sexual topics with their peers, and the mean differences were statistically significant, $F(6,389)=3.3, p=.003$. Differences in religiosity among race/ethnicity were not statistically significant, $F(6,389)=1.24, p=$ .28. Family structure was also not statistically significant across race/ethnicity in the sample of multi-problem youth, $F(6,389)=1.58, p=.15$. Mean differences across race/ethnicity were statistically significant for the parent-adolescent relationship variable, acceptance, $F(6,389)=2.27, p=.04$, but not statistically significant both for psychological control, $F(6,389)=.99, p=.43$, and firm control, $F(6,389)=.76, p=$ 60 .

The chi-square $14.97(6 d f), p=.021$ for the association between grade retention and race was statistically significant, with Hispanic Black (61.3\%) and Non-Hispanic Black (59\%) study participants more likely to have experienced grade retention than 
other racial/ethnic groups. The association between grade retention and gender, had a chisquare of $.17(1 d f), p=.676$, which was not statistically significant. Males $(53.2 \%)$ were more likely to have experienced grade retention than females $(50.9 \%)$. The association between primary caregiver and race had a statistically significant chi-square of 101.4 (54 $d f), p=.001$. Hispanic Black participants (64.5\%) were more likely to live in single mother households.

Table 12

Mean Differences by Gender for Observed Variables

\begin{tabular}{|c|c|c|c|c|c|}
\hline Variable & Gender & $\mathrm{M}$ & SD & $\mathrm{SE}$ & $\mathrm{F}$ \\
\hline \multirow[t]{2}{*}{ Co-occur } & Male & 3.66 & .99 & .059 & .63 \\
\hline & Female & 3.57 & 1.12 & .105 & \\
\hline \multirow[t]{2}{*}{ Peer Relationship } & Male & 5.17 & 3.88 & .231 & $30.21 * * *$ \\
\hline & Female & 7.65 & 4.48 & .419 & \\
\hline \multirow[t]{2}{*}{ Religiosity } & Male & 2.83 & .85 & .051 & .42 \\
\hline & Female & 2.89 & .80 & .075 & \\
\hline \multirow[t]{2}{*}{ Acceptance } & Male & 3.49 & .79 & .047 & 1.24 \\
\hline & Female & 3.38 & 1.02 & .095 & \\
\hline \multirow[t]{2}{*}{ PControl } & Male & 2.98 & .76 & .045 & 2.22 \\
\hline & Female & 2.85 & .80 & .075 & \\
\hline \multirow[t]{2}{*}{ Firm Control } & Male & 2.40 & .84 & .050 & .05 \\
\hline & Female & 2.38 & .79 & .074 & \\
\hline
\end{tabular}


Table 13

Mean Difference by Race/Ethnicity for Observed Variables

\begin{tabular}{|c|c|c|c|c|c|}
\hline Variable & Race/Ethnicity & $\mathrm{M}$ & SD & $\mathrm{SE}$ & $\bar{F}$ \\
\hline \multirow[t]{5}{*}{ Co-occur } & Non-Hispanic White & 3.37 & 1.01 & .101 & $2.78 * *$ \\
\hline & Hispanic White & 3.57 & 1.07 & .088 & \\
\hline & Hispanic Black & 3.74 & .78 & .141 & \\
\hline & African-American & 3.95 & 1.00 & .109 & \\
\hline & Asian & 3.74 & 1.07 & .233 & \\
\hline \multirow[t]{5}{*}{ Peer Relationship } & Non-Hispanic White & 6.98 & 4.47 & .447 & $3.33 * *$ \\
\hline & Hispanic White & 5.46 & 4.31 & .356 & \\
\hline & Hispanic Black & 7.06 & 4.30 & .772 & \\
\hline & African-American & 4.90 & 3.52 & .387 & \\
\hline & Asian & 6.24 & 3.79 & .828 & \\
\hline \multirow[t]{5}{*}{ Religiosity } & Non-Hispanic White & 2.94 & .79 & .079 & 1.24 \\
\hline & Hispanic White & 2.81 & .87 & .072 & \\
\hline & Hispanic Black & 2.97 & .75 & .135 & \\
\hline & African-American & 2.84 & .82 & .090 & \\
\hline & Asian & 2.52 & .81 & .178 & \\
\hline \multirow[t]{5}{*}{ Acceptance } & Non-Hispanic White & 3.58 & .87 & .087 & $2.27^{*}$ \\
\hline & Hispanic White & 3.28 & .83 & .068 & \\
\hline & Hispanic Black & 3.36 & 1.11 & .200 & \\
\hline & African-American & 3.56 & .84 & .092 & \\
\hline & Asian & 3.79 & .68 & .148 & \\
\hline
\end{tabular}


Table 13 (continued)

\begin{tabular}{llllll}
\hline Variable & Race/Ethnicity & M & SD & SE & F \\
\hline PControl & Non-Hispanic White & 2.91 & .76 & .076 & .99 \\
& Hispanic White & 2.91 & .79 & .066 & \\
& Hispanic Black & 2.97 & .74 & .132 & \\
& African-American & 3.01 & .79 & .087 & \\
& Asian & 3.11 & .64 & .139 & \\
Firm Control & Non-Hispanic White & 2.29 & .78 & .078 & .76 \\
& Hispanic White & 2.48 & .82 & .067 & \\
& Hispanic Black & 2.42 & .76 & .136 & \\
& African-American & 2.35 & .89 & .097 & \\
& Asian & 2.29 & .93 & .204 & \\
\hline *p<.05; ** $p<.01 ; * * p<.00$ & & & & & \\
Multigroup Analysis & & & & &
\end{tabular}

The study conducted a multi-group solution for gender. The first model tested had no equality constraints across groups. This model fit the data well. The chi-square test of model fit was statistically non-significant (chi-square $(4)=5.38, p=.251$. The RMSEA was .03. The $p$ value for the test of close fit was .65. The Comparative Fit Index was .99. More focused tests of fit revealed no sizeable modification indices. The constrained model also yielded good fit to the data. The chi-square test of model fit was statistically non-significant (chi-square $(15)=20.38, p=.158$. The RMSEA was .03 . The $p$ value for the test of close fit was .84 . The Comparative Fit Index was .95. More focused tests of fit revealed no sizeable modification indices. The nested chi-square test comparing the 
default model to the constrained model yielded a statistically non-significant chi-square difference (chi-square diff $(11)=15.00, p=.182$, which is consistent with invariance across groups.

A multi-group solution was conducted for race/ethnicity also, and compared White non- Hispanic participants to White Hispanic participants. The first model tested had no equality constraints across groups. This model fit the data well. The chi-square test of model fit was statistically non-significant (chi-square $(5)=8.63, p=.125$. The RMSEA was .06. The $p$ value for the test of close fit was .38. The Comparative Fit Index was .95 . More focused tests of fit revealed no sizeable modification indices. The constrained model also yielded good fit to the data. The chi-square test of model fit was statistically non-significant (chi-square $(16)=17.01, p=.385$. The RMSEA was .02 . The $p$ value for the test of close fit was .86. The Comparative Fit Index was .99. More focused tests of fit revealed no sizeable modification indices. The nested chi-square test comparing the default model to the constrained model yielded a statistically nonsignificant chi-square difference (chi-square $\operatorname{diff}(11)=8.38, p=.679$, which is consistent with invariance across groups. Black participants were not included in the comparison across groups because the small sample size of 83 in the study would have been inadequate to obtain stable parameter estimates. 
Figure 3

Hypothesized Model of Co-occurring Substance Use and Sexual Activity Among Adolescents

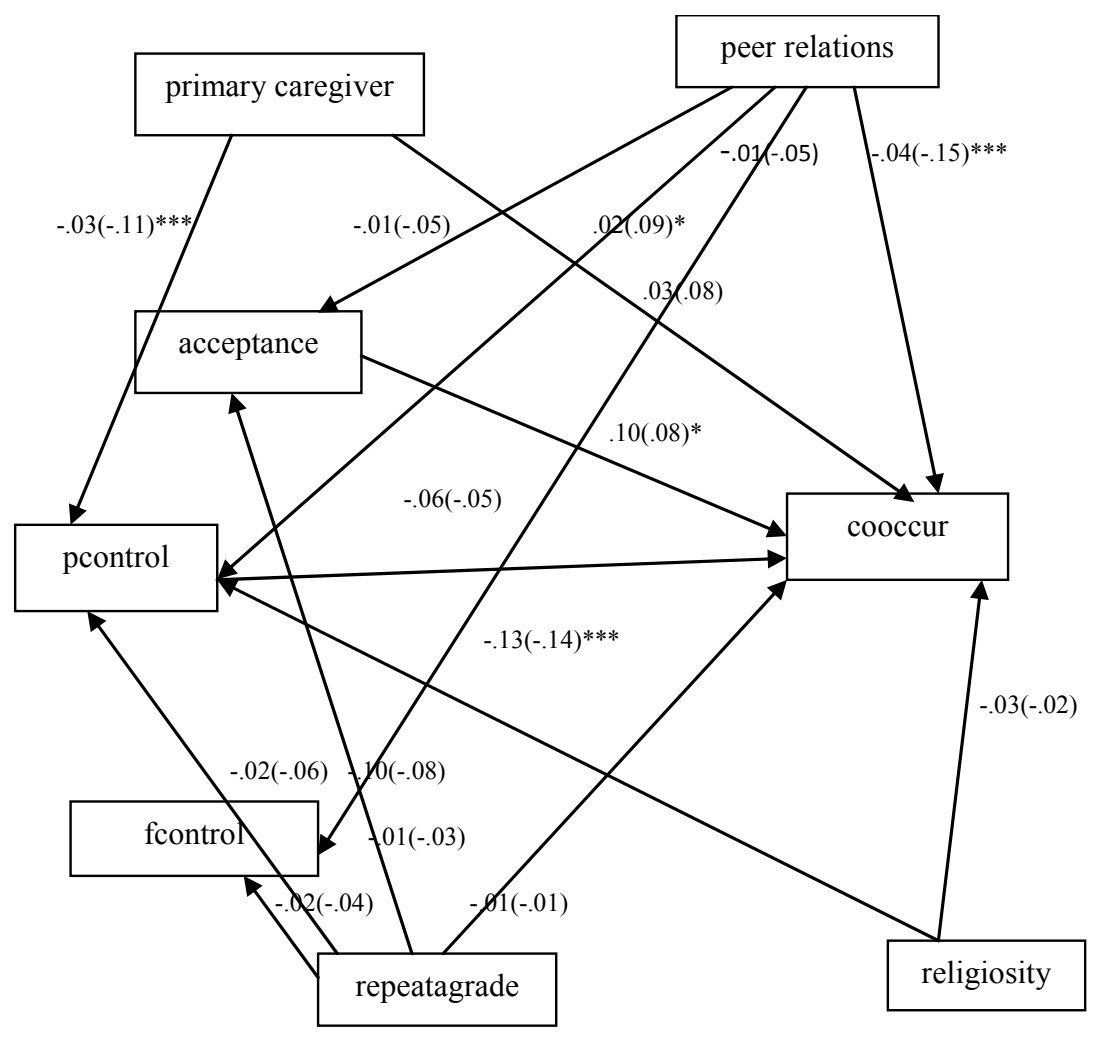

$* * * * \mathrm{p}<.001 ; * * * \mathrm{p}<.01 ; * * \mathrm{p}<.05 ; * \mathrm{p}<.10$

Standardized coefficients in parenthesis 
Figure 4

Final Model of Co-occurring Substance Use and Sexual Activity Among Adolescents

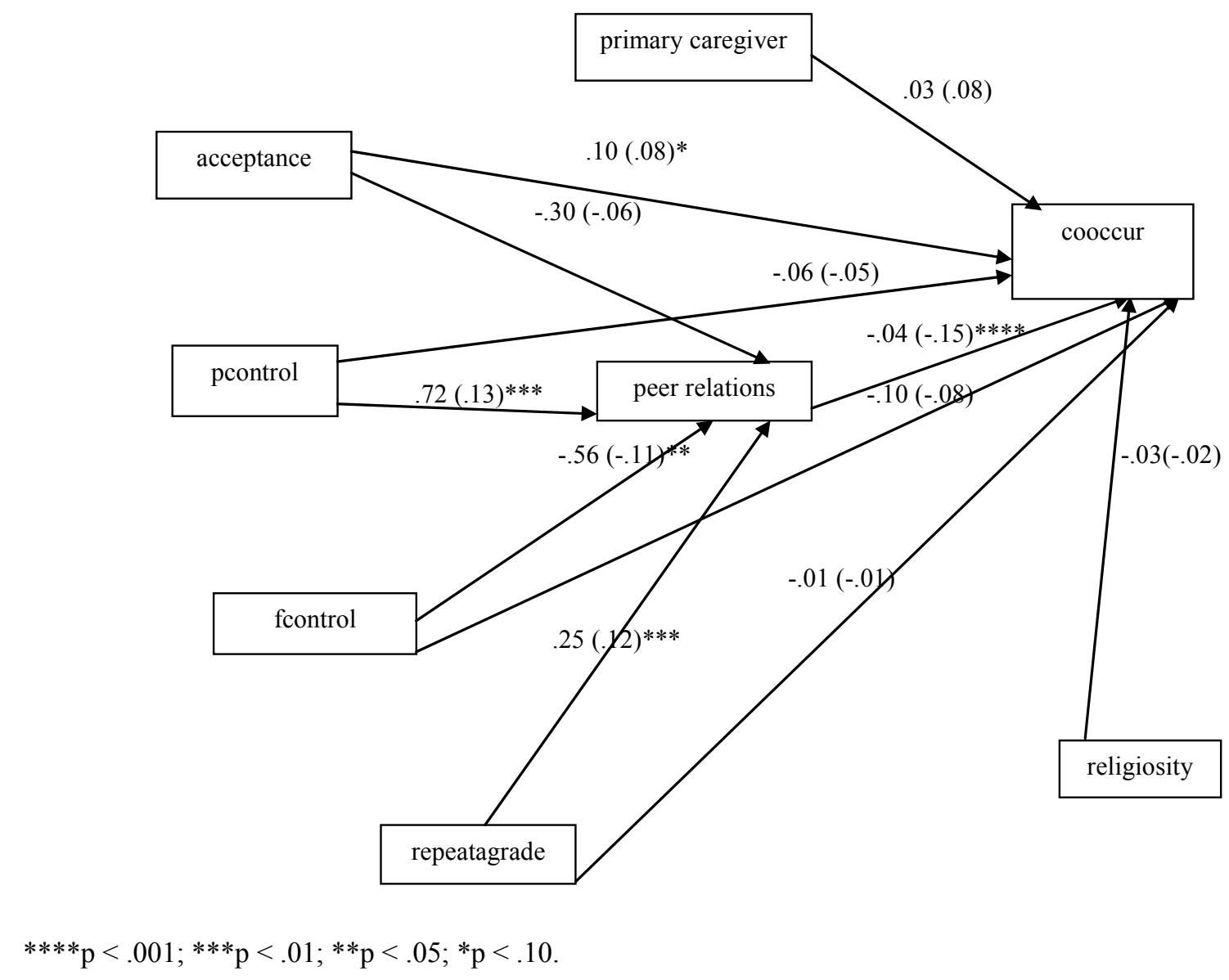

Standardized coefficients in parenthesis 


\section{Chapter V: DISCUSSION}

“... in most empirical research, the model under investigation is tentative and only an approximation to reality."

Crano and Mendoza, 1987, p. 38

Crano and Mendoza's (1987) assertion may be more valid in this instance, given that the current study is based on a sample of multi-problem youth in a substance use treatment program and, therefore, empirically less likely to reflect behavior among most community-based or school-based samples of adolescents. Cognizant of Crano and Mendoza's (1987) contention, the current study sought to determine the key variables and processes associated with adolescents' participation in co-occurring substance use and sexual activity. Specifically, the study assessed whether parent-adolescent relationship variables mediated the relation between the predictor variables - grade retention and peer relationship - and the outcome variable, co-occurring substance use and sexual activity. The study tested direct associations between the exogenous variables in the study and the endogenous variable co-occurring substance use and sexual activity. The study also considered an alternative conceptual mediation model that examined whether peer relationships mediated the relation between the predictor variables - parent-adolescent relationship variables, and grade retention - and the criterion variable, co-occurring substance use and sexual activity. The testing of competing models is considered fundamental to theory building (Guo, Perron \& Gillespie, 2008). The results of both models in the study suggest that parents and peers both play significant roles pertaining to adolescent participation in co-occurring substance use and sexual activity. Both models demonstrate the importance of support to adolescents in influencing behavior, and the 
differential roles played by parents and peers. In situations where adolescents lack parental support and live in dysfunctional families, peer support manifested through communication on sexual topics may be protective against adolescents' engagement in substance use and sexual activity.

Predicated on a multivariate, dynamic systems framework, this study developed a model based on Bronfenbrenner's ecological treatise, and Bogenschneider's (1996) risk and protective theory, which integrates Bronfenbrenner's ecological conceptualization with Lerner's developmental contextualism discussed in the earlier chapters of this dissertation. Jessor's Problem Behavior Theory, described in previous chapters, provided a conceptual framework for analyzing the data in the study. The current study sought to address several questions: 1) What is the association between the independent variable primary caregiver and the outcome variable co-occurring substance use and sexual activity?; 2) What is the association between parent-child relationships and co-occurring substance use and sexual activity?; 3) What is the association between the independent variable grade retention and (a) parent-adolescent relationship and (b) the outcome variable co-occurring substance use and sexual activity?; 4) What is the association between the predictor variable peer relationship and the criterion variable co-occurring substance use and sexual activity?; and, 5) What is the relationship between the predictor variable religiosity and the outcome variable co-occurring substance use and sexual activity? The alternative model replaced parent-adolescent relationship with peer relationship as the mediator between the predictor variables, grade retention, and parentadolescent relationship. 


\section{Summary of Research Findings}

Based on the achievement of convergence, acceptable global and focused fit indices, and the expected direction of proposed paths, the results of the alternative model supported several of the hypotheses in the current study. The results are consistent also with the notion that problem behaviors are correlated and likely to have similar causes (Guilamo-Ramos, Litardo \& Jaccard, 2005). The results demonstrated that peer relationship fully mediated the influence of grade retention, and two parent-adolescent relationship variables, firm control and psychological control, on co-occurring substance use and sexual activity.

The peer relationship variable, which measures sample participants' communication with their peers on sexual topics, had a statistically significant association $(p=.003)$ with the outcome variable, co-occurring substance use and sexual activity. This finding is consistent with the extant literature (Vesely, Wyatt, Oman, Aspy, Kegler \& Rodine, 2004), advances the discussion of the impact of peer communication on risk behavior among adolescents, and promotes the development of efficacious interventions. This finding supports the contention also that communication among peers on intimate topics may serve a protective function, especially among adolescents who have negative parent-adolescent relationships and dysfunctional family environments. The current study indicated earlier that more than half (51.7\%) of participants would prefer to reside with another family, $58.7 \%$ thought seriously about running away from home, and $47.2 \%$ felt left out and lonely at home. The top five topics discussed most commonly among peers were sexual intercourse (64.6\%), dating and sex behavior (62.9\%), using a condom (59.6\%), HIV-AIDS (53\%), and pregnancy (50.5\%). These topics, arguably, reflect a 
desire for information to enhance self-protective behaviors among study participants and, therefore, likely to manifest a negative relation between discussing these topics with peers and engaging in co-occurring substance use and sexual activity. The results of the study did not support the hypothesized direct paths between the predictor variables and co-occurring substance use and sexual activity.

\section{Relationship of Study Findings to Extant Literature: Importance of the Present Model}

There is evidence in the literature to support the findings in the current study. Several studies have investigated the association of parental and peer influences on adolescent substance use, and while parental influences have been the focus of fewer studies, most studies that have considered both "found peer influences to be substantially more important" (Henry \& Slater, 2007, p. 673). The results of the peer mediated model in the present study is consistent with peers being better predictors than parents of adolescent participation in co-occurring substance use and sexual activity. Peer influence was found also to be a mediator of parenting influence on substance use, and to have a stronger mediated than direct effect (Henry \& Slater, 2007), which support the results of the tested alternative model in the present study. There was consistency also with the extant literature concerning the effects of family variables being mediated by peers (Bahr et al., 2005). These findings are congruent with adolescents increasing autonomy from parents, and more affinity to interaction with peers.

Several studies, with non-clinical samples, have found also that positive parenting behaviors are protective against adolescent substance use and progression, and although the relative importance of specific practices is less definitive, communication, knowledge and involvement, support, monitoring, and parental expectations and social norms have 
been proven effective in this regard (Henry \& Slater, 2007). The association between the parent-adolescent relationship variables and co-occurring substance use and sexual activity was not statistically significant. More than half of the participants in the study had parents who used and abused substances, thereby potentially modeling inappropriate behavior. It is conceivable, therefore, that adolescents in these families, who felt parental acceptance, construed substance use as acceptable. At the other end of the spectrum, adolescents experiencing firm or psychological control may have less opportunity to participate in co-occurring substance use and sexual activity, or perceive lower parental approval for these risk behaviors.

The current study did not support family structure, as measured by primary caregiver, a predictor of co-occurring substance use and sexual activity. Parentadolescent relationships are considered more important than the type of family structure Blum et al., 2000; Dekovic et al., 2003), because the support associated with positive parental relations is protective against participation in risk behaviors. Moreover, family structure is a matter of personal choice, and not readily amenable to public policy influence. It is more practical, therefore, to focus efforts on measures that address the risk factors associated with single-parenthood, such as poverty and inadequate parenting. Family-based interventions, that strengthen parent-adolescent communication and improve parental support, as well as mentoring programs that contribute to reducing deficits in parental resources, are potentially efficacious approaches for mitigating the negative effects associated with single-parenthood.

The relation between religiosity and co-occurring substance use and sexual activity was in the expected inverse direction, but it was not statistically significant. 
Previous research, however, indicated that religiosity served a protective function against substance use (Rew \& Wong, 2006), and was associated with lower scores for sexual activity among adolescents (Lammers, Ireland, Resnick \& Blum, 2000). In their systematic review of the literature, Rew and Wong (2006) found that $84 \%$ of the studies reviewed indicated that religiosity/spirituality measures had a positive impact on adolescents' health attitudes and behaviors, including those related to substance use and sexual activity. In relation to race/ethnicity and gender, existing research revealed that black and Hispanic youth were more religious than white youth, and females among this age group more religious than males. There was also some published evidence that among adolescents, those who were younger were more religious than older adolescents (Rew \& Wong, 2006). Interestingly, this could explain the lack of statistical significance between religiosity and the outcome variable, co-occurring substance use and sexual activity, since the mean age of participants in the current study was 16.4 years old. The measure of religiosity in the study also did not distinguish between ritualistic and relational practices, which in a clinical sample would have been an important distinction and potentially more illustrative of the association between religiosity and the outcome variable. It is also plausible, that the lack of consensus among researchers on a theoretical and operational definition of religiosity (Rew \& Wong, 2006) could have contributed to the lack of support for the hypothesized relation in the current study.

The importance of academic achievement in promoting positive adolescent development cannot be overestimated. School connectedness is considered protective against risk behavior among adolescents, and as Henry and Slater (2007) cogently contend "students who demonstrate a positive attachment to school are less likely to be 
involved in delinquency, drop out of school, become pregnant as a teen, and use drugs" (p. 68). Although the present study did not support the hypothesized direct association between grade retention and co-occurring substance use and sexual activity, it did support the hypothesis in which peer relationship factors mediated the associated between grade retention and co-occurring substance use and sexual activity. There is evidence in the literature that as adolescents get older peer relationships become increasingly important, and that peer influences are substantially more dominant than parental influences with regard to adolescent substance use (Simons-Morton, 2007). It is, therefore, not surprising that the data in the present study supported the mediated over the direct association pertaining to grade retention and co-occurring substance use and sexual activity.

\section{Implications of the Current Findings}

Despite the evidence that problem behaviors are likely to co-occur, most interventions tend to be behavior specific and are, therefore, designed singularly to prevent sexual risk-taking, smoking, drug use, and alcohol use (Guilamos-Ramos, et al., 2005), rather than adopting a broader, more holistic approach. These authors argue for the singular approach, because of unique factors associated with specific behaviors.

However, there seems to be enough commonality in the contributing factors to support a holistic approach, especially since it is generally accepted that adolescents function in multiple interrelated social contexts.

Interventions associated with positive youth development programs "assume that the same individual, family, school, and community factors that influence positive outcomes in youth also affect youth problem behaviors" (Guilamos-Ramos, et al., 2005, p. 83). The current study concurred with this contention and developed a multivariate 
model that identified individual, family, peer, and school factors that influence adolescent behavioral outcomes. It advances the argument of positive youth development programs that focus on promoting, among other attributes, spirituality, social skills, moral competence, self-efficacy, and prosocial norms (Gavin, Catalano \& Markham, 2010). The study, therefore, provides a framework on which to develop programs that integrate the factors associated with the promotion of positive youth development. Specifically, more supportive parent-adolescent relationships, through family-based interventions to improve parent-adolescent communication and interaction, could provide the foundation for more positive adolescent outcomes. Programs that target improved school connectedness could reduce the incidence of grade retention and the associated increased risk of dropping out of school. Relational religiosity could be fostered through churchbased youth programs that promote positive development. Interventions that promote prosocial peer interactions and develop adolescents' self-efficacy could lead to the incidence of more positive trajectories among youth.

\section{Clinical Implications of the Current Findings}

Based on research conducted in the current and previous studies, there seems to be incontrovertible evidence that adolescents participate in two social networks, the family and peer networks, both of which influence behavior differently (Wills et al., 2004). It has been established also that the quality of parent-child relationships indirectly impacts adolescents' peer competency, which in the present study was operationalized as communication on sexual topics among peers. However, the directionality of this relationship remains an issue, especially at different developmental stages. Autonomy 
from parental influence becomes more germane, at later developmental stages (Parke, MacDonald, Burks, Carson \& Bhavnagri, 1989).

Parental and other adult support are considered protective, while peer support is more consistent with a detrimental effect. Wills et al., (2004) argue that this may be due to these networks operating through dissimilar behavioral influences. Multivariate models found that there was an inverse relation between family support and maladaptive behavior, while there was a positive association for peer support. This is in contrast to the findings in the present study, where peer support was indexed as communication on sexual topics. The present study did not collect information on peer behavior, and found initial evidence that peer communication may be protective, especially in this sample of multi-problem youth experiencing negative parental relationships and living in dysfunctional families. It is surmised that "the effects of peer support are complex and may involve several pathways, with different types of relations to substance use" (Wills et al., 2004, p. 123). In this regard, Krappmann (1989) makes a cogent argument concerning the distinction between these relationships, and states "the view that social capacities acquired in parent-child relationships are simply generalized to peer relationships disregards the structurally different demands to negotiate expectations and intentions in the latter domain of interactions" (p. 94). As adolescents become more autonomous from parental influence, peer groups provide what Krappmann (1989) refers to as "the agency of socialization." It is plausible to argue, therefore, that these different relationships are likely to have profoundly different effects on adolescents' decision to participate in co-occurring substance use and sexual activity, and the strength of this 
effect is likely to be impacted by the developmental stage, the particular context, and level of autonomy adolescents have achieved.

\section{Study Limitations}

Bentler and Chou (1987), in their discussion of issues associated with developing a structural model, encapsulate a profound limitation in this pursuit, and aptly state "most valuable substantive theories are quite complex, and it is easy to hope that most of the complexity can be studied in the context of a single structural model. Rarely is this possible: the data are almost always far more complex than even the best theory" (p. 97). Arguably, one can make the case that a clinical sample of multi-problem adolescents in a substance use treatment program poses even greater challenges. Bentler and Chou (1987) continue their contention that "although one's theory may capture a substantial amount of variation in the data, statistical tests can lead to model rejection when only a few effects in the data have been overlooked" (p. 97). While the current study did not result in rejecting the alternative model, some hypotheses were not supported, and data limitations could be a plausible contributing factor.

Kotchick et al., (2001) stipulated that assessment issues are likely to be a problem in research studying sexual behavior among adolescents. Adolescent self-reports are not necessarily unbiased, because of the tendency, based on their motivation, to exaggerate or understate their sexual activity. However, the present study used computer-assisted interview techniques, which are considered more likely to elicit accurate responses (Sieving \& Shrier, 2009). Nevertheless, there are two disadvantages to Likert scales, in their lower precision and potential limitations as a barometer of sexual risk behaviors (Schroder, Carey, \& Venable, 2003). In addition, several of the measures used in the 
study were very brief, and this lack of extensiveness can increase the potential for significant error variance.

The generalizability of the study may be limited, because the sample was comprised only of participants receiving outpatient treatment for substance use, who are likely to be different from a community-based adolescent population or a population of adolescents in residential substance abuse treatment. More than half of the parents of adolescents in the study drank heavily or abused drugs. This is also not the norm among parents of adolescents in general, and research indicates that adolescents who observe their parents or other significant adults using drugs may be more disposed to experiment with drugs, develop acceptance toward drug use, and select friends who use drugs. Parental drug use has been found to be positively associated with drug use among adolescents (Bahr et al., 2005). The disproportionate representation of Hispanics in the sample, also restricts the generalizability of findings from the study. Although Hispanics represent an increasing proportion of the national population, they have not reached the magnitude of the $44.7 \%$ reflected among study participants. Hispanics represented $15 \%$ of the total U.S. population in 2008. The data also did not allow a determination of married biological versus cohabiting biological parents, because no information on parental marital status was collected. It has been established already in the current study that there is a distinct difference between married and cohabiting parent households. The data also limited the ability to determine peer characteristics, to facilitate a better understanding of peer relationship in the study that went beyond peer communication on sexual topics. 
Cross-sectional studies have advantages in being less expensive, less time consuming, and less likely to manifest attrition of participants. However, the use of crosssectional data in the study limits the interpretation of directional influences, and presumptions of causality, because of the concurrent measurement of variables, which prevents such effects from being modeled and determined (MacCallum \& Austin, 2000).

Despite the limitations evident in the present study, they do not negate the results which substantially support the hypotheses associated with the tested multivariate model of factors associated with co-occurring substance use and sexual activity among adolescents.

\section{Directions for Future Research}

The present study used data collected on a sample of multi-problem adolescents in an outpatient substance use treatment program to develop a multivariate model aimed at identifying the individual, family, school, and peer variables associated with co-occurring substance use and sexual activity. While a multivariate approach provided important findings on the factors associated with co-occurring substance use and sexual activity among adolescents, a multidisciplinary focus would have allowed a broader perspective from which to understand this behavior. Consistent with the philosophy of lifespan development science, a multidisciplinary approach that focuses on the brain, behavior, and social-context interactions that occur during adolescent maturation would provide a more holistic conceptual framework for understanding this pivotal developmental period (Dahl, 2004). Dahl articulates a growing consensus in the field that there is the need for transdisciplinary discourse that integrates work in areas of neuroscience and normative development with clinical and social policy research to facilitate proactive intervention 
and prevention strategies. In essence, "stronger scientific bridges need to be built across disciplines that will allow previously separate bodies of knowledge to be linked and more effectively applied to the large-scale problems affecting youth. The stakes are high: the problems affecting adolescents in our society are both enormous and complex" (Dahl, 2004, pp. 1-2).

The non-normative sample on which the current study was based and the brief nature of several measures used in various assessments limit the generalizability of the findings. There is evidence that substance use and precocious sexual activity remain intractable problems (U.S. Department of Health and Human Services, 2010). It is necessary, therefore, to conduct a similar multivariate study with a normative sample of adolescents, with more extensive measures, to develop a model with broader applicability, that could facilitate the development of efficacious interventions.

Based on the established dominance of peer relationship factors in adolescent risk behavior, it is imperative that peer relationship be operationalized in research studies in a manner that allows the nature of the relationship to be multiply determined, in terms of activities in which adolescents engage with peers. A distinction between prosocial and maladaptive peers is important to determine the nature of peer influence. It is important also to determine whether the maintenance of positive parenting over time is protective (Simons-Morton, 2007), and whether this serves to mitigate the dominance of peer influence.

A longitudinal study would provide important insight into directional and causal influences impacting adolescents' participation in co-occurring substance use and sexual activity. Promoting positive youth development requires a definitive determination of the 
risk and protective processes associated with risk behavior among adolescents. While it is believed that the results of the study advanced the understanding of relations among the variables associated with risk behaviors among adolescents, the limitations of the study provide an opportunity for further research that is more compelling in identifying the determining factors. Simons-Morton (2007) articulated this sentiment, when he stated that "useful interventions can be developed only with a clear understanding of the predictors of substance use" (p. 681). 


\section{REFERENCES}

Akers, R. L., Krohn, M. D., Lanza-Kaduce, L., \& Radosevich, M. (1979). Social learning and deviant behavior: A specific test of a general theory. American Sociological Review, 44, 636-655.

Alexander, K., Entwisle, D., \& Kabbani, N. (2001). The dropout process in life course perspective: early risk factors at home and school. Teachers College Record, 103 (5), 760-822.

Allen, J. \& Land, D. (1999).Attachment in adolescence. In J. Cassidy \& P. Shaver (Eds.), Handbook of attachment (pp. 319-335). New York: Guilford.

Amato, P.R. (1995). Single-parent households and children's development, well-being, and attainment: A social network/resources perspective. Sociological Studies of Children, 7, 19-47.

Amato, P. R. (2001). Children of divorce in the 1990s: An update of the Amato and Keith (1991) meta-analysis. Journal of Family Psychology, 15, 355-370.

Amato, P. R. (2005). The impact of family formation change on the cognitive, social and emotional well-being of the next generation. The Future of Children, (15) 2, 7596.

Apel, R., \& Kaukinen, C. (2008). On the relationship between family structure and antisocial behavior: Parental cohabitation and blended households.

Criminology, 46 (1), 35-70.

Bachman, H. J., Coley, R. L., \& Chase-Lansdale, P. L. (2004).The influence of marriage, cohabitation, and family structure changes on low-income adolescents' development. Prepared for presentation at the annual meeting of the Population Association of America, Boston, MA.

Bachman, J. G., O’Malley, P. M., Schulenberg, J. E., Johnston, L. D., Freedman-Doan, P., \& Messersmith, E. E. (2007). The education-drug use connection: How successes and failures in school relate to adolescent smoking, drinking, drug use, and delinquency. Mahwah, NJ: Lawrence Erlbaum Associates.

Bahr, S. J., Hoffmann, J. P. \& Yang, X. (2005). Parental and peer influences on the risk of adolescent drug use. Journal of Primary Prevention, 26(6), 529-551. 
Baron, R. M. \& Kenny, D. A. (1986). Moderator-mediator variables distinction in social psychological research: Conceptual, strategic, and statistical considerations. Journal of Personality and Social Psychology, 51 (6), 1173-82.

Barrett, A. E. \& Turner, R. J. 2006. Family structure and substance use in adolescence and early adulthood: Examining explanations for the relationship. Addiction, 101, 109- 120.

Bengston, V. L. (2001). Beyond the nuclear family: The increasing importance of multigenerational bonds. Journal of Marriage and Family, 63, (1), 1-16.

Benson, P. L., Scales, P. C., Hamilton, S. F., \& Sesma, A., Jr. (2006). Positive youth development: Theory, research, and applications. In R. M. Lerner (Ed.). Theoretical models of human development. Volume 1 of Handbook of Child Psychology (6th ed.). Editors-in-chief: W. Damon \& R. M. Lerner. Hoboken, NJ: Wiley.

Bentler, P. M. \& Chou, C. (1987). Practical issues in structural equation modeling. Sociological Methods \& Research, 16, (1), 78-117.

Biglan, A., \& Cody, C. (2003). Preventing multiple problem behaviors in adolescence. In D. Romer, (Ed.) Reducing adolescent risk: Towards an integrated approach (pp. 125-131). Thousand Oaks, CA: Sage.

Biglan, A. \& Hinds, E. (2009). Evolving prosocial and sustainable neighborhoods and communities. Annual Review Clinical Psychology, 5, 169-196.

Blum, R. W., Beuhring, T., \& Rinehart, P. M. (2000).Protecting teens: Beyond race, income and family structure. Minneapolis, MN: Center for Adolescent Health, University of Minnesota.

Bogenschneider, K. (1996). An ecological risk/protective theory for building prevention programs, policies, and community capacity to support youth. Family Relations, 45(2), 127-138.

Bonino, S., Cattelino, E., \& Ciairano, S. (2005). Adolescents and risk: Behavior, functions and protective factors. Italy: Springer-Verlag.

Borawski, E. A., Ievers-Landis, C. E., Lovegreen, L. D., \& Trapl, E.S. (2003). Parental monitoring, negotiated unsupervised time, and parental trust: The role of perceived parenting practices in adolescent health risk behaviors. Journal of Adolescent Health, 33, 60-70. 
Bowlby, J. (1988). Secure Base. New York: Basic Books.

Bronfenbrenner, U. (1990). Discovering what families do. In D. Blankenhorn, S. Bayme, \& J. B. Elshtain (Eds.), Rebuilding the nest: A new commitment to the American family. Milwaukee, WI: Family Service America.

Bronfenbrenner, U. \& Morris, P. A. (1998). The ecology of developmental processes. In W. Damon \& R. M. Lerner (Eds.), Handbook of Child Psychology: Vol 1: Theoretical Models of Human Development (pp. 993-1028). New York: Wiley.

Brown, J. E. \& Mann, L. (1990). The relationship between family structure and process variables and adolescent decision making. Journal of Adolescence, 13, 25-37.

Brown, S. (2004). Family structure and child well-being: the significance of parental cohabitation. Journal of Marriage and Family, 66, 351-367.

Browne, M. W. \& Cudeck, R. (1993). Alternative ways of assuming model fit. In K. A. Bollen \& J. S. Long (Eds.), Testing structural equation models (pp. 136-162). Newbury Park, CA: Sage.

Byrne, B.M. (2001). Structural Equation Modeling with AMOS: Basic Concepts, Applications, and Programming. Mahwah, NJ: Lawrence Erlbaum Associates.

Carey, M. P., Carey, K. B., Maisto, S. A., Gordon, C. M., \& Weinhardt, L. S. (2001). Assessing sexual risk behavior with the Timeline Follow-back (TLFB) approach: Continued development and psychometric evaluation with psychiatric outpatients. International Journal of STDs and AIDS, 12, 365-375.

Caspers, K. M., Yucuis, R., Troutman, B., \& Spinks, R. (2006). Attachment as an organizer of behavior: implications for substance abuse problems and willingness to seek treatment. Substance Abuse Treatment, Prevention, and Policy, (1), 32,110.

Centers for Disease Control and Prevention, Youth Risk Behavior Surveillance - United States, Surveillance Summaries, 2009, MMWR 2010: 59(No.SS-5).

Chan K. S., Wenzel S., Orlando M., Montagnet C., Mandell, W. (2004). How important are client characteristics to understanding treatment process in the therapeutic community? American Journal of Drug \& Alcohol Abuse, 30(4), 871-891.

Clarke-Stewart, A. \& Dunn, J. (Eds.) (2006).Families count: Effects on child and adolescent development. New York: Cambridge University Press. 
Crano, W. D. \& Mendoza, J. L. (1987). Maternal factors that influence children's positive Behavior: Demonstration of a structural equation analysis of selected data from the Berkeley growth study. Child Development, 58, 38-48.

CSR, Inc. (1997). Understanding youth development: Promoting positive pathways of growth. Washington, DC: CSR, Inc.

Dahl, R. (2004). Adolescent brain development: A period of vulnerabilities and opportunities. Annals of New York Academy of Sciences, 1021, 1-22.

Damon, W. (2004). What is positive youth development? Annals of the American Academy of Political \& Social Science. Special Issue, Positive Development: Realizing the Potential of Youth, 591, 13-24.

Davies, E., Wood, B., \& Stephens, R. (2002). From rhetoric to action: A case for a comprehensive community-based initiative to improve developmental outcomes for disadvantaged children. Social Policy Journal of New Zealand, 19, 28-47.

Davies, S., Crosby, R. A., \& DiClemente, R. J. (2009). Family influences on adolescent health. In R. J. DiClemente, J. S. Santelli, \& R. A. Crosby (Eds.). Adolescent Health: Understanding and Preventing Risk. San Francisco, CA: Jossey-Bass Wiley.

Day, R. D., Orthner, D. K., Hair, E. \& Kelleen, K. (2008). Marital quality and parent-adolescent relationships: Effects on adolescent religiosity and religious practice. ASPE Research Brief. Washington, D.C.: U.S. Department of Health and Human Services.

DeAngelis, T. (2010). Closing the gap between practice and research. Monitor on Psychology (41), 6, 42-46.

Demo, D. H., \& Acock, A. C. (1996). Family structure, family process, and adolescent well-being. Journal of Research on Adolescence, 6, 457-488.

DiIorio, C., Kelley, M., \& Hockenberry-Eaton, M. (1999). Communication about sexual issues: Mothers, fathers, and friends. Journal of Adolescent Health, 24, 181-189.

Dishion, T. J., Kavanagh, K., \& Kiesner, J. (1999). Prevention of early adolescent substance use among high-risk youth: A multiple gating approach to parent intervention. In R. S. Ashery (Ed.), Research meeting on drug abuse prevention through family interventions. (NIDA Research Monograph No. 177) (pp. 208228). Washington, DC: U.S. Government Printing Office. 
Dollahite, D. C., \& Thatcher, J. Y. (2008). Talking about religion: How religious youth and parents discuss their faith. Journal of Adolescent Research, 23, 611-641.

Donovan, J. E. (2004). Problem behavior theory. In Fisher, C. B. \& Lerner, R. M. (Eds.), An Encyclopedia of Developmental Science (Vol. 2). Thousand Oaks, CA: Sage.

Drug Strategies, (2002). Treating Teens: A Guide to Adolescent Drug Programs. Washington, DC:Drug Strategies.

Elliot, D. S., Huizinga, D., \& Ageton, S. S. (1985). Explaining delinquency and drug use. Newbury Park, CA: Sage.

Enders, C. K. (2001). A primer on maximum likelihood algorithms available for use with missing data. Structural Equation Modeling, 8(1), 128-141.

Federal Interagency Forum on Child and Family Statistics. (2006). America's Children: Key National Indicators of Well-Being, 2005. Washington, DC: U.S. Government Printing Office, 63-72.

Gavin, L. E., Catalano, R. F., \& Markham, C. M. (2010). Positive youth development as a strategy to promote adolescent sexual and reproductive health. Journal of Adolescent Health, 46(3), Supplement: S1-S6.

Gordon, C.P. (1996). Adolescent decision making: A broadly based theory and its application to the prevention of early pregnancy. Adolescence, 31, 561-584.

Gottfredson, M. R., \& Hirschi, T. (1990). A general theory of crime. Stanford, CA: Stanford University Press.

Grolnick, W. S., \& Ryan, R. M. (1992). Parental resources and the developing child in school. In M. E. Procidano \& C. B. Fisher (Eds.), Contemporary Families. New York, NY: Teachers College Press.

Guilamo-Ramos, V., Litardo, H., \& Jaccard, J. (2005). Prevention programs for reducing adolescent problem behaviors: Implications of the co-occurrence of problem behaviors in adolescence. Journal of Adolescent Health, 36(1), 82-86.

Guo, B., Perron, B. E. \& Gillespie, D. F. (2008). A systematic review of structural equation modeling in social work research. British Journal of Social Work, 1-19. Available at http://deepblue.lib.umich.edu/bitstream/2027.42/61156/1/SEM.pdf

Hair, J. F. Jr., Black, W. C., Babin, B. J., Anderson, R. E., \& Tatham, R. L. (2006). Multivariate data analysis. Upper Saddle River, NJ: Pearson Prentice Hall. 
Hao, L., \&Xie, G. (2001). The complexity and endogeneity of family structure in explaining children's misbehavior. Social Science Research, 31, 1-28.

Harris, K. M., Duncan, G. J., \& Boisjoly, J. (2002). Evaluating the role of "nothing to lose" attitudes on risky behavior in adolescents. Social Forces (8) 3, 1005-1039.

Henry, K. L. \& Slater, M. D. (2007). The contextual effect of school attachment on young adolescents' alcohol use. Journal of School Health (77) 2, 67-74.

Hirschi, T. (1969).The causes of delinquency. Berkeley, CA: The University of California Press.

Hirschman, C., Pharris-Ciurej, N., \& Willhoft, J. (2006). How Many Students Really Graduate from High School: The Process of High School Attrition. Available from https://depts.washington.edu/uwbhs/docs/HS Graduation.pdf

Holmbeck, G. N. (2002). A developmental perspective on adolescent health and illness: An introduction to the special issues. Journal of Pediatric Psychology, (27), 8, 409-415.

Howard, S. \& Johnson, B. (2000). Young adolescents displaying resilient and nonresilient behavior: Insights from a qualitative study - can schools make a difference? Australian Association for Research in Education Conference. Available from http://www.aare.edu.au/00pap/how00387.htm.

Hoyle, R. H. \& Smith, G. T. (1994). Formulating clinical research hypotheses as structural equation models: A conceptual overview. Journal of Consulting and Clinical Psychology, (62) 3, 429-440.

Igra, V., \& Irwin, C., Jr. (1996). Theories of adolescent risk-taking behavior. In R. J. DiClemente, W. B. Hansen, \& L. E. Ponton (Eds.).Handbook of Adolescent Health Risk Behavior. New York: Plenum Press.

Information Technology Services (2001). Structural equation modeling using Amos: An introduction. Available from www.utexas.edu/its/rc/tutorials/stat/amos/

Jaccard, J. \& Wan C. K. (1996). LISREL approaches to interaction effects in multiple regression. Thousand Oaks, CA: Sage Publications. 
Jaccard, J., Blanton, H., \& Dodge, T. (2005). Peer influences on risk behavior: An analysis of the effects of a close friend. Developmental Psychology, 41, 135147.

Jelicic, H., Bobek, D. L., Phelps, E., Lerner, R. M., \& Lerner, J. V. (2007). Using positive youth development (PYD) to predict contribution and risk behaviors in early adolescence. Findings from the first two waves of the 4-H Study of PYD. International Journal of Behavioral Development, (31) 30, 263-273.

Jessor, R., \& Jessor, S. (1977). Problem behavior and psychosocial development: A longitudinal study of youth. New York, NY: Academic Press.

Jessor, R. (1982). Problem behavior and developmental transition in adolescence. Journal of School Health, 52, 295-300.

Jessor, R. (1987). Problem-behavior theory, psychosocial development, and adolescent problem drinking. British Journal of Addiction, 82, 331-342.

Jessor, R. (1991). Risk behavior in adolescence: A psychosocial framework for understanding and action. Journal of Adolescent Health, 12, 597-605.

Jessor, R. (1998). New perspectives on adolescent risk behavior. In R. Jessor, (Ed.), New perspectives on adolescent risk behavior. New York: Cambridge University Press.

Jessor, R., Donovan, J. E., \& Costa, F. (1991). Beyond adolescence: Problem behavior and young adult development. New York: Cambridge University Press.

Jessor, R., Van Den Bos, J., Vanderryn, J., Costa, F. M., \& Turbin, M.S. (1995). Protective factors in adolescent problem behavior: Moderator effects and developmental change. Developmental Psychology, 31, 923-933.

Kilmann, P. R., Vendemia, J. M. C., Parnell, M. M., Urbaniak, G. C. (2009). Parent characteristics linked with daughters' attachment style. Adolescence, 44 (175), 557-568.

Kline, R. B., Canter, W. A., \& Robin, A. (1987). Parameters of teenage alcohol use: A path-analytic conceptual model. Journal of Consulting and Clinical Psychology, 55, 521-528.

Kline, R. B. (2005). Principles and practice of structural equation modeling (2nd Ed.), New York: Guilford. 
Kline, R. B. (2011). Principles and practice of structural equation modeling (3rd Ed.), New York: Guilford.

Kotchick, B. A., Shaffer, A., Forehand, R., \& Miller, K. S. (2001). Adolescent sexual risk behavior: A multi-system perspective. Clinical Psychology Review, 21, 493-519.

Kowaleski-Jones, L. (2000). Staying out of trouble: Community resources and problem behavior among high-risk adolescents. Journal of Marriage and the Family (62), $449-464$.

Krappmann, L. (1989). Family relationships and peer relationships in middle childhood: An exploratory study of the associations between children's integration into the social network of peers and family development. In Kreppner, K. \& Lerner, R. M. (Eds.) Family Systems and Life-Span Development, pp. 93-104, New Jersey: Lawrence Erlbaum Associates.

Kurtines, W. M., Ferrer-Wreder, L., Berman, S. L., \& Lorente, C. C. (2008). Promoting positive development: New directions in developmental theory. Journal of Adolescent Research, 23(3), pp. 233-244.

Lammers, C., Ireland, M., Resnick, M., \& Blum, R. (2000). Influences on adolescents' decisions to postpone onset of sexual intercourse: A survival analysis of virginity among youths aged 13 to 18 years. Journal of Adolescent Health, 26, 42-48.

Langer, M. L. \& Tubman, J. G. (1997). Risky sexual behavior among substance-abusing adults: Psychosocial and contextual factors. American Journal of Orthopsychiatry (67), 2, 315-322.

Larson, R., Eccles, J., \& Gootman, J. A. (2004). Features of positive developmental settings. The Prevention Researcher, 11(2), 8-13.

Lee, G., Akers, R. L., \& Borg, M. J. (2004). Social learning and structural factors in adolescent substance use. Western Criminology Review, 5(1) 17-34 (2004).

Leigh, B. \& Stall, R. (1993).Substance use and risky sexual behavior for exposure to HIV. Issues in methodology, interpretation, and prevention. American Psychology, 48, 1035-1045.

Lerner, R. M. (2006). Developmental science, developmental systems, and contemporary theories of human development. In Damon, W. \& Lerner, R.M. Handbook of Child Psychology: Theoretical Models of Human Development, Volume 1( $6^{\text {th }}$ ed. $)$, pp.1-17. New York: Wiley. 
Liddle, H. A. (2003). Multidimensional family therapy for early adolescent substance abuse treatment manual. Center for Treatment Research on Adolescent Drug Abuse, Department of Epidemiology and Public Health, University of Miami School of Medicine, Miami, Florida.

Little, R. J. A. \& Rubin, D. B. (1987). Statistical analysis with missing data. New York: Wiley.

Lo Conte, J. S., O’Leary, A., \& Labouvie, E. (1997). Psychosocial correlates of HIVrelated sexual behavior in an inner-city STD clinic. Psychology \& Health, 12, 589-601.

Loehlin, J. C. (1987). Latent variable models: An introduction to factor, path, and structural analysis. Hillsdale, NJ: Erlbaum.

MacCallum, R. C. \& Austin, J. T. (2000). Applications of structural equation modeling in psychological research. Annual Review of Psychology, 51, 201-226.

MacKinnon, D. P. (2008). Introduction to statistical mediation analysis. New York: Lawrence Erlbaum Associates.

Magnusson, D. \& Stattin, H. (2006). The person in the environment: Towards a general model for scientific inquiry. In R. M. Lerner (Ed.). Theoretical models of human development. Volume 1 of Handbook of Child Psychology (6th ed.). Editors-inchief: W. Damon \& R. M. Lerner. Hoboken, NJ: Wiley.

Manning, W. D. (1999).Childbearing in cohabiting unions: Racial and ethnic differences. Paper presented at the annual meeting of the Population Association of American, New York.

Manning, W. D., \& Bulanda, R. E. (2006). Cohabitation and family trajectories. In S. L. Hofferth \& L. M. Casper (Eds.), Handbook of Measurement Issues in Family Research, Mahwah, NJ: Lawrence Erlbaum.

Manning, W. D., Smock. P. J., \& Majumdar, D. (2004). The relative stability of cohabiting and marital unions for children. Population Research and Policy Review, 23, 135-159.

Mardia, K. V. (1970). Measures of multivariate skewness and kurtosis with applications. Biometrika, 57, 519-530.

Marquardt, E. (2005). Between two worlds: The inner lives of the children of divorce. Bethel, CT: Crown. 
Mayes, L. C. \& Suchman, N. E. (2006). Developmental pathways to substance abuse. In D. Cicchetti, \& D. Cohen (Eds.), Developmental Psychopathology, $2^{\text {nd }}$ ed., Vol. 3, p. 599-619. New Jersey: John Wiley \& Sons.

McDonald, R. P. \& Ho, M.-H.R. (2002). Principles and practice in reporting structural equation analyses. Psychological Methods, 7, 64-82.

Micceri, T. (1989). The unicorn, the normal curve, and other improbable creatures. Psychological Bulletin, 105, 156-166.

Midanik, L. T., Hines, A. M., Barrett, D. C., Paul, J. P., Crosby, G. M., \& Stall, R. D. (1998). Self-reports of alcohol use, drug use and sexual behavior: Expanding the Timeline Follow-back technique. Journal of Studies on Alcohol, 59(6), 681-689.

Miller, P. A. \& Hauser, R. (1989). Self-report measures of parent-child relationships. In H. D. Grotevant \& C. I. Carlson (Eds.), Family Assessment: A Guide to Methods and Measures. New York, N.Y.: The Guilford Press.

Morgan, P. (2000). Marriage-lite. Trowbridge, Wiltshire: The Cromwell Press.

National Research Council and Institute of Medicine (2002).Community Programs to Promote Youth Development. Committee on Community-Level Programs for Youth. In J. Eccles \& J. A. Gootman, (Eds.), Board on Children, Youth, and Families, Division of Behavioral and Social Sciences and Education. Washington, DC: National Academy Press.

O'Hare, W. \& Mather, M. (2003). The growing number of kids in severely distressed Neighborhoods: Evidence from the 2000 census. The Annie E. Casey foundation and the Population Reference Bureau.

Parke, R. D., MacDonald, K. B., Burks, V. M., Carson, J. \& Bhavnagri, N. (1989). Family and peer systems: In search of the linkages. In K. Kreppner, \& R. M. Lerner (Eds.) Family Systems and Life-Span Development, pp. 93-104, New Jersey: Lawrence Erlbaum Associates.

Parker, J. S., \& Benson, M. J. (2004). Parent-adolescent relations and adolescent functioning: Self-esteem, substance abuse, and delinquency. Adolescence, 39 (155), 519-530.

Petraitis, J., Flay, B. R., \& Miller, T. Q. (1995). Reviewing theories of adolescent substance abuse: Organizing pieces of the puzzle. Psychological Bulletin, 117(1), 67-86. 
Riesch, S. K., Anderson, L. S., \& Krueger, H. A. (2006). Parent-child communication processes: Preventing children's health-risk behavior. Journal for Specialists in Pediatric Nursing (11), 1, 41-56.

Resnick, M., Bearman, P., Blum, R., Bauman, K. (1997). Protecticting adolescents from harm: Findings from the National Longitudinal Study on Adolescent Health. Journal of the American Medical Association, 278, 823-832.

Rew, D. L. (2005). Adolescent health: A multidisciplinary approach to theory, research and intervention. California: Sage.

Rew, L., \& Wong, Y. J. (2006). A systematic review of associations among religiosity/spirituality and adolescent health attitudes and behaviors. Journal of Adolescent Health, 38, 433-442.

Riggs, P. D. (2003). Treating adolescents for substance use and comorbid psychiatric disorders. Science \& Practice Perspectives, 18-32.

Roberts, M. C., \& Llardi, S. S. (2003). Research methodology and clinical psychology: An overview. In M. C. Roberts \& S. S. Llardi (Eds), Handbook of Research Methods in Clinical Psychology. Malden, MA: Blackwell Publishing Ltd.

Rolison, M. (2002). Factors influencing adolescents' decisions to engage in risk-taking behavior. Adolescence, 37, (147), 585-596.

Rowe, C. L., \& Liddle, H. A. (2003). Substance abuse. Journal of Marital and Family Therapy, 29 (1), 97-120.

Sanders, B., \& Becker-Lausen, E. (1995). The measurement of psychological maltreatment: Early data on the child abuse and trauma scale. Child Abuse and Neglect, (19), 3, 315-323.

Schluderman, E., \& Schluderman, S. (1970). Replicability of factors in children's reports of parent behavior (CRPBI). Journal of Psychology, 76, 239-249.

Schroder, K.E., Carey, M.P., Venable, P.A. (2003). Methodological challenges in research on sexual risk behavior: I. Item content, scaling, and data analytic options. Ann Behav Med., 26(2): 76-103.

Schwartz, J., Barton-Henry, M., \& Pruzinsky, T. (1985). Assessing child-rearing behaviors: A comparison of ratings made by mother, father, child, and sibling on the CRPBI . Child Development, 56, 462-479. 
Shonkoff, J. P. \& Phillips, D. A. (Eds.), (2000).From neurons to neighborhoods: The science of early childhood development. Washington, D.C.: National Academy Press.

Sieving, R. \& Shrier, L. A. (2009). Measuring adolescent health behaviors. In R. Di Clemente, J. Santelli \& R. Crosby (Eds.), Adolescent health: Understanding and preventing risk behaviors (pp. 473-492). San Francisco, CA: John Wiley \& Sons.

Simons-Morton, B. (2007). Social influences on adolescent substance use. American Journal of Health Behavior, 31,( 6), 672-684.

Sobell, L. C., Sobell, M. B., \& Ward, E. (Eds.). (1980). Evaluating alcohol and drug abuse treatment effectiveness: Recent for alcohol problems: A dialogue. New York: Haworth Press.

Sobell, L., \& Sobell, M. (1992).Timeline follow-back: A technique for assessing selfreported alcohol consumption. In: R. Z. Litten \& J. P. Allen (Eds.), Measuring Alcohol Consumption. Totowa, NJ: The Human Press, pp. 41-72.

Sokol-Katz, J., Dunham, R., \& Zimmerman, R. (1997). Family structure versus parental attachment in controlling adolescent deviant behavior: a social control model. Adolescence, 32, (125), 199-215.

Steinberg, L. (2001). We know some things: Parent-adolescent relationships in retrospect and prospect. Journal of Research on Adolescence, 11(1), 1-19.

Steinberg, L., \& Morris, A. (2001). Adolescent development. Annual Review of Psychology, 52, 83-110.

Steinberg, L. (2008). A social neuroscience perspective on adolescent risk-taking. Developmental Review, 28, 78-106.

Stevens, J. (1996). Applied multivariate statistics for the social sciences. Mahwah, NJ: Erlbaum.

Sullivan, C.J. (2006). Childhood Emotional and Behavioral Problems and Prediction of Delinquency: A Longitudinal Assessment of an Empirically-Identified Latent Profile. The Louis De La Parte Florida Mental Health Institute Research and Training Center Annual Research Conference, Tampa, FL.

Taylor, R. D., Casten, R., \& Flickinger, S. (1993). The influence of kinship social support on the parenting experiences and psychosocial adjustment of African-American adolescents. Developmental Psychology, 29, 382-388. 
Theokas, C. \& Lerner, R. M. (2006). Observed ecological assets in families, schools, and neighborhoods: Conceptualization, measurement, and relations with positive and negative developmental outcomes. Applied Developmental Science, (10), 2, 6174.

The National Center on Addiction and Substance Abuse (CASA) at Columbia University (2004). Criminal neglect: Substance abuse, juvenile justice and the children left behind. NY: New York.

The National Center on Addiction and Substance Abuse (CASA) at Columbia University. (2005). Family matters: Substance abuse and the American family.

Tremblay, G. C. \& Landon, B. (2003). Research in prevention and promotion (adults \& children). In M. Roberts \& S. Ilardi (Eds.), Methods of research in clinical psychology: A handbook (pp. 354-373). Oxford, U.K.: Blackwell Publishers.

Upchurch, D. M., Mason, W. M., Kusonuki, Y. \& Kriechbaum, M. J. (2004). Social and behavioral determinants of self-reported STD among adolescents. Perspectives on Sexual and Reproductive Health (36), 6, 276-287.

Vesely, S., Wyatt, V., Oman, R., Aspy, C., Kegler, M., Rodine, S., Marshall, L., \& McLeroy, K. (2004). The potential protective effects of youth assets from adolescent sexual risk behaviors. Journal of Adolescent Health, (34) 5, 356-365.

Wallace, J. M. Jr., \& Bachman, J. G. (1991). Explaining racial/ethnic differences in adolescent drug use: the impact of background and lifestyle. Social Problems, 38, 333-357.

Werner, E. \& Johnson, J. (2004). The role of caring adults in the lives of children of alcoholics. Substance Use and Misuse, 39(5), 699-720.

Wilcox, R. (1997). Introduction to robust estimation and hypothesis testing. San Diego: Academic Press.

Wilcox, R. (1999). Fundamentals of modern statistical methods. New York: Springer.

Wilcox, R. (2003). Applying contemporary statistical techniques. San Diego: Academic Press.

Wilder, E. I. \& Watt, T. T. (2002). Risky parental behavior and adolescent sexual activity at first coitus. The Milbank Quarterly, (80),3, 481-524. 
Wills, T. A., Resko, J. A., Ainette, M. G., \& Mendoza, D. (2004). Role of parent support and peer support in adolescent substance use: A test of mediated effects. Psychology of Addictive Behaviors, 18(2), 122-134.

Wojtkiewicz, R. A. (1993). Simplicity and complexity in the effects of parental structure on high school graduation. Demography, 30 (4), 701-717.

Wolfe, D. A., Jaffe, P. G., \& Crooks, C. V. (2006). Adolescent risk behaviors: Why teens experiment and strategies to keep them safe. New Haven, CT: Yale University Press.

Wu. L. L., \& Martinson, B. C. (1993). Family structure and the risk of a premarital birth. American Sociological Review, 58, 210-232.

Wu, Z., Hou, F., \& Schimmele, C. M. (2008). Family structure and children's psychosocial outcomes. Journal of Family Issues, 29, (12), 1600-1624.

Yates, T. M., \& Masten, A. S. (2004). Fostering the future: Resilience theory and the practice of positive psychology. In P. A. Linley \& S. Joseph (Eds.), Positive psychology in practice (pp. 521-539).New Jersey: John Wiley \& Sons, Inc.

Youngblade, L. M., Theokas, C., Schulenberg, J., Curry, L., Huang, I-C., \& Novak, M. (2007). Risk and promotive factors in families, schools, and communities. A contextual model of positive youth development in adolescence. Pediatrics (119), 1, S47-S53. 
VITA

BEVERLEY E. MCDERMOTT

1975

B.S., Economics

University of the West Indies

St. Andrew, Jamaica

1986

M.A., Economics

University of Miami

Coral Gables, Florida

2009-2012

Doctoral Candidate

Florida International University

Miami, Florida

\section{MANUSCRIPT IN PREPARATION}

Life coaching to promote positive development among adolescents 